University of Louisville

ThinkIR: The University of Louisville's Institutional Repository

Electronic Theses and Dissertations

8-2017

\title{
Articulating the new normal(s) : mental disability, medical discourse, and rhetorical action.
}

Andrew Wesley Holladay

University of Louisville

Follow this and additional works at: https://ir.library.louisville.edu/etd

Part of the Rhetoric Commons

\section{Recommended Citation}

Holladay, Andrew Wesley, "Articulating the new normal(s) : mental disability, medical discourse, and rhetorical action." (2017). Electronic Theses and Dissertations. Paper 2787.

https://doi.org/10.18297/etd/2787

This Doctoral Dissertation is brought to you for free and open access by ThinkIR: The University of Louisville's Institutional Repository. It has been accepted for inclusion in Electronic Theses and Dissertations by an authorized administrator of ThinkIR: The University of Louisville's Institutional Repository. This title appears here courtesy of the author, who has retained all other copyrights. For more information, please contact thinkir@louisville.edu. 
ARTICULATING THE NEW NORMAL(S): MENTAL DISABILITY, MEDICAL DISCOURSE, AND RHETORICAL ACTION

\author{
By \\ Andrew Wesley Holladay \\ B.A., Union University, 2005 \\ M.A., University of Louisville, 2009

\begin{abstract}
A Dissertation
Submitted to the Faculty of the

College of Arts and Sciences of the University of Louisville

in Partial Fulfillment of the Requirements

for the Degree of
\end{abstract} \\ Doctor of Philosophy \\ in English/Rhetoric and Composition \\ Department of English \\ University of Louisville \\ Louisville, Kentucky
}

August 2017 
Copyright 2017 by Andrew Wesley Holladay

All rights reserved 

ARTICULATING THE NEW NORMAL(S): MENTAL DISABILITY, MEDICAL DISCOURSE, AND RHETORICAL ACTION

\author{
By \\ Andrew Wesley Holladay \\ B.A., Union University, 2005 \\ M.A., University of Louisville, 2009 \\ A Dissertation Approved on
}

June 12, 2017

by the following Dissertation Committee:

Dissertation Director

Dr. Brenda Jo Brueggemann

Dr. Karen Kopelson

Dr. Mary P. Sheridan

Dr. Amy Clukey

Dr. Margaret Price 


\section{DEDICATION}

For Beth 


\section{ACKNOWLEDGMENTS}

At many times along the way, completing this dissertation seemed an impossible task; I benefited from the advice and kindness of so many people who offered a hand even when I was not looking for one.

First, I want to acknowledge the boundless knowledge and patience of my dissertation director, Brenda Brueggemann. She helped me navigate a project that mixed perspectives, methods, and disciplines, letting me explore the academic landscape while keeping me grounded in the work of Rhetoric and Disability Studies. I hope to follow Brenda's example of personal investment, relentless care, and uncompromising honesty in my academic and personal life.

My committee members have been enormously supportive and given me invaluable direction as I, often less than gracefully, worked through the dissertation process. Karen Kopelson, who reminds me of her support while challenging me to be more thorough; Mary P. Sheridan, a model of consistency and transparency who eases tension with her humor; Amy Clukey, who brought an outside perspective to my academic work; and Margaret Price, who helped me situate myself in a specialty and whose writing about mental disability will always be a guiding influence.

Thank you also to the other faculty at the University of Louisville that have mentored and supported me over the last nine years of graduate school, administration, and teaching. Bronwyn Williams helped me discover a passion for teaching writing and 
rhetoric, both in the Composition program and the Writing Center; he was instrumental in my entrance into the $\mathrm{PhD}$ program, and then into professional life as an academic.

Most importantly, this dissertation would not exist without tireless support and persistent encouragement from my wife, Beth. You believe in me when I don't believe in myself. Thank you for showing me that a better, more just world is possible and worth fighting for. 


\section{ABSTRACT \\ ARTICULATING THE NEW NORMAL(S): MENTAL DISABILITY, MEDICAL DISCOURSE, AND RHETORICAL ACTION \\ Andrew Wesley Holladay}

June 12, 2017

"Articulating the New Normal(s): Mental Disability, Medical Discourse, and Rhetorical Action" studies the writing of people diagnosed with autism and posttraumatic stress disorder within online discussion boards related to mental health and outlines their unique rhetorical strategies for interacting with biomedical ideologies of psychiatry and activist discourses. The opening chapter situates this dissertation in relation to previous scholarship in Rhetoric, Disability Studies, and other fields. I also provide a summary of the set of mixed methods I use to gather and analyze my data, including rhetorical analysis, corpus analysis, and qualitative interviews.

In Chapter 2, "Medical Terminology and Discourse Features of Online Discussions of Mental Health," I explore the ways in which medical discourse appears in discussions of mental disability through medical terms that writers and speakers use when discussing a diagnosis. Using methods borrowed from linguistics, I demonstrate that the writers in my study make different linguistic choices than the general public, and that the most prominent differences are related to the social construction of mental health and medicine. 
In Chapter 3, "Inhabiting Biological Primacy with Chiasmic Rhetoric in Mental Health Forums," I describe and analyze a variety of common topics in online conversations that connect mental health and expert knowledge of the brain. I argue that this connection of mental experience and brain science constitutes a chiasmic rhetoric. The writers foregrounded in this chapter acknowledge and accept much of the claims of medicine and neuroscience regarding the brain but, uniquely, work to divide that knowledge from the path of normativity and optimization.

Chapter 4, "Classified Conversations: Psychiatry and Technical Communication in Online Spaces," examines the practices of participants in online mental health discussion forums conversations as they interpret technical documents. I detail four salient forms of the manipulation of medical discourse in online communities. At the close of this chapter, I explain how these insights can inform academic study of writing in mental health contexts and transform the content and application of medical and technical texts.

In Chapter 5, "Re-Forming Mental Health: Rhetorical Innovation and the Language of Advocacy," I summarize and synthesize the core arguments of earlier chapters, with an extended caveat regarding the ethical dilemmas of this study. Finally, I offer a set of practical recommendations for different communities with which my research has been conversant, the fields of Rhetoric and Rhetoric of Health and Medicine, Disability Studies, and activism related to mental disabilities. 


\section{TABLE OF CONTENTS}

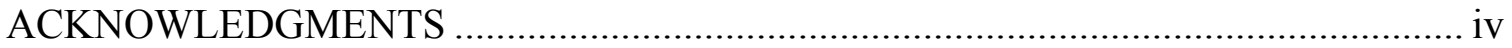

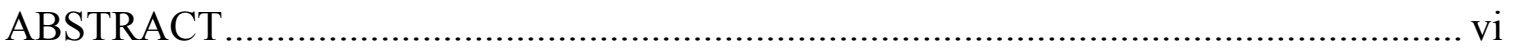

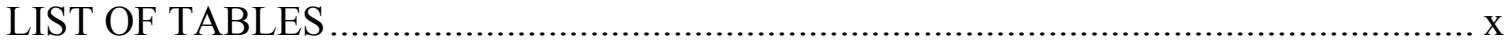

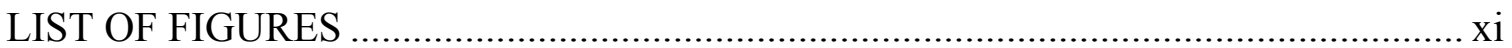

CHAPTER I: UNDERSTANDING THE PSYCHIATRIC SUBJECT: GROUNDING

CRITIQUE IN LANGUAGE AND RHETORIC ..................................................... 1

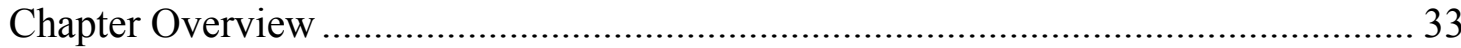

CHAPTER II: MEDICAL TERMINOLOGY AND DISCOURSE FEATURES OF

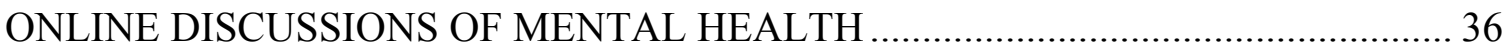

Competing Conceptions of Mental Disability ........................................................... 39

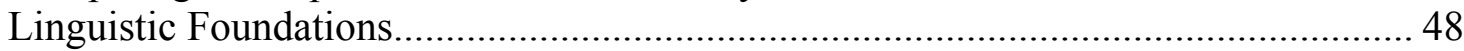

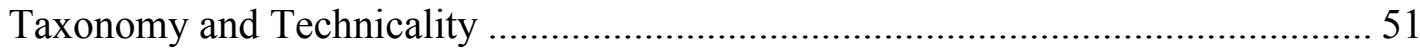

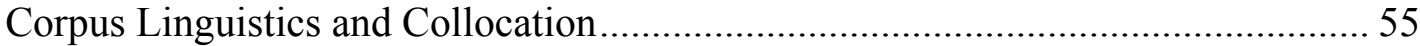

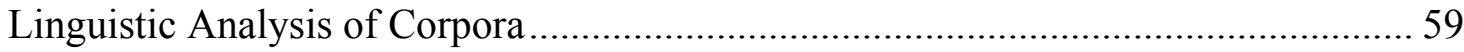

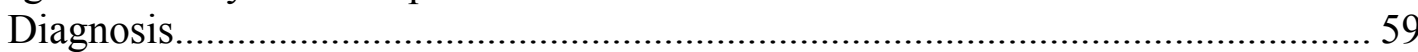

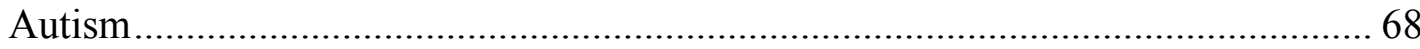

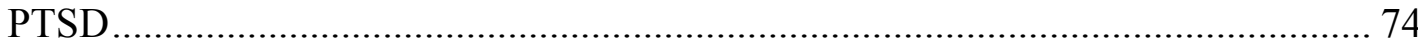

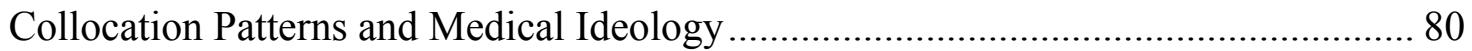

CHAPTER III: INHABITING BIOLOGICAL PRIMACY WITH CHIASMIC

RHETORIC IN MENTAL HEALTH FORUMS ...................................................... 82

Biological Primacy and the Rise of Brain Science .................................................. 82

Biology, Medicalization, and Mental Health ......................................................... 88

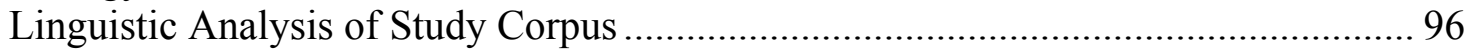

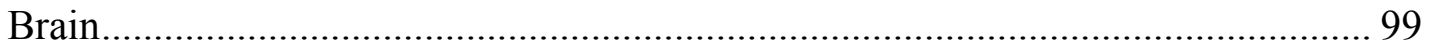

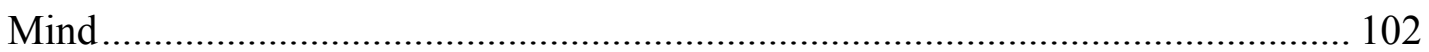

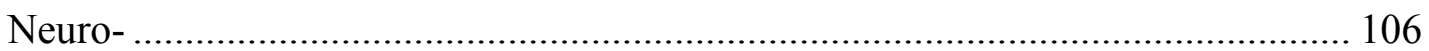

Naming and Complicating the Biological Brain with a Mental Disability ................ 110

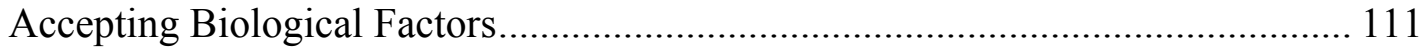

Connecting the Condition with Experience, Emotion, and Psychology ................ 114

Medicalization and Negotiation of Expertise ................................................... 121

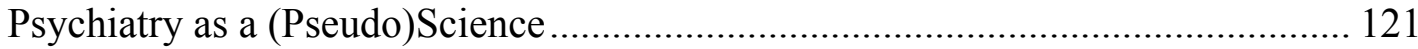

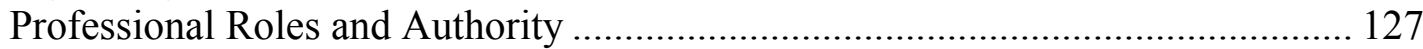

Medicalization, Chiasmic Rhetoric, and Activism ............................................. 130

CHAPTER IV: CLASSIFIED CONVERSATIONS: PSYCHIATRY AND TECHNICAL

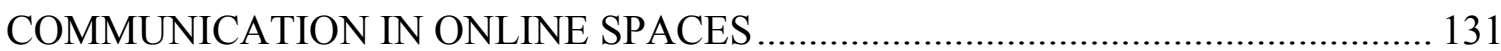

Medical Discourse in Mental Health ................................................................... 135 


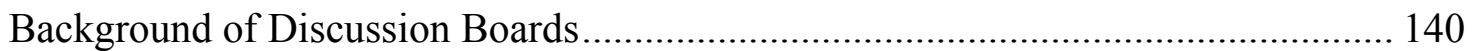

Medical Discourse in Online Communities ............................................................. 141

Demonstrating Ethos through Scientific Literacy.............................................. 143

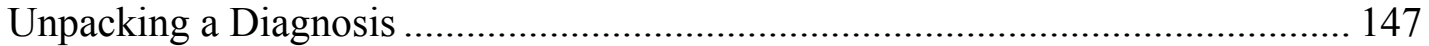

Navigating Medical Institutions and Support Services..................................... 151

Changing Diagnostic Language to Benefit the Community ................................ 155

Classified Conversations and Tactical Technical Communication ........................... 159

CHAPTER V: RE-FORMING MENTAL HEALTH: RHETORICAL INNOVATION

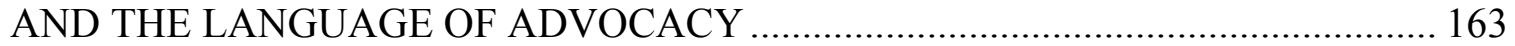

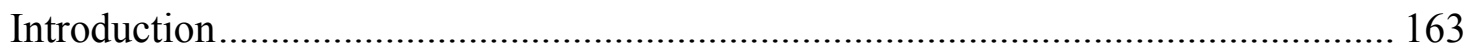

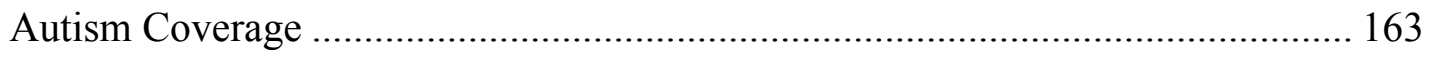

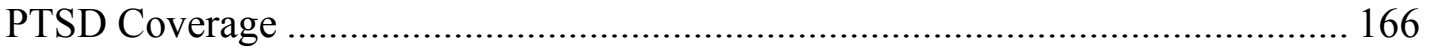

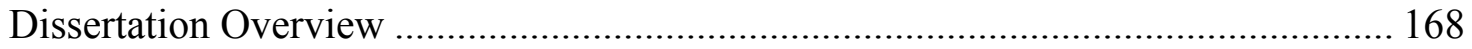

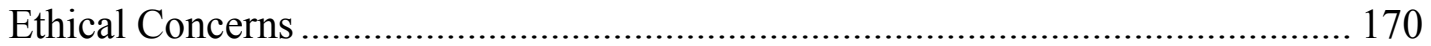

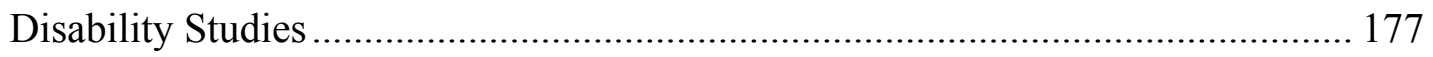

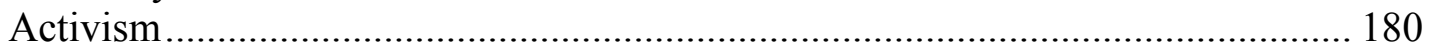

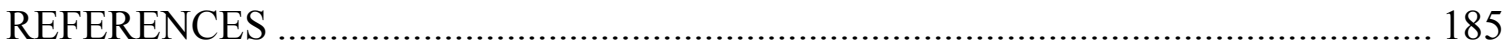

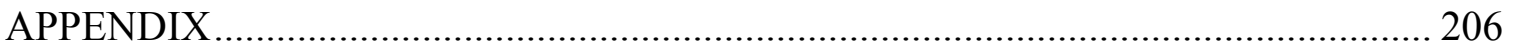

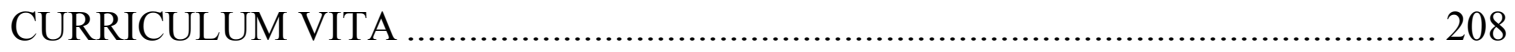




\section{LIST OF TABLES}

Table 1. Collocates of diagn* in COCA, condition names. Psychiatric or neurological

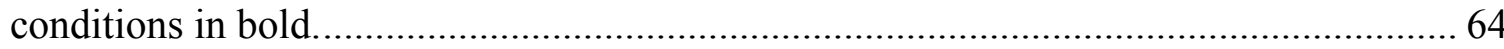

Table 2. Person referents collocated with diagn* in COCA and study corpus................. 67

Table 3. Frequent collocates of autism in study corpus and COCA, category of person referents. Words listed by rank according to frequency in corpus. ................................ 73

Table 4. Words related to biomedicine in the 150 most frequent collocates of PTSD,

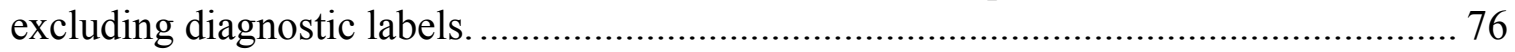

Table 5. Military-related words in the 150 most frequent collocates of PTSD............... 77

Table 6. Person referents in the 150 most frequent collocates of PTSD. ....................... 79 


\section{LIST OF FIGURES}

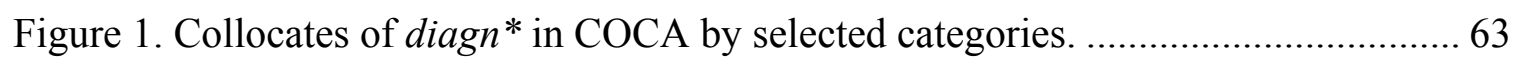

Figure 2. Instances of diagn* collocates expressing certainty and uncertainty

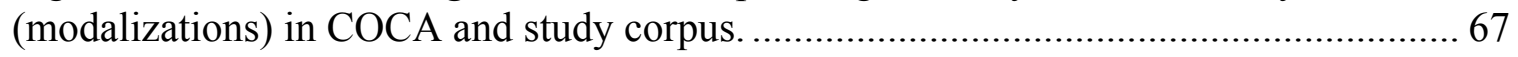

Figure 3. Frequent collocates of node autism by word type in study corpus and COCA. 73

Figure 4. Word types in the 150 most frequent collocates of PTSD ............................. 77

Figure 6. Instances of brain in study corpus by category. Science/Medicine is the most

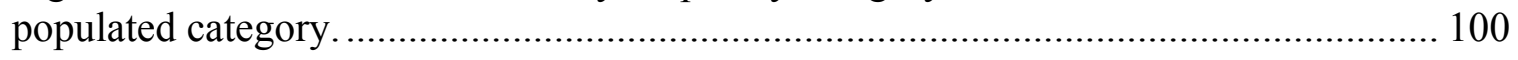

Figure 7. Instances of mind in study corpus by category. Vernacular is by far the most

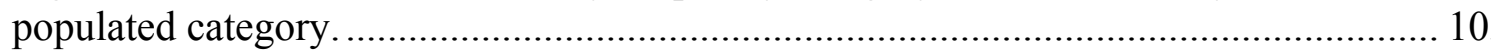

Figure 8. Percentage of total instances of mind in study corpus by theme................... 103

Figure 9. Instances of neuro- in study corpus by category. Science/Medicine and Activism are represented in near equal number 107 


\section{CHAPTER I}

\section{UNDERSTANDING THE PSYCHIATRIC SUBJECT: GROUNDING CRITIQUE IN LANGUAGE AND RHETORIC}

\section{Introduction}

In 2015, the powerful and controversial organization Autism Speaks marked its tenth anniversary. Through well-funded and pervasive media campaigns, Autism Speaks is a force of philanthropy and persuasion: the statements, films, and images that drive funding for medical research also reinforce existing cultural biases about autism as a condition, including its exclusive status as a biologically-based mental disorder that should be controlled and, eventually, cured. In this way, Autism Speaks agrees with modern psychiatry's sharp focus on mental disorder as biological, physical rather than social, and most importantly medical. People who ally with the neurodiversity movement, however, contest a medicalized view of autism and see persons with autism as part of a spectrum of diversity in human behavior and cognition, not disordered deviants from the normal. These two groups clashed on Twitter in February, when Autism Speaks asked people to tweet about "how AS has touched your life." While many posted responses that conformed to the organization's philosophy, autistic self-advocates and neurodiversity proponents used the moment to criticize Autism Speaks and its paternalistic stance toward individuals with autism. Medicine doesn't tell the whole story, these activists argue, and a purely medical view of autism will distort all our actions toward people with the condition. 
Within this controversy lies a cultural tension about medicalization—do scientific and medical terms capture the true definition of human normality in body and mind, and are the experts of science and medicine the arbiters of that truth? The expansive and overwhelming growth of medical knowledge in the 20th century has led to its broad cultural power of defining what is true about the human body and mind, advancing what scholars in disability studies call the "medical model." Diagnostic terms in psychiatry like "bipolar," "PTSD," and "obsessive-compulsive" have entered into everyday usage and many consider medicine, especially psychopharmacology, to be the most effective means of treating mental illness. For those who are diagnosed with mental disorders, these terms may be a judgment or a relief, a window to community or an alienation from others; but for all, the terms define the direction of their care, the medicines they are prescribed, and their interactions with institutions who require such conditions to be reported. Academic studies of these individuals have largely centered around either their lives from a strictly medical point of view (in publications from medicine, psychiatry, and nursing) or movements that run counter to medicalization, such as the consumer/expatient/survivor movement, but these approaches are seen as distinct and mutually exclusive. The methods and terms used by psychiatrists and published in the American Psychological Association's Diagnostic and Statistical Manual (DSM) are frequent targets of criticism, However, few studies exist of the individuals diagnosed and their use of the medical language that experts in psychiatry have crafted—language inflected by a long heritage of empiricism in science (Halliday and Martin).

In this dissertation, I analyze the discourse of individuals diagnosed with mental disorders as they write about their own experiences of disability and difference. In 
particular, I explore a cross-pollination between scientific discourse and popular discourse: the way that the medical model language of current psychiatry inflects individuals' descriptions of experiences of mental disability. Throughout my project, I weave together rhetorical criticism on mental disability, which has largely emerged within disability studies and "neurorhetorics," with accounts of discursive power in medicine and psychiatry from other disciplines, including many scholars from the humanities and social sciences but also clinicians who deviate from the mainstream models of mental disorder. These perspectives are sufficient theoretical tools to analyze the specific instances of discourse I gather in online communities as well as the historical context for medical-psychiatric language use in everyday life.

My primary sites of study are discussion forums devoted to particular diagnoses. To limit the scope of my study and allow some comparison across examples, I focus on individuals diagnosed with autism spectrum disorder (ASD) and post-traumatic stress disorder (PTSD). My methodology, described in full detail below, includes systematic qualitative empirical methods for data collection and a variety of methods for analysis, including corpus analysis and rhetorical theory. This project addresses a disciplinary gap in Rhetoric and Composition scholarship on mental disability by providing a close study of the appearance of medical terms and logic in the discourse of individuals diagnosed with mental disorders and the rhetorical purpose of such terms in the contexts where they occur.

While sustained attention to the language used by and between patients is less common, academics and physicians have written many critiques and defenses of the language used by psychiatrists to describe mental states and conditions over the last fifty 
years (a full description of these perspectives comes later in this chapter). Suzanne Kirschner, a professor of psychology, summarizes the pattern of academic resistance to forms of psychiatric diagnosis over the past few decades by placing the projects into two main categories: descriptive projects, which focus on the language of medical professionals; and contextualizing projects, which focus on the effects of diagnosis in a particular social context (11-12). Both the descriptive and contextualizing projects have a moral or ethical concern at their root: the resistance to biomedical psychiatry is mounted to produce a positive change in psychiatric discourse and practices. In this dissertation, I argue that efforts at critique can be aided by analyses that emerge from the fields of rhetoric, sociolinguistics, and cultural studies. In Kirschner's terms, my research uses a "contextualizing" framework, since I investigate the discourse of those diagnosed rather than those giving the diagnosis. In constant view, however, is the medical discourse embodied in the DSM and other medical documents, which in many ways structures the political, bureaucratic, and social actions of those with mental disabilities.

This chapter describes the various interdisciplinary theories that I seek to coordinate in this dissertation toward analysis of the rhetorical and discursive strategies of those with mental disabilities. To begin, I consider accounts of medical and biopolitical agency that point to the context of power relations in which my research participants are speaking and writing. Next, a historical sketch of competing theories of psychiatry traces the many ways that people with mental disabilities have been evaluated, labeled, treated, and studied since the biomedical turn exemplified by the third edition of the DSM (1980). Finally, I provide an overview of critical disability theory, its 
conceptualization of normality and social discipline, and the instantiations of Disability Studies within Rhetoric and Composition.

An explanation of methodology follows this theoretical landscape. Drawing upon the array of investigative methods employed by scholars in Rhetoric and Disability Studies, this composite methodology approaches language as constitutive of identity and political in nature. My primary research stance is one of rhetorical critic, studying the persuasive effects of texts with special attention paid to constructions of identity and appeals to identification (Burke, Rhetoric of Movies; Charland; Crable). I use methods borrowed from sociolinguistics (primarily analysis of function, collocation, and concordance) to trace the conversations of my research participants and locate discursive "vehicles" for persuasion.

\section{Interdisciplinary Threads}

\section{Power and Agency in Medicine}

The conceptions of medical power that drive and undergird my rhetorical analysis are varied in their disciplinary orientation but share important assumptions: that power is systemic, and often institutional; that power is unequal between groups and that institutional systems tend to reinforce such inequality; that dominant cultural groups have outsize influence on common cultural ideas within a population. These power relations are manifested through medicine's economic and cultural power, both of which work to reinforce biomedical conceptions of body and mind: that biological phenomena dominate a person's un/health. The aura of truth surrounding medicine, and physicians as its experts, maintains the separation between doctor and patient with their respective (and binary) social roles and responsibilities. Various institutional, governmental, and 
educational conventions restrict the inclusion of patient (read as non-expert) perspectives in the regulation of medical practice. The production of knowledge in medicine, with its dominant research method of randomized double-blind controlled trials, privileges empirical positivism and sidelines humanistic or interpersonal inquiry.

These trends, taken together, have resulted in an American culture in which authority and power over the body reside in medical institutions and their constituents. As bioethicist Katrina Karkazis observes, medicine holds an "unequaled power to define what is normatively human" and its practices "can be construed as a productive power using scientific knowledge to buttress particular social views, and thus treatment practices" while excluding others (283-284). Rhetorically, one finds that medical knowledge is quite uniformly identified with scientific truth and thus employed as a powerful persuasive tool in conflicts over appropriate conceptions of, and treatments for, disordered bodies. In Karkazis's account of intersex advocacy, the sedimented practices of physicians and the primacy of biological knowledge combined to resist advocates' calls for a shift in terminology for intersex conditions from disorders to differences in sex development. Medical judgments about intersex "disorders" are rhetorically symbiotic with dominant cultural ideologies of gender, which see male/masculine and female/feminine bodies as mutually exclusive and distinct in appearance and behavior. Individuals ("patients") who resist coinciding medical and cultural perceptions find their efforts discounted as non-expert and subjective, with biomedical ideology wielded as an epideictic tool to lift the physician and suppress the medical subject.

The current privileging of medical perception in interpreting the body is a continuation of power relations and trends of thought Michel Foucault identified in his 
influential analyses of medicine and psychiatry. His central concept of the medical gaze represents an array of reciprocal positions that define the physician and subject, doctor and patient: in evaluating a patient, the medical gaze- "plurisensorial," making use of touch, hearing, sight (Birth of the Clinic 164) — makes the body into a corpse, peering past the opaque exterior to systems of physiology brought to light through the legacy of gross anatomy. Conceiving of the person as an object, the silent physician seeks to exclude any extra-bodily phenomena in his observation (even in disregarding the speech of the patient). The evolution of the medical gaze thus indexes a "recasting at the level of epistemic knowledge itself, and not at the level of accumulated, refined, deepened, adjusted knowledge" (Birth of the Clinic 137). Physicians did not build the gaze on past knowledge, but followed it to the "insistent, impenetrable density of the object" that is the "residence of truth" (Birth of the Clinic xiii). The body itself, not the patient seen holistically, is the origin of knowledge; in this new configuration of knowledge, a "minute but decisive change," "the question: 'What is the matter with you?'...was replaced by... 'Where does it hurt?'” (Birth of the Clinic xviii).

The overriding concern for objectivity and empiricism in modern medicine marks any non-physical entity as an intrusion, a threat to rational inquiry into the body. ("The clinic...silently lets things surface to the observing gaze without disturbing them with discourse" [Birth of the Clinic xix].) An essential binary between the medico-scientific and the discursive-rhetorical generates medical authority and shields it from cultural critique. The survival of medical power relies on the invisibility of its disciplining force in behavior and speech as much as physical subjection. If properly "conceal[ed]," "the discursive formulation in which [disciplinary practices] circulate" may continue "to be 
naturalized and legitimized" (Tremain 8). Medicine's perceived status as non-rhetoric rests upon powerful, invisible, self-directed acts of persuasion that divide the physical from the cultural and enshrine science as the privileged arbiter of reality.

While such an ideology of science, and modern medicine as its progeny, has its philosophical roots in the Enlightenment, a particular form of self-relation (and, in my view, self-discipline) has arisen in recent decades: seeing life as a biological phenomenon best understood through scientific knowledge. Sociologist Nikolas Rose explains this cultural shift:

We are increasingly coming to relate to ourselves as "somatic" individuals, that is to say, as beings whose individuality is, in part at least, grounded within our fleshly, corporeal existence, and who experience, articulate, judge, and act upon ourselves in part in the language of biomedicine. (Politics, 25)

In his explorations of biopolitics, Rose finds the authority of biomedicine spreading further and further from traditional medical domains into every corner of lived experience, "from office discourses of health promotion through narratives of the experience of disease and suffering in the mass media, to popular discourses on dieting and exercise" (Politics, 26). In these new frontiers of medical expertise, the division of physical and cultural is performed once again. Medico-scientific knowledge becomes the primary account of at least part of each sphere: the action of antioxidants on individual cells when we eat, the neurochemistry of connection in our conversations, the stress on our eyes, spine, and tendons when working on a computer. The spread of recognized authority leads to disciplinary power in these same areas. Having recognized the "somaticized" body woven into every experience, one might form an exercise routine to prevent aging and gain a healthy appearance, expect a neurochemical response that increases happiness and reduces stress, eat particular foods to prime our limbs and organs 
and cells for efficiency, and see each of these actions as not simply preferable but necessary in light of our medical knowledge. People discipline themselves toward biomedical ideals and expect others to do the same. (What incredulous rage we find in public discussions of the "obesity epidemic"!) And somatic considerations naturally draw attention away from other dimensions of such behaviors - the cultural dimensions of cooking and eating, for example, or the social construction of health and vitality.

The broad cultural persuasiveness of biomedicine and its privileging in everyday life coexists with an economic system whose trade is rooted in knowledge of the body, which Rose calls the "bioeconomy" and its correspondent "biocapital." The bioeconomy encompasses a wide array of interrelated industries that trade on the culture of the body, from traditional pharmaceutical companies to homeopathic practices to genetic testing companies. The surge in bioeconomic activity reinforces the primacy of medical knowledge in everyday life, where medical power and discipline now also exert great influence on the places that individuals spend and invest wealth. In addition, as documented by many scholars, medical industries have extensive effects on the practice of medicine and medical research [citation string]. When an industry's growth depends on the recognition of medical authority, its advertising tends toward depicting the problems of consumers in biomedical terms - as well as, of course, the solutions which they are marketing.

The resulting picture of power in medicine is a dense and interdependent network of social institutions and relationships. At the root, however, medicine's power stands on its perception as disinterested, physically oriented, and anti-cultural-rhetorical. 


\section{Psychiatry and Mental Disorder}

The rising cultural power of medicine and its biological orientation served as a principal catalyst for gathering consensus around a biomedical model of mental illness. In the 1970s and 1980s, psychosocial models, after decades of dominance in psychiatry, gave way to biomedical assumptions. While the psychosocial models often focused on the cause of a condition, its etiology, the biomedical model demanded psychiatrists categorize it without distinguishing a cause (Horwitz; Metzl, Prozac; Lewis, Moving; Compton and Guze). The DSM-III marked a sea-change in psychiatric theory, upending psychosocial assumptions and presenting a new tiered "axis" system for classifying mental disorders. The psychiatrists responsible for this momentous change, led by Robert Spitzer, hoped to bring precision and coherent taxonomy to research in the field while also standardizing diagnosis and practice. In the years since, biomedical psychiatry has been overwhelmingly dominant in shaping both professional and popular conceptions of mental disability and difference. Dovetailing with persuasive biological accounts of life processes, biomedical psychiatry proposes similar accounts of mental disorder: focusing on genes in autism, serotonin in depression, brain regions in schizophrenia, neural responses in PTSD. Such explanations support the logic of pharmaceutical intervention, whose uses and effects are explained in biochemical terms both by psychiatrists themselves and the companies marketing the drugs.

Spurred by this dramatic shift in approach in psychiatry, several movements cohered around resistance to purely medical and biological views of mental disorder. Many writers applied the principles of the anti-psychiatry movement, most influential in the 1960s and 1970s, to the new theories; consistent skepticism was directed toward the 
claims of validity in newly created diagnoses. The consumer/survivor/ex-patient (c/s/x) movement exposed stories of mistreatment by physicians and institutions and promoted a vision of mental differences as "mad gifts" and unique experiences rather than pathologies (Morrison). A substantial amount of criticism has also been levied against the DSM, especially for its increasing expansion of diagnosis into experiences many do not consider unusual or pathological, such as grief. Critiques from within the psychiatric establishment, such as the recent objections of psychiatrist Allan Frances to the DSM-5 revision process, seek to "reform" the process of diagnosis or treatment while retaining the general medical model over against social and psychological explanations. Critical accounts of biomedical psychiatry have emerged from the fields of anthropology (Gaines), sociology (Horwitz), critical psychiatry (Wilson; Lewis), feminist psychology (Kirschner; Lafrance and McKenzie-Mohr), and various interdisciplinary actors (Metzl; Segal; Berkenkotter). The critical perspective calls the medical model into question, and may even envision a new organization of psychiatric practice, as in the "postpsychiatry" of Bradley Lewis. In addition, almost all critiques from within or outside the establishment condemn the cozy relationship between psychiatric institutions and pharmaceutical companies, blamed for both the remarkable increase in prescription drug use and the decrease in "talk" treatments or social interventions.

\section{Disability Studies}

Taking shape in the late 20th century, the disability rights movement sought to improve the lives of people with disabilities by changing social attitudes toward their conditions. The bedrock notion of the disability rights movement is the social model of disability, which asserts that disability is a social, not an individual, phenomenon: "it is 
society which disables physically impaired people. Disability is something imposed on top of our impairments, by the way we are unnecessarily isolated and excluded from full participation in society" (UPAIS 3). As such, the social conditions that produce disability—policies, prejudices, environments—should be changed to accept with equity people with impairments. Though at first largely focused on physical disability, the movement also encompasses mental disability.

Seeing that many stereotypes and stigmas related to people with disabilities were connected to medical views of their conditions, people in the disability rights have worked actively to reduce the influence of the "medical model" of disability, a particular modern instantiation of the individual model. According to the medical model, disabilities reflect an underlying disease or disorder of normal physiology in an individual; accordingly, interventions focus on physical aids or pharmaceuticals that will correct or ameliorate the "problem" and return the individual to a more normal state. In the medical model, social circumstances surrounding disability are, at best, secondary to the physical or biological disorder, and in many cases are considered irrelevant to planning disability interventions. Following the shift from psychosocial theories of mental illness to a biomedical orientation, psychiatry emphasizes the same types of mechanisms of disability, and "mental disorders are understood, like physical diseases, as discrete entities, generic across cultures, which are clearly bounded from each other and from normal conditions" (McCarthy and Gerring 150). As such, apologists of the medical model in psychiatry describe it as more objective and verifiable than competing models; while "other models seeks to 'explain' psychiatric illness in terms of various external factors," the medical model does not "neglect the primary organ of psychiatric illness, 
the brain/mind" and is "without a priori theory" (Compton and Guze 200). In contrast, the work of disability studies shifts responsibility away from the individual (brain) to the society that refuses to create accommodations for cognitive and behavioral differences. For critical disability studies of psychiatry, the medical model is a primary cause for the individualization of mental disability and the rapidly increasing use of psychopharmaceuticals rather than addressing social stigmas and inequities.

The medical model assumes some distinction between the normal body/mind and the abnormal difference that constitutes disorder. Those working in disability studies commonly deconstruct the social norms themselves, which allows them to uncover the mechanisms by which perceived difference, in any form, can marginalize groups of people. Influenced by the writing of Michel Foucault, Lennard Davis writes that disability is "a socially driven relation to the body" that is "part of a more general project to control and regulate the body" (Enforcing Normalcy 3). As such, disability is not the only target of social norms; these norms also "[makes the idea of disability (as well as the ideas of race, class, and gender) possible" (Enforcing Normalcy 158). Echoing and expanding such a critique of normativity, Rosemarie Garland-Thomson writes that "disability is a broad term within which cluster ideological categories as varied as sick, deformed, crazy, ugly, old, maimed, afflicted, mad, abnormal, or debilitated—all of which disadvantage people by devaluing bodies that do not conform to cultural standards" ("Integrating Disability" 5). Garland-Thomson works to "denaturalize the cultural encoding of...extraordinary bodies" as disabled - "the attribution of corporeal deviance" (Extraordinary Bodies 5-6). The converse of disability, which GarlandThomson calls the "normate," are instead "the corporeal incarnation of culture's 
collective, unmarked, normative characteristics" (“Integrating Disability" 10). Taken together, the unspoken cultural norms of body and behavior constitute an ever-present discourse of power that pressures individuals toward conformity with a social ideal, with the disabled body serving as the ultimate Other.

Foucault wrote that "Power is collective at its center, but it is always individual at the point where it arrives" (Psychiatric Power 75). In turn, scholars in disability studies build on this work of exposing the mechanisms of social norms with detailed accounts of the lived experiences of individuals with disabilities. In many cases, this work involves close attention to people marked as "freaks," "cripples," or "crazy" in the past, as with Garland-Thomson's analysis of the freak show as a fetishized exhibition of disability. Autobiographies have also played a key role in connecting people with similar conditions and presenting disability rights to a public audience. In "claiming disability," as Simi Linton writes, people with disabilities can enter the public sphere from which they have been hidden and excluded, "in the institutions that have confined us, the attics and basements that sheltered our family's shame, the 'special' schools...or riding in...those 'invalid' coaches that shuttle disabled people from one of these venues to another" (3). By openly writing about their disabilities, these authors hope to reduce the stigma connected to their conditions and rally support for assistance and accommodation. Finally, in their research practices, scholars in disability studies maintain a spotlight on the individual experience of people with disabilities, often privileging the perspectives and interpretations of research "subjects" over those of researchers in their respective fields. 
For this dissertation, the concepts above that organize much of disability studies - the medical model, the norm, and lived experience — create a strong frame through which to analyze the online conversations of people with mental disabilities. Many of the writers in this study are conversant with both the medical model and the social norms that govern behavior. For some, the terms of the medical model are the way of understanding their condition and their lives. For others, the medical model and the norm are symbols of oppression to be dismantled or dismissed. The emphasis on individual writers allows this study to provide a deep and textured account of the discursive and rhetorical practices of people with mental disabilities, especially as they intersect with concepts already built up in disability studies.

\section{Current Connections to Rhetoric}

The strands of analysis brought together in disability studies—of medicine, science, and norms - have an ample presence in the field of Rhetoric and Composition. Rhetorical studies of disability in culture have been wide-ranging in their subjects but consistent in their conclusions: that our acts of persuasion often bear the mark of ableism and stigma (Dolmage; J. Johnson). Rhetorical scholars have also attended to the place of disability in the history and practice of rhetoric. Brenda Brueggemann and James Fredal write that rhetoric has long been considered an art of control:

In fact, until fairly recently one could, without much injustice, define rhetoric as the cultivation and perfection of performative, expressive control over oneself and others. ... While the particular principles, rules and proscriptions that make up the art of rhetoric vary from one age to the next, rhetoricians and orators took for granted that anyone who hoped to control the will of an audience had first to control their own voice and body. (129-130)

Though derided, at least since Plato, as a manipulative practice, rhetoric was an act of self-discipline as well. The bodily discipline that Brueggemann and Fredal reference is of 
course implicit, "[taken] for granted," as the most powerful and persistent disciplines tend to be. As Garland-Thomson argues with regard to "freaks" who index the normate, those without rhetorical efficacy because of disability index the ideal able-bodied, smoothtalking rhetor. The judgment of such norms fall especially hard on those with mental disabilities, whose ability to work within the basic appeals of the rhetorical tradition is called into question: to reason with logic, express and appeal to socially appropriate emotions, to build credibility through perceived stability and trustworthiness, to act quickly and decisively. Catherine Prendergast argues that cultural scripts of disability "place the mentally ill and schizophrenics in particular in a rhetorical black hole: whether it's music or word salad, one never has to think about 'it' at all" ("On the Rhetorics of Mental Disability," 53). Jenell Johnson explains that this "black hole" results from an impoverishment of ethos — what she calls kakoethos or "bad character." Kakoethos arises from the diagnosis or attribution of mental disability, and it does not seem to fade with time or change with circumstance: mental illness is "a permanent identity" (Johnson 470). Dismantling these grave and disempowering rhetorical situations, then, necessitates modes of political action suggested by disability studies: critiquing the assumptions and norms that created the social reality of disability and the reshaping our view of humanity (and rhetoric) to include marginalized groups. Cynthia Lewiecki-Wilson focuses in particular on political agency, writing that we might abandon the traditional liberal model of the public sphere and instead understand "the rhetoric of the public sphere... as a collaborative action for specific, interested ends (such as for the benefit of a mentally disabled person), which in its exercising, mutually constitutes intersubjectivity, agency and interdependency, as well as human dignity and caring" (164). 
This dissertation intends to build on scholarship in our field by illuminating the rhetorical and discursive patterns within online forums devoted to particular mental differences and disabilities. The successes of the disability rights movement have put into motion changes in cultural attitudes toward non-normative bodies and minds, and these changes have produced different ways of speaking and arguing about disability. The neurodiversity movement has been particularly important for the treatment of autism, bringing the "difference not deficit" slogan into mainstream venues of psychology and education.

But people are not choosing either/or between medical and disability rights ideologies. The growing awareness and political momentum for disability rights has coincided with the continued dominance of biomedical views of the body. In many contexts, scientific and medical knowledge about the body and brain has been used by disability rights activists to make claims for inclusion. ${ }^{1}$ The political utility of the social model of disability as a counter-action to the medical model fades as discourses of disability and science find some common ground. Many scholars have questioned the social model, and some find its binarism unworkable in the face of medicine's intertwined history with disability. As Lewiecki-Wilson writes, the "social constructivist move" presents a false choice: "the mentally disabled do not need to choose between a medical or social model of disability; they need both, and both have material and social dimensions and consequences" (163). The work of disability studies scholarship, then, should account for these "dimensions and consequences" of different ideologies of

\footnotetext{
${ }^{1}$ For example, arguments that the genetic basis of autism proves it is a common condition with a long history, rather than a recent "epidemic"; or that the omnipresence of medical risk makes all people temporarily able-bodied.
} 
embodied life. And as I argue in this study, the intersections of sometimes competing ideologies present a particularly fruitful lens for tracing the prevailing attitudes toward mental disability, some of which may be embedded in our discourse but unarticulated in social arguments. Unusual combinations of discourses may also be more common in everyday conversations, where a rhetor may background a committed political orientation toward disability in favor of an emphasis on describing experience. Our understanding of these trends can aid in creating persuasive arguments for those working in neurodiversity and disability rights, as I describe further in Chapter 5.

Using these various perspectives in concert, this dissertation addresses the following research questions:

1. How does the broad and intense influence of biomedical psychiatry affect the language that people use to make sense of their own psychological experience? Where does the technical phrasing show through in an individual's account of their disability? When does the use of technical language seem to indicate a strategic use of rhetorical agency? When does it suggest adhering to the scientistic ideology of psychiatric research and practice?

2. How might medical explanations of mental disability be used in one context to persuade a professional or clinical audience but abandoned in more private or colloquial settings? What does the uptake of medical language and logic reveal about the rhetor's conception of self and disability?

3. What strategies of language use emerge in online communities for interacting with institutions and their representatives in medical, governmental, and insurance contexts? How does a person's expression of mental disability change 
(or not) according to rhetorical purpose? What expressions of identity does one perceive as "core" or "authentic" and, others, as strategic or contextual?

\section{Where can one find intersections between the methods and aims of rhetorical} theory and critical psychiatry? Where have connections, explicit or implicit, been made between these fields? What interventions can rhetorical theory make to criticism of psychiatric discourse, power, and practice?

\section{Methodology}

In this dissertation, I combine methods from rhetoric, writing studies, and sociolinguistics to gather and analyze data from online discussion forums devoted to mental disability or disorder. Following the approach of corpus-assisted discourse studies, I investigate linguistic data from a large set of forum conversations to identify categories common among research participants discussing mental disability in varying degrees of specialized medical terminology. Using findings from this more distant analysis, I conducted interviews with forum participants about their discursive and rhetorical choices. I have chosen these particular methods to pair macro-cultural trends with the individual experiences of research participants. In doing so, I am able to contribute to the production of knowledge within rhetoric and sociolinguistics while maintaining a focus on the participants affected by constructions of mental disability. I have found instances of medical language emerging in the discourse of online communities that vary widely but are crafted to the specific ideologies and purposes of individual writers. In a similar manner to its utility in popular discourse, writers sometimes invoke medical knowledge and language to support a particular argument about their disability. In parallel, however, writers on these forums also offer up other 
instances of medical language to be critiqued or satirized. In the observations and interviews I conducted, very few writers gravitate toward extreme poles of current thought on psychiatry, either claiming to be fully invested in the biomedical model of mental disorder or resisting all medical and institutional definition of mental conditions. Instead, writers take care to delimit which parts of biomedical knowledge they see as valuable while putting other aspects up to critique. In some cases, the result is a "chiasmic rhetoric" (as I explain further in Chapter 3) that intertwines the assumptions of claims of seemingly opposed ideologies into something new and distinct. The combinations that occur in this chiasmic rhetoric appear in specific ways that, generally, uphold the value of scientific literacy in relation to mental disability while also conferring great authority to the individual with a diagnosis. Even while building their own novel rhetorical approaches, writers are also cognizant of the power medical institutions retain in relation to mental disability; suggested changes to medical language and practice exist alongside "tactical" methods for obtaining the supportive care and institutional resources an individual needs.

\section{Overview of Methods for Data Collection and Interpretation}

To begin my data collection, I read conversations on public online forums designated for individuals with a mental disorder diagnosis and/or a self-identification with a mental disability. Using keyword searches, I isolated conversations that revolve around key issues in my research questions, including the use of medical language to describe psychological experience, the negotiation of power in medical settings, and discursive tactics to leverage power by and for those individuals with mental disabilities. 
When conversations fitting such questions were identified, they were copied and archived for later analysis.

As Baker et al. argue, the quantitatively-oriented methods of corpus linguistics, including collocation and concordance study, can be used to identify patterns useful in more "subjective" and committed scholarship in critical discourse analysis (CDA). A data collection methodology drawn from corpus analysis might begin with "examination of relative frequencies and emerging statistically significant lexical patterns in the corpus" (277). After establishing these patterns, concordance analysis can be used to sort discursive moves, which "can be grouped (e.g., topoi related to a specific word or cluster) and quantified in absolute and relative terms for possible patterns to be identified (e.g., the tendency of words/clusters to be employed in the utilization of particular topoi)" (Baker et al. 279). Such topical and functional discourse identifications has allowed me to sift through [just how many] pages of online conversation to plot their relative frequencies and find segments worthy of further investigation.

From the most interesting and relevant conversations, I solicited participants for discourse-based interviews on their views relating to medical language and mental disability. These interviews were semi-structured and focused upon features of the individual's writing in the online community that connect with my project. (See Appendix for the initial interview questionnaire.) Throughout the interviews, I learned about the writer's participation in online conversations or forum threads and discuss their discursive and rhetorical choices. Available mediums for the interviews were messaging within an online forum, synchronous chat, telephone conversation, and email exchange; 
all participants chose to either exchange emails or send direct messages in their home forum.

The methodological and ethical function of discourse-based interviews was to balance the comparatively distant and quantitative linguistic analysis with personal accounts of the participants' practices. Research methods Rhetoric and Composition have a rich history of qualitative inquiry, which often focus on particular actors, students, and texts, rather than more "scientific" analysis of large groups. While quantitative research in our field has its own unique purposes (Barton, "Design"; Haswell), faithful accounts of literacy practices must take into account the complex individual contexts in which people produce texts. Such methods are especially important when looking at unusual combinations of purpose, genre, and voice like those found in this dissertation. Elaborating on notions of intertext, Kevin Roozen writes that "texts and activities can be said to be linked not just through streams of discourse, but trajectories of practice as well" (321). In this compelling article, Roozen was able to investigate writing processes and intertextuality in depth by following one student's writing practices, a move that afforded him a great deal more detail and internal validity than a quantitative approach could have yielded. Furthermore, qualitative research allows for the more substantial involvement of those whose writing is being studied; research "subjects" become instead participants with a stake and say in the direction of the project. Feminist methods stress the benefit toward research participants and suggest a relationship of reciprocity (Kirsch and Ritchie; Powell and Takayoshi) and movements toward service-learning and community literacy (Peck et al.; Flower; Deans) and activist research (Cushman) have highlighted the need for different ethical practices when research is conducted outside the 
university and with marginalized populations. For my project, an ethical research approach includes vigilance toward protecting vulnerable participants, careful and collaborative means of representation, and a method tailored for the unique online settings in which I gather data. In addition, as described above, research in disability studies often privileges the individual over the population to push against a history of people with disabilities being described by outsiders. As a researcher from outside entering these online forums, I was wary of my own assumptions and biases that might influence interpretation. Where possible, I let the participants describe their own rhetorical work rather than supposing an intention without knowledge of the writer.

Throughout the research process, I used grounded theory (Glaser \& Strauss) as a recursive process to bridge data collection and interpretation, a process that privileges themes occurring in data rather than preexistent theoretical commitments. I look for emergent themes and rich features (Barton, "Linguistic Discourse Analysis") in discourse gathered from both online community conversations and interviews. Following Schryer et al.'s "modified grounded theory" approach, I "first identif[ied] emergent themes but then allow...theoretical orientations to affect our interpretations of those themes" (95). The initial corpus study allowed me to identify trends and phenomena to sharpen my methods for later stages of research.

My primary interpretive lens has been rhetorical analysis, and in particular rhetorical theories that account for the effects of power in acts of persuasion. While my participants' descriptions of their conditions are deeply personal, the semi-public context of the online community presupposes larger social goals for the discourse there-from a simple Burkean aim of building identification to more complex systems of responding 
discursively and institutionally to medical power. From the perspective of an individual, the online conversations often center around discussions of identity and difference, with rhetorical moves toward affirming one's identity, connecting one with others, and of speaking and negotiating the experiences of difference that brought them to the discussion forum. In many cases, the writers seem to employ an "interactional rhetoric," "the attempt to act upon another's experience in order to gain support for the rhetor's desired identity" (Crable 16). The collective uncovering of mental experience provides a foundation for emotional support between community members and can produce identities like the "awe-tistic" or the person with "dangerous gifts." The writers in my study also engaged in "marking difference," where "rhetors and audiences alike display and respond to...rhetorical cues that signal the presence of difference between two or more participants" (Kerschbaum 619). Such acts need not put distance between individuals; often writers mark differences to affirm diversity within an identity (e.g. various ways of being autistic) or to build solidarity in the experience of difference.

The texts I analyze have important connections to larger groups and collective rhetorics, which influence writers in varying ways. The experiences and identities these writers reference have roots in other, institutional and public, discursive contexts. Scholars working in the rhetoric of health and medicine have described in detail the practices of medical institutions and their effects on people under their authority. Building on insights from the rhetoric of science, some studies demonstrate the inherently rhetorical nature of knowledge production in medicine, including the marking of illness and abnormality (Graham; Yergeau), interpretive acts in research (Schryer, "The Lab"; Jack and Appelbaum), construction of diagnoses (McCarthy and Gerring). Rhetorical 
investigations of the application of medical knowledge again point to its negotiated and interest-laden nature, in medical training (Schryer and Spoel; Schryer et al. 2003; Brodkin; Detweiler), diagnosis (Berkenkotter and Ravotas; Berkenkotter; Segal, "Illness"), documentation (Popham), policies (Keränen, “'Cause Someday We All Die"), and recruitment for clinical trials (Barton, "Further Contributions"; Barton and Eggly). While the specific research contexts vary, these studies share in common a concern for power, rhetorical and otherwise, and demonstrate the consistent advantage of medical institutions over patients and patient organizations.

These institutional concerns point further toward publics involved in the discourse of health, whether or not they organize themselves socially or politically. By taking a dynamic rhetorical stance toward health research, "we can appreciate biomedical and health discourses and practices as the result of complex sets of interacting rhetorical performances that bridge public, private, institutional, and technical concerns" (Keränen, "Public Engagements" 104). The institutional and personal rhetorics described above, then, are also interwoven with public discourse for advocacy, debate, and political power. Rhetorical scholars have paid special attention to the agency afforded to individuals in the politics of health, critiquing misrepresentations of public concerns while also looking for moments of rupture and resistance. Many have studied the strategies and effects of advocacy groups (Kopelson; Koerber; Owens; Spoel; "Communicating”; Stone). Others focus on the identities and ideologies that inform debates around health issues, along with their appearance in popular culture (Condit, Decoding, Meanings, "Bad Science," "Women's Reproductive Choices"; Condit and Condit; Segal, "Rhetoric" and "What"; Scott; Jack, Autism and Gender; Carmack; Emmons; Koerber et al.; Bennett). Attention 
has been paid to subjects as varied as pharmaceutical advertisements (Segal, "What"), online communication (Koerber; Emmons; Spoel), illness rhetorics (Scott), "pinkwashing" (Kopelson), gender ideologies (Jack, Autism and Gender), rhetorics of epidemic (Keranen, “Addressing"; Heifferon; Ding), and conceptions of genetic knowledge (Condit and Condit; Wilson).

As scholars in rhetoric began to engage with disability studies, studies of mental health and its particular modes of private and public rhetoric proliferated. Catherine Prendergast and Cynthia Lewiecki-Wilson explore how ideas of "mental illness" affect an individuals agency in society. Paul Heilker and Jason King explain that autism is rhetorical because "it is being constructed and reconstructed in the public sphere via strategic and purposeful language use" (114). Margaret Price draws attention to stories and stereotypes surrounding mental health, arguing that attention to the DSM and specific diagnoses is important for rhetorical scholars because "a [psychiatric] diagnosis is in essence a story—especially in DSM, which relies mainly upon descriptive criteria" (3). John Duffy and Rebecca Dorner write that "Theory of Mind," one way of explaining autism, is "a discourse of affect and value, or a rhetoric of scientific sadness" rather than a disinterested empirical model (201). Jordynn Jack extensively traces the "gendered characters" that have helped form and influence ideas about autism since it was first described in the early 20th century (Autism and Gender). The various rhetorical research approaches to mental health issues have, as in the wider rhetoric of health and medicine, a critical attention toward the subjectification of those deemed ill, the power of psychiatrists and other professionals, and the influence of "cultural" ideals and values on "scientific" views of illness and normality. My project works to extend this inquiry into 
particular online spaces with a primary focus on the individual at the intersection of stereotypes, values, narratives, and institutions.

In their report on the future of rhetorics of health and medicine, Scott, Segal, and Keranen acknowledge its expanding methodological diversity to "account for the complexities of language as social action" (3). Instead of studying persuasive strategies alone, new research in this subfield is often "shifting our focus from texts to the networks, ecologies, and activity systems that shape health-related discourse and its effects" (3). My project exemplifies this trend by using discourse analysis to complement rhetorical theories of language use. Initial readings of the data were performed using discourse analysis to investigate the ways that pieces of texts, however small, can reflect a speaker/writer's stance and ideology as well as contribute to social attitudes and relations when viewed as functional linguistic components. Ellen Barton describes this process and looking for "rich features" that connect text to context and form "the basis for conventions of meaning and interpretation" (Barton, "Linguistic" 66). Attention to rich features alone does not take a study outside traditional rhetorical studies, however. In their introduction to the collection Rhetoric in Detail: Discourse Analyses of Rhetorical Talk and Text, Christopher Eisenhart and Barbara Johnstone point out how the volume's studies differ from other scholarship in the field: "a mostly qualitative, interpretive approach...that differs from the approaches often taken in rhetorical studies in being data-driven rather than theory-driven" and methods that "[work] upward from particular, situated instances of text and talk rather than downwards from abstract models of discourse" (2). Similarly, my project builds its conclusions from instances of a particular phenomenon - the appearance of medical language in particular online communities - to 
build a productive description of how the power of medical discourse affects individuals' lives and writing. With Barton and Eisenhart and Johnstone, I affirm that discourse analysis and rhetorical analysis can aid one another, and that rhetorical perspectives can be augmented usefully 'by discourse analysts' attention to how lexicon and syntax can evoke styles, genres, and prior texts and speakers, and thereby create social relations and experiential worlds in talk and writing" (Eisenhart and Johnstone 3).

Given the importance of using extra-disciplinary methods "in ways that leverage our uniquely rhetorical contributions" (Scott, Segal, and Keranen 3), I have adopted two forms of linguistic analysis that fit most closely, for my work, with the goals of rhetorical inquiry — systemic functional linguistics (SFL) and critical discourse analysis (CDA). Some forms of linguistics seek to explain how language works as a system, with a goal of describing internal relationships and comparing language systems to one another. In SFL, on the other hand, more attention is paid to the social function of language forms. A certain formulation, then, becomes interesting in SFL not simply for its grammatical or stylistic uniqueness but for how it connects to a nested set of larger contexts. M. A. K. Halliday and James R. Martin, in their collection Writing Science, explicitly invoke rhetoric numerous times as a complementary concern with discourse analysis. Explaining how language shaped scientific reasoning, Halliday and Martin argue that technical terms and compounded nominalizations "could be combined to construe a particular form of reasoned argument: a rhetorical structure which soon developed as the prototypical discourse pattern for experimental science" (7). Further, since "a scientific theory is a linguistic construal of experience" (8), it reflects certain interests and ideologies, each of which with their own rhetorical trajectory in wider discourses. The connections that SFL 
analysis makes between language and context can help to illuminate rhetorical strategies in a single text as well as identify similar strategies in other texts. The methodological "leap" from SFL to rhetoric is more of a step because of their already congruous goals of inquiry.

Another variant of linguistic study, critical discourse analysis, works "to explicate abuses of power promoted by...texts, by analyzing linguistic/semiotic details in light of the larger social and political contexts in which those texts circulate" (Huckin, Andrus, and Clary-Lemon 107). Describing the broader category of critical language study, Norman Fairclough notes that the term "critical" in this method

is used in the special sense of aiming to show up connections which may be hidden from people - such as the connections between language, power and ideology...[this method] analyzes social interactions in a way which focuses upon their linguistic elements, and... set out to show up their generally hidden determinants in the system of social relationships, as well as the hidden effects they may have upon that system. (Language and Power 5)

Critical language studies share some common ground, then, with SFL in looking for larger social functions for the pieces of language under analysis. Methods like CDA go further, however, in attempting to trace the relations of power that are manifested in language. Alongside and complementarily to the analysis of power, CDA can also investigate the effects of social practices on language; Theo van Leeuwen writes that "all texts, all representations of the world and what is going on in it, however abstract, should be interpreted as representations of social practices" (Discourse and Practice 5). On this point, van Leeuwen and other CDA scholars assume that social practices generate institutions and forms of knowledge, rather than assuming abstract systems generate practices. CDA, like SFL, also takes into account segments of language much larger than the sentence, opening up any pattern — genres, theoretical frames, metaphors, 
governmental laws - as a potential vehicle of social significance. Above all, the analytical goal of CDA is social critique: illuminating social problems and inequities, identifying their construction in language, and offering alternatives that create more balanced systems of social power.

Certain ways of employing SFL and CDA in my project make its methods and conclusions relevant for Rhetoric and Composition. Ellen Barton summarizes the myriad approaches to discourse analysis as work that "somehow considers the structure of language and its functions in social and cultural contexts" ("Linguistic" 60). One method of focusing discourse analysis is to look for "rich features" that connect text to context and form "the basis for conventions of meaning and interpretation" (Barton, "Linguistic" 66). In my study, the rich features are structured as specialized language drawn from diagnostic criteria or neurological research, yet their function varies widely. Further, my research reaches toward critical discourse analysis, I have explicated, in part, the influence of the DSM and the general biomedical model on the self-reported experiences of individuals. These concerns necessarily implicate power relationships between doctor and patient, as well as institution and public - relationships ripe for study through CDA.

\section{Ethical Considerations}

Building on the ever-present concern for student welfare common in our field since its inception, scholars in Rhetoric and Composition have devised practices for classroom research that respects the students' needs, their privacy, and their dignity. Feminist methods stress the benefit toward research participants and suggest a relationship of reciprocity (Kirsch and Ritchie; Powell and Takayoshi). Movements toward service-learning and community literacy (Peck et al.; Flower; Deans) and activist 
research (Cushman) have highlighted the need for different ethical practices when research is conducted outside the university and with marginalized populations. For my own study involving online communities of individuals with mental disabilities, an ethical research approach included a vigilance toward protecting vulnerable participants, careful and collaborative means of representation, and a method tailored for the unique online settings in which I gathered data.

My primary research participants are individuals with a mental disorder diagnosis and/or a self-identification with a mental disability who are involved in online communities dedicated to a certain diagnosis or condition. All participants are adults, but the digital environment may create a variety leaning toward young populations. Since members of these communities organize themselves online rather than in a physical location, they are dispersed geographically.

Taking into account pitfalls identified in prior research (Galegher, Sproull, and Kiesler; Gajjala), I have avoided privileging the research target (natural talk) over individual consent in this study. To determine an ethical stance toward my research participants, I employed Heidi A. McKee and James E. Porter's “casuistic heuristic," which was developed in order to meet the needs of writing researchers in online spaces to estimate appropriate levels of consent. In their book The Ethics of Internet Research, McKee and Porter argue that we cannot simply import ethical guidelines from ethnography, linguistics, or sociology; we must create guidelines that fit the new research situation. The heuristic on informed consent takes four variables into account: privacy, topic sensitivity, degree of interaction, and subject vulnerability (McKee and Porter 88). By rating the extent to which each variable is a risk, a researcher can judge whether 
consent is necessary and what kind of documentation is needed. Applying these categories to my own project, the possible research participants likely have moderate, and varying, expectations of privacy in online communities; the topic sensitivity is high; my degree of interaction with the participants was moderate but direct; and the subject vulnerability is high. Given my high degree of ethical responsibility in this research venture, I made the following efforts toward acknowledgement and consent.

During the project, I made my presence and intentions as a researcher in these online communities known in several ways. First, I began relationships with moderators of these forums when possible and explain to them my perspective on mental disability and my research plan for qualitative observation and interaction. These moderators informed me about the conventions in a particular forum and perhaps point me toward likely research participants in the group. Second, I identified myself in each online community as a researcher before engaging in conversations or soliciting interviews, and I made a post describing my research project where possible and permissible. Before beginning the consent process, participants were fully informed of my position as a researcher and the direction of this project in personal communications as well as the IRB documentation.

Further, I have rendered the conversations anonymous. If any particular section was quoted for the analysis, I contacted the writer to obtain consent before publishing. Participants were given the opportunity to comment on my representations of their writing and offer corrections or ask that certain parts be omitted.

I have worked to provide the greatest possible benefit to participants, however modest, including the chance to tell their stories in forms, and to audiences, that might 
not otherwise have been available to them. If their stories and opinions are included in my published research, they have had a chance to affect how they, and others with similar experiences or conditions, are represented to and perceived by the public and the academic community. Gathering individuals' self-representations maintains the participants' voices in my research and also counters the dehumanizing effects of medical discourse that generalizes experience across populations and marks identity solely according to a condition or illness; these self-representations are an essential unit of study for my analysis. Echoing Melanie Yergeau, these methods have allowed me to ethically "[examine] the complex interplay of body, self, mind, narrative, and being” (n.p.).

\section{Chapter Overview}

In this chapter, I have contextualized my overall dissertation project, which analyzes the discursive and rhetorical means that writers in online mental health discussion forums use to make arguments about a particular diagnosis and their experience of mental disability. I situated my research in relation to previous scholarship in Rhetoric, Disability Studies, and other fields, finding common ground in the accounts of power and agency in medicine; histories and critiques of psychiatry; and focus on the experiences, and social advocacy, of people with disabilities. I provided a summary of the set of mixed methods I use to gather and analyze my data, including rhetorical analysis, corpus analysis, and qualitative interviews.

In Chapter 2, "Medical Terminology and Discourse Features of Online Discussions of Mental Health," I explore the ways in which medical discourse appears in 
discussions of mental disability, in particular through medical terms ${ }^{2}$ that writers and speakers use when discussing a diagnosis of autism or post-traumatic stress disorder (PTSD). Using methods borrowed from linguistics, I analyze online conversations to identify repeated patterns of discourse and connect them with rhetorical moves in their respective communities. Through the analysis of my archive of online conversations, and in comparison with the Corpus of Contemporary American English, I demonstrate that the writers in my study make different linguistic choices than the general public, and that the most prominent differences are related to the social construction of mental health and medicine.

Chapter 3, "Inhabiting Biological Primacy with Chiasmic Rhetoric in Mental Health Forums," I describe and analyze a variety of common topics in online conversations that connect mental health and expert knowledge of the brain. I argue that this connection of mental experience and brain science constitutes a chiasmic rhetoric, a rhetoric of crossing in which discourses often separate, or even opposed, are combined in novel ways. The writers foregrounded in this chapter acknowledge and accept much of the claims of medicine and neuroscience regarding the brain but, uniquely, work to divide that knowledge from the path of normativity and optimization. In so doing, these writers are embarking on a rhetorical reconstruction of medical(ized) knowledge that separates scientific observations from the exaggerated applications often peddled in popular reporting of science.

\footnotetext{
${ }^{2}$ While I do mean "medical terms" in the strict sense of the disciplinary language used to describe the body or diagnosis, I also include terms that refer to medicine, such as references to knowledge-making or clinical practice (e.g., trial, treatment, patient).
} 
Chapter 4, "Classified Conversations: Psychiatry and Technical Communication in Online Spaces," examines the practices of participants in online mental health discussion forums conversations as they interpret technical documents, including American psychiatry's "charter document," the DSM. I detail four salient forms of the manipulation of medical discourse in online communities: (a) demonstrating ethos through scientific literacy, (b) "unpacking” a diagnosis, (c) navigating medical care and support services, and (d) changing diagnostic language to benefit the community. At the close of this chapter, I explain how these insights can inform academic study of writing in mental health contexts and transform the content and application of medical and technical texts.

In Chapter 5, "Re-Forming Mental Health: Rhetorical Innovation and the Language of Advocacy," I describe the terrain of popular thought and advocacy for the two diagnoses studied in this dissertation, autism and post-traumatic stress disorder. Afterward, I summarize and synthesize the core arguments of earlier chapters, with an extended caveat regarding the ethical dilemmas of this study. Finally, I offer a set of practical recommendations for different communities with which my research has been conversant, the fields of Rhetoric and Rhetoric of Health and Medicine, Disability Studies, and activism related to mental disabilities. 


\section{CHAPTER II}

\section{MEDICAL TERMINOLOGY AND DISCOURSE FEATURES OF ONLINE}

\section{DISCUSSIONS OF MENTAL HEALTH}

The model of technical terms as accumulations of less specialized meaning is however not adequate. Meaning accumulation is just one aspect of their function. This is because at the same time as they gather together meanings, technical terms also construct new relationships among them. They establish new valeur. (J. R. Martin, "Life as a Noun: Arresting the Universe in Science and Humanities" 229)

When exploring the uses of texts in medical settings, scholars of rhetoric have found various ways in which medical power is instantiated through speech, writing, and other semiotic behavior. The persuasive strength of medical discourse derives from its cultural and institutional power. Doctors, professional organizations, and pharmaceutical companies have outsize influence in the creation of medical policies and regulations, which in turn direct the treatment and status of patients. Medical diagnosis represents a truth about someone's physical or mental state, and a person's denial of diagnosis can sometimes itself be considered a symptom.

What current approaches to medical rhetoric address less frequently, however, is the way such power can be embodied in the smallest microstructures of language. Many studies analyze power as it is realized in genre, stance, and conversation, yet these levels of symbolic action also interact with, and are grounded by, the smaller level of grammatical resources chosen by the speaker/writer. That is, as a set of medical genres can comprise an institutional chain of action, such as the treatment of patients in their 
end-of-life care (Keränen, “'Cause Someday”; Hyde, "Medicine, Rhetoric, and Euthanasia"; Schryer et al., "Creating Discursive Order"), the genres themselves are composed of pieces of discourse that are associated with medical settings, including terms, abbreviations, phrases, clause complexes, and word forms. These associations are not random but reflect a particular configuration of knowledge, authority, and behavior that is extended through professional convention and institutional structure. In the terms of systemic functional linguistics (SFL), we might say that medical discourse takes certain linguistic forms because of the social functions those forms serve. Medical discourse is not simply jargon or technicality; it "constructs new relationships," as Martin writes, between ideas, things, and actors that conform to its underlying ideology of activity.

When medical discourse, or discourse produced in the service of medicine, appears in other contexts, then, it will to some degree impart the ideological content of biomedical practice alongside the "dictionary meaning" of a term or phrase. When someone uses a word like "bipolar," she implicates the wider biomedical taxonomy of mental disorder of which it is a part; she also accedes, to some degree, to the biomedical logic of mental disorder, that it presents in discrete forms that may be diagnosed and that reflect individual, physical realities over against social ones (see Chapter 3 for further exploration of this "biological primacy"). In this way, using bipolar to describe someone's behavior-as opposed to other terms like mad, eccentric, crazy, colorful, etc. - carries significant ideological weight. The medical term may be chosen for its lexical "precision" or "technical" quality, but it brings with it a particular view of human 
emotion and behavior, of our knowledge of the brain and body, of the authority of scientific knowledge, and of relative power between scientists/physicians and laypeople.

In this chapter, I explore the ways in which medical discourse appears in discussions of mental disability, in particular through medical terms ${ }^{3}$ that writers and speakers use when discussing a diagnosis of autism or post-traumatic stress disorder (PTSD). Using methods borrowed from linguistics, I analyze online conversations to identify repeated patterns of discourse and connect them with rhetorical moves in their respective communities. To perform this analysis, I used a powerful corpus analysis software, AntConc, to find words and phrases that were quantitatively associated with the terms autism, post-traumatic stress disorder/PTSD, and diagnosis. Through the analysis of my archive of online conversations, and in comparison with the Corpus of Contemporary American English, ${ }^{4}$ I demonstrate that the writers in my study make different linguistic choices than the general public, and that the most prominent differences are related to the social construction of mental health and medicine.

Corpus linguistics provides a set of powerful empirical methods for studying large amounts of text accurately within the limits of the analysis program's central functions. The patterns I describe below focus primarily on collocations, or words that appear before or after the target term within a particular corpus. Systemic functional linguistics (SFL), as described by Halliday, Martin, and Eggins, allows me to identify significant patterns of usage and place them in their grammatical and generic context. Critical discourse analysis (CDA) offers a framework for connecting linguistic phenomena with

\footnotetext{
${ }^{3}$ While I do mean "medical terms" in the strict sense of the disciplinary language used to describe the body or diagnosis, I also include terms that refer to medicine, such as references to knowledge-making or clinical practice (e.g., trial, treatment, patient). ${ }^{4}$ The corpus methods and rationale are explained later in the chapter.
} 
social ideologies and practices, with an additional emphasis on frequently overlooked manifestations of power in language.

Each of these linguistic approaches has been represented in scholarship in Rhetoric and Composition, but their representation has been low compared to other frameworks for research. SFL holds particular importance for comparative studies of academic writing (cf. Aull and Lancaster 2014; Hewings; Hyland 1998 and 2005; Lancaster 2014; Mao; North; Vande Kopple), some of which employ corpus methods to examine their subject texts. Corpus methods have also informed research in rhetoric and the digital humanities, such as Nelya Koteyko's study of the appearance of carbon-related phrases in environmental blogs over time. As I describe below, articles by Huckin, Andrus, and Clary-Lemon and Price suggest CDA as useful tool for rhetoricians to study power in discourse and writing. For the purposes of these scholars, as well as my own, the discipline of linguistics offers a complex and unique lens through which to view the mechanics of persuasion in language, utilizing terms, categories, patterns, and modes of meaning not typically taken up in rhetorical scholarship.

- In the following section, "Competing Conceptions of Mental Disability," I describe the social contexts and scholarly conversations that inform my corpus analysis.

- Next, in "Linguistic Foundations," I explain how linguistic theories of taxonomy and technicality offer a way to see medical ideologies in discourse.

- Then, in "Linguistic Analysis of Corpora," my central results section demonstrates the differences between general American discourse around mental health and the language chosen in my archive of online conversations.

- Finally, in "Collocation Patterns and Medical Ideology," I conclude with a summary of implications from the corpus analysis.

\section{Competing Conceptions of Mental Disability}

As I described in Chapter 1, this dissertation intends to build on scholarship in our field by illuminating the rhetorical and discursive patterns within online forums devoted 
to particular mental differences and disabilities. Three essential contexts I use to view these patterns are (1) the authority and power of medical institutions, (2) the shift in psychiatric theory and treatment to the biomedical model, and (3) the disability rights and neurodiversity movements. The complex of cultural relations between institutions, physicians, care providers, and consumers has resulted in a great deal of power conferred to medical experts alongside a growing skepticism among some groups about medical treatment of mental health issues. One might expect conversations about mental health to vacillate between these poles, especially in communities of people diagnosed with mental disorders — one group siding with the medical establishment and another resisting it. My research reveals much more nuanced arguments built in online discussions forums, however, demonstrating that the private discourse of these participants does not fit cleanly with a pro- or anti-medical model political stance. Instead, the participants engage in conversations that often, if sometimes indirectly, seek to establish the limits of medical and scientific authority with regard to mental disabilities.

Of course, such topics are discussed in the popular media, frequently in relation to a particular event, like cases of physician or caretaker abuse, mass shootings, or homelessness. In media accounts, quotes from medical and policy experts usually serve as evidence for one stance or another. In contrast to much public discourse on such authority, the participants in forums I studied use their own experience of mental difference or disability as pieces of evidence and instruments of ethos. The accounts of personal experience function as much more than complements to medical knowledgethey also frequently work to counter medical and institutional "facts" about their disability. In more public arenas, these writers might feel the need to counteract the 
stigma of their condition to be heard, to remove what Jenell Johnson terms the kakoethos ("bad character") carried with an identification of mental disorder. Within forums devoted to these conditions, however, a common understanding and solidarity arises: the mental difference is not a barrier to persuasion but an essential part of it. An "NT" or neurotypical, to use one term, stands outside the condition and cannot faithfully describe its personal or social effects; someone who is neurodiverse or "neuroqueer" can. As one study participant told me in an interview, neurotypicals simply cannot faithfully describe autism: "If they [psychiatrists] are not fellows on the journey, how do they know what it's like?" (IR). At its most extreme, the NT perspective is parallel to the disconnected and "disinterested" physician who may deny the presence of a condition or apply treatment to an individual who does not want it. One writer [non-participant] on an autism forum says that "NTs" consider any hidden health concerns (i.e., invisible disabilities) as "an excuse to get out of something." Another writer [non-participant] asserts that they have more knowledge of Asperger's Syndrome than most clinicians, and they feel that "NTs" consider autism an "illness to be cured" through medication or therapy.

Yet scientific and medical language permeate the online forum conversations I studied for this dissertation, often functioning as a central warrant for persuasion. When discussing the issue of self-diagnosis, for instance, writers frequently posted as evidence links to studies in the scientific mainstream, from academic journals or the National Institutes of Health (see the discussion of scientific ethos in chapter 4). Joanna, a study participant from a PTSD forum, describes how, after being "misdiagnosed" by a number of doctors and therapists in her life, she conducted research through a local library and 
"came across PTSD in the medical journals." Joanna includes this research as part of her process of self-understanding, but also to demonstrate her knowledge of PTSD in a conversation where she offers advice to others with the diagnosis.

Even when writers were critical of medical institutions or the field of psychiatry, the issue at hand was the method for establishing validity, the parameters of medical certainty. Thus, while some apologists of psychiatry characterize neurodiversity as an anti-science movement, ${ }^{5}$ the conversations I studied had no such attitude. The skepticisms that writers in these online conversations put forward were amenable to scientific knowledge and similar to those offered by prominent psychiatrists like Allen Frances. In fact, many of the writers echoed some historic insecurities of psychiatry: that their practice is not medicine, not scientific, but made of cultural stuff. The critique itself is driven by what might be called a scientific impulse - to consider knowledge in flux until conclusive evidence can be gathered. Thus, theories of mental disorder with limited or incomplete evidence, such as the oft-lamented "Theory of Mind" but also the more favorable "Intense World Theory" of autism, ${ }^{6}$ should be treated as contingent rather than

\footnotetext{
${ }^{5}$ Neurologist and blogger Manuel Casanova claims neurodiversity is a "catastrophic movement for autistic individuals" and a "world of excesses, ruled by black-and-white principles." Casanova believes neurodiversity advocates are an entitled "elite" whose personal accounts are "biased" and "science by press release."

${ }^{6}$ Theory of Mind (ToM), a theory about autism championed by psychopathologist Simon Baron-Cohen, posits that people with autism (especially children) have difficulty imagining the "inner thoughts" of other people, a problem that leads to a supposed lack of empathy and emotion. ToM is routinely criticized in autistic self-advocacy as perpetuating negative stereotypes and misunderstandings of autism. The Intense World Theory, by contrast, posits that people with autism have a hyper-reactive neurology that leads to "obsessively detailed information processing of fragments of the world and an involuntarily and systematic decoupling of the autist from what becomes a painfully intense world" (Markram and Markram n.p.). This depiction of autism is more wellreceived as sympathetic of the autistic individual's experience and less prone to stigmatizing statements of deficit or dysfunction.
} 
definitive pictures of those conditions. In an argument I explore further in Chapter 3, a few writers [non-participants] on autism forums refer to psychiatry as a "soft" science with standards based on description rather than measurement, and thus its conclusions should not be taken as definitive in the same way that we treat the principles of, say, physics or chemistry.

In other words, the writers are not trying to substitute another worldview, another type of rationality, but are rather participating in "scientific" thinking and the chain of philosophies this implies. What makes their statements distinct, with respect to mainstream medical and psychiatric theory, is the emphasis on the experience of the "patient" as an essential factor in diagnosing, treating, and supporting those with mental disabilities. ${ }^{7}$ In sum, much of the writing in my archive contributes to or works within scientific conversation rather than objecting to it.

The significance of this quality becomes clear when we reflect on a commonplace binary in disability studies: the medical model versus the social model. While the logic and utility of the social model of disability has been critiqued from many angles (see Shakespeare 2006, 2013; Clare 2000; Crow 1996; Kafer), its premise continues to function in opposition to the medical model; in turn, social constructivism and traditional science seem to be opposed.

This social/medical model divide — and essentialism—are mirrored in the debate surrounding the status and definition of "mental illness." Neil Pickering outlines this historical debate in The Metaphor of Mental Illness, where he contextualizes and critiques different approaches to conceptualizing mental illness. Pickering writes that the

\footnotetext{
${ }^{7}$ In contrast with patient-centered care, $\ldots$
} 
broad approaches can be broken down to three general groups, one that takes mental illness to be a literal, physical thing and two that are "skeptical." group claims that "mental illness" is a only a metaphor, and a deceptive one at that; further, psychiatry itself is a kind of pseudo-science based upon behavior and outside the more legitimate medical sciences. Epitomized by the writing of Thomas Szasz, people in this group find "mental illness" to be a concept used against vulnerable people to their detriment, resulting in a voiding of human rights. The second skeptical group follows the "strong programme of the sociology of knowledge" and claims that "mental illness" is created by those practicing psychiatry —as is the case with all objects of all sciences that "create their objects by creating the categories of things" (Pickering 113). In this debate, as with the divide between the medical model and the social model of disability, those arguing for the individual and physical basis of disability find the skeptical views to be wrongheaded and counterproductive, while those arguing from social concerns find the mainstream views to be reductive, overreaching, and even demeaning.

The political effects of the debate are potent not only in their divisive power: many psychiatrists seek to rid their profession of the stain of the "medical model" in its most offensive, paternalistic form. In their editorial "The Medical Model is Dead—Long Live the Medical Model," published in the British Journal of Psychiatry, Premal Shah and Deborah Mountain write that a "refinement of definition" (375) is necessary to demarcate what exactly the medical model is and how it is followed within psychiatry. For Shah and Mountain, the medical model should be defined as "a process whereby,

\footnotetext{
${ }^{8}$ Pickering himself works to present a novel view of "mental illness" distinct from these groups, "hold[ing] on to the idea that psychiatry may be a science while at the same time thinking that some of the objects of the science are created by scientists" (102).
} 
informed by the best available evidence, doctors advise on, coordinate or deliver interventions for health improvement" (375). They contend their approach is "ideology and assumption free," with a treatment's basis rooted in evidence rather than ideology or "gut feeling" (Shah and Mountain 376). ${ }^{9}$ Though a number of critiques could be leveled against their argument, and the accusations of philosophical "extremism" that underlie it, I would like to highlight the intentions of the writers here- that they want to discredit the "caricature" (375) they see posed by those resisting the authority of psychiatry and avoid "los[ing] the hard-earned gains in defining effective psychiatric treatments," all while "improv[ing] the credibility of psychiatry as a medical specialty" (Shah and Mountain 376).

Shah and Mountain may have found a sympathetic audience in the $B J P$. However, their efforts are unlikely to make headway with those who mounted critiques of the medical model in the first place-including those in various groups promoting disability rights, like the Disabled People's Movement that they mention. I would like to parse out the pitfalls in their brief argument, attending to the rhetorical effects of certain argumentative moves and definitions as they relate to my larger analysis. First, the argument begins by portraying those critical of the medical model as extreme and reductionist themselves: "We suggest that the difficulty lies in accepting that the human mind is also biological. ... Banishing biology to reductionism merely defends our need to preserve the sanctity of "the mind"" (375). In writing that resistance stems from an antibiological stance, Shah and Mountain misunderstand the motivation for confronting the medical model and elide its problematic effects. Elisions also appear in relation to

\footnotetext{
${ }^{9}$ Note that "true" scientific inquiry is viewed here as free of ideology. Further, Shah and Mountain do not attempt to define what counts as evidence in their model.
} 
medical authority and patient agency. The doctor is portrayed as an "advisor" who only informs the patient's decisions. Since "medicine has always been about helping patients 'take charge' of their recovery by whatever means available," they conclude that “"patient empowerment'... has little to do with rescuing patients from the medical model" (376). These statements fly in the face of the history of psychiatric treatment, most especially the decades-long dominance of asylums, as well as current situations involving involuntary hospitalization, psychiatric treatment in the judicial system, and children whose parents serve as arbiters of treatment. (I know of no one protesting the medical model because a psychiatrist might offer someone the option of taking antidepressants.) Finally, the nature of "evidence" is never defined or justified, and the reader is led to infer that useful evidence only comes from conventional medical studies that focus on etiology rather than effect. The concern for medical evidence implicitly denies the value of patient experiences in psychiatry, and, once again, misses the point of the original social critiques.

The justification for medical practices offered by Shah and Mountain illustrates how those within the psychiatric establishment and advocates for its reform often speak across one another, with genuine dialogue a rare occurrence. The public dissonance is not always carried into more private settings, however, and the language we find in the everyday online conversations of those with mental disabilities does not cleanly line up with this pro-/anti-medical model opposition. In contrast, when discussing their diagnosis(-es), my study participants can be found discussing the merits and drawbacks of medical accounts of mental disability without rejecting or accepting them outright. For instance, Stephen, a PTSD forum writer, argues for changes in psychiatry like the formal 
recognition of Complex PTSD, but also says that "I can't do it on my own," and so he will "go on bothering the NHS mental people until I get help" through medication and therapy (OC). Rather than dealing with sweeping, abstract generalizations, these conversations often reflect a different perspective on care and services provided through medical institutions: a limited and individual view, but a detailed one that takes into account not only the philosophy of treatment but also that philosophy's precursors and successors, its scientific validity, its effects on quality of life and self-perception, and its implications for the politics of mental health in the public realm. This combination of considerations amounts to a substantial cultural and institutional critique that unfolds in disparate fashion within discussion board threads.

One might observe that issues of quality of life and the politics of patienthood have been associated with the patients' rights movement for decades, with parallel concerns in women's health and disability rights. The model of patients' rights most often taken up in medical settings, however, makes these issues the sole territory of patient expertise with the authority of the doctor in medical matters left intact. Perhaps the patient is given a choice or legal provision, or treated with more respect, but the physician-patient power inequity is maintained. Some may be content with this dynamic, ceding the scientific authority of the physicians and researchers who create treatments.

Many conversation participants I studied, however, took a different stance: they both questioned the boundless authority of the medical establishment while also using its terms, documents, and research to argue for new conceptions of mental health and its treatment. In other words, they sought to enter the scientific conversation surrounding their conditions, and psychiatry more generally, rather than oppose it uniformly. A 
significant number of thread posts in my archive quoted medical documents like the DSM in order to parse its relevance and application, not discredit it, and several discussed scholarly medical articles from psychiatry and neuroscience to build their arguments. Rhetorically, these participants were refusing the reductive binary easily visible in the politics of mental health without abandoning a reformist motivation. To preview two such moves outlined in Chapter 3, study participants accept many findings of neuroscience about the brain's inner workings but place those findings in context with accounts of emotional reactions and personal experiences; and participants actively discussed the limits of medical authority regarding their diagnosis, acknowledging the scientific and social function of psychiatric practice without granting them exclusive expertise. In these online spaces, the use of individual experience as a basis for both credibility and affective knowledge does not supplant, but works alongside, traditional appeals to rationality that invoke the authority of experts and a disinterested scientific method. This combination of persuasive appeals is illuminated in this chapter by the functional and critical linguistic analysis of online conversations.

\section{Linguistic Foundations}

In Writing Science, Halliday and Martin write that new terms or grammatical forms construct new relationships between the things they are thought to represent. Halliday and Martin focus on linguistic and taxonomic relationships in that volume, but I expand their observation to include a broader realm of social interaction—between ideas, agents, texts, and organizations. ${ }^{10}$ And the crossing of different systems of relationships

\footnotetext{
${ }^{10}$ The vertical connection between language, texts, and social practices mirrors the approach of institutional ethnography developed by Dorothy E. Smith, who finds that
} 
breeds a new form altogether: it's never one or the other, medical model or social disability model, but rather dynamic systems of relationships that evolve with the political landscape, new scientific knowledge, and changing social values. While the conversations studied here do not represent a unified and comprehensive strategy, their patterns of topic and argument point to an emergent orientation toward medical institutions that reflects recent developments in disability and neurodiversity activism.

Before mapping the rhetorical and political work that medical and scientific language might be doing, however, we need a method for identifying it presence and function. Since my study corpus is drawn from vernacular settings, without enforced genre conventions or rules of style and usage, medical terms appear within everyday writing and outside of the context of its original production. Medical writing shares many conventions with other types of scientific writing, and thus the discourse features common to scientific writing are useful in identifying the appearance of medical language in everyday conversation.

Given the strong conventional pressures in academic and specialized scientific writing, certain linguistic features increase in frequency and consistency. Systemic functional linguistics refers to the "syndromes" or "patterns of co-occurrence" (Halliday and Martin 4) in the language structures as a register. While technical terminology is perhaps the most recognizable aspect of the scientific register, "the distinctive quality of scientific language lies in the lexicogrammar (the 'wording') as a whole, and any response it engenders in the reader is a response to the total patterns of the discourse" (Halliday and Martin 4). That is, a range of features is producing the scientific register, at

"technologies of social control are increasingly and pervasively textual and discursive" (DeVault 294). 
many levels of complexity—from prefixes to paragraphs. These features include specialized terminology, lexical density, Latinate taxonomies, frequent use of nominalization, and lack of first-person pronoun subjects (Banks, The Development of Scientific Writing). While none of these features are exclusive to the scientific register, and no one feature constitutes that register on its own, their co-occurrence points to a scientific manner of representing things and ideas. No matter where they occur. When they appear within online discussion boards, these features tether informal conversations to a wider system of producing and communicating knowledge and its particular way of ordering experience.

As implicated in the SFL conception of language as socially "driven," the linguistic forms of the scientific register and its undergirding assumptions are not rhetorically neutral (see chapter 1 for a full explanation of SFL and its utility in this dissertation). Halliday and Martin see the nature of the scientific register as a confirmation of a constructivist view of language:

The language of science demonstrates rather convincingly how language does not simply correspond to, reflect or describe human experience; rather, it interprets, or as we prefer to say, "construes" it. A scientific theory is a linguistic construal of experience. (8)

This "linguistic construal" is one of many possible perspectives with its unique affordances and limitations. In discourses of mental health, a multiplicity of perspectives is apparent in the division between, say, biomedical and social constructivist views of mental illness. The linguistic patterns connected with these views, then, can function as signifiers of particular ideologies or methods of persuasion where they appear. 


\section{Taxonomy and Technicality}

For this chapter's analysis, I will focus upon the linguistic patterns associated with vernacular and technical taxonomies of mental health to observe how they're employed individually, combined, used in tandem, or contrasted to achieve rhetorical goals. Table 1 lists some of the most common rhetorical functions of scientific terminology or register I observed in discussion board conversations. These labels will be further explained and applied in the results section later in this chapter. Some of these functions use the "native" ideology of the scientific register-as when a writer names "facts" about the world proven by science without comment; others may be used to critique scientific ideology, making it an object of discussion. Scientific terminology or register may also operationalize the cultural functions of science- to make observations seem objective or to take on the intellectual authority of scientific research. While these functions do not exclude one another, they often appear in certain patterns according to the writer's social and rhetorical goals - like the linguistic resources of which they are composed.

The specific resources I explore in this chapter, technical and vernacular taxonomies of mental health, point to the functioning ideology of the field or social group in which they are formed and certainly manifest themselves in linguistically distinct ways. Disentangling the various meanings of the taxonomic terms in context is not simple, however, since the lasting connections between technical and vernacular ways of conceptualizing mental differences makes simple binary (technical or non-technical) categorization difficult. 
In their essay, "The Discourse of Geography: Ordering and Explaining the Experiential World," Wignell et al. note that classification is not a uniquely scientific endeavor but "is characteristic of all fields, including everyday or nontechnical ones" (138). While technical taxonomies are often perceived as distinct from everyday categories, and judged as "better" or more accurate, they arise from everyday uses of language in the present and past. Wignell, Martin, and Eggins write that scientific taxonomies are not "made from nothing" in a direct line from observed phenomena to technical term:

...scientific taxonomizing typically involves two steps: the renaming of vernacular terms in order to then reclassify them into scientific taxonomies. A precondition of taxonomizing is the naming of things to be ordered. In the natural sciences, the process of naming is highly formalized. (143)

Technical terms are made technical by their reclassification and formalization, whatever their origin in outside discourses, including everyday talk. Of course, such formalization — epitomized by the Latin binomial system — usually follows strict rules, with names for individual things or phenomena (e.g., a species) and a defined hierarchy of organizing categories that increase in generalization (e.g., genus, family, order...). Care is taken to ensure that categories are mutually exclusive, or at least distinct in description, so that a member of one "genus" cannot simultaneously occupy another "genus." These organizational moves allow scientists to create categories that stay relatively consistent across space and time, may be externally and internally verified, and - importantly—embody the relationships between phenomena theorized in the field. In this way, technical taxonomies demonstrate how scientific terms produce a different construal of experience from everyday talk, where relationships between terms are more fluid and names are not coterminous with particular phenomena. 
For this project's purposes, technical taxonomies will comprise both psychiatric classification and treatment of mental illness and medical-neurological explanations of mental states. While my approach groups together a number of different, and sometimes competing, conceptions of mental illness, it allows for recognition of terms associated with a more general scientific register. The fields that produce these technical termsprimarily psychiatry and neurology—share a scientific approach committed to explaining mental and behavioral phenomena in terms of anatomical, biological, and chemical variation and that seeks to isolate individual differences from environmental and social influences. In pursuit of these goals, these fields produce vast classification structures that define particular conditions according to an expert's empirical observations or measurements. As Sue E. Estroff et al. argue, the technical taxonomies create value for clinicians and researchers, but perhaps not for others: "within the embrace of authorized naming and treating, the unknown becomes known and its nature ex- posed (or constructed, depending on one's point of view) at least to those with the authority to know, name, and treat" (332).

Vernacular taxonomies will comprise the wide range of terms (and systems of terms) used to describe mental experiences and differences outside of medical and psychiatric discourse. Vernacular taxonomies arise out of common usage and are regulated by a community's values and social purposes, making them less stable in their definitions and more fluid in their application in comparison with technical taxonomies. Vernacular terms to describe mental differences carry a range of evaluative meanings: relatively positive (“ecstatic"), neutral/descriptive (“anxiety," "fear"), relatively negative (“obsessive," "depressed"), and derogatory ("crazy," "insane," "looney"). While many of 
these vernacular terms are purely informal in origin, others are connected with technical taxonomies either by parallel/coincidence ("depression") or a history of abandoned technical usage (the derogatory term "hysteria" was until the mid-20th century a formal psychiatric diagnosis). Despite these connections, however, I consider vernacular taxonomies and terms to remain conceptually separate from the technical because of their perceived lack of positivist scientific basis.

While the perceived lack of positivist basis (an audience's judgment) may result from a number of factors - both linguistic and extra-linguistic — this lack is rooted in context rather than lexis. Because some terms have both a specialized and vernacular use (like "depressed"), the term's relative technicality is impossible to establish outside of their context of use: its surrounding rhetorical situation. The term's context is needed for the analyst to determine its meaning and rhetorical purpose - and of what kind of taxonomy, if any, it is playing a part. ${ }^{11}$ The word "depressed" can serve as a useful illustration. A psychiatrist can use a word in a professional context and call up a technical meaning (a hypothetical set of therapist notes might read, "I've noticed that Michelle exhibits symptoms of major depressive disorder"); anyone might use the word in another context and not imply the technical meaning ("Reading the news makes Michelle depressed"). In the first example, the context and utterance make it likely that Michelle is reporting recurring periods of deep sadness and lethargy that last weeks or months, fitting with the DSM definition of depression as a mental disorder. In the second example, the audience would make no such inference. Instead, we only find the vague message that reading news, for Michelle, creates some kind of sadness (though we gather nothing

${ }^{11}$ In the terms of SFL, a word has "meaning potential" but gains its meaning from its position and function in a particular utterance. 
about its duration, quality, frequency, etc.). In another sense, people may "reclaim" or recontextualize technical terms for their own purposes, as when autistic self-advocates use "autism" and "autistic" as descriptive and sometimes laudatory terms related to a particular identity rather than in relation to a set of clinical symptoms.

Typically in SFL, the word's context, and thus its specific meaning, would be determined through an analysis of smaller pieces of text—sentences or paragraphs, at most; this kind of local analysis makes the study of large texts or corpora impractical. However, methods from corpus linguistics can provide systematic analysis of texts or sets of texts using computer programs developed to study certain patterns in language. As described below, I study my corpus looking for relationships of collocation and clustering and then compare those results with a large representative corpus, the Corpus of Contemporary American English (COCA). Comparing my own corpus with COCA will allow me to show ways in which the writing from mental health discussion forums differs from the language used elsewhere. Statistical results from COCA can reveal patterns of average American usage and will serve as a "control" or baseline against which I can compare the results I have found in my corpus.

\section{Corpus Linguistics and Collocation}

As Mike Scott and Christopher Tribble explain, when studying large sets of texts, the analyst must employ corpus methods or rely on its "established alternative...intuition" (3). Scholars can use intuition to create profounds insights and directions for further study, but intuitive results are difficult to verify externally (except 
by agreement with others' intuition).${ }^{12}$ Corpus methods, in contrast, create data that can be quantitatively documented, reproduced, and verified. Though by no means exhaustive, the data produced by corpus methods provide a limited empirical measure of a set of texts - a measure that can then be used to identify, inductively, patterns occurring in the corpus. When Scott and Tribble write that "the tools we use [in corpus methods] generate patterns....and it is when we see these that in some cases the pattern 'jumps out' at us" (6), they admit, ironically, the role of informed intuition in making sense of the data produced by corpus methods. A recursive process arises, then, of producing data, interpreting it, and reviewing or re-producing data with an interpretation in mind.

In corpus linguistics computer programs, the "Collocates" function finds what words in a corpus most often occur within a certain range of a target word, or node. That is, the program finds each instance of the node in the corpus, marks what words occur (for example) four words to the left and right, and then returns a quantified list of the words that co-occur with the node (collocates). Using this list, one can compare the frequency or probability of collocates for a specific node within a corpus or compare the patterns of collocation with results from another text or corpus. Like most of the measures provided through corpus methods, the significance of collocation patterns in a given corpus is dependent on an informed interpretation of its context rather than an "objective" reading of the data.

Halliday and Mathiessen define collocation as "the degree to which the probability of a word (lexical item) increases given the presence of a certain other word

\footnotetext{
${ }^{12}$ I do not mean to imply that "unverified" intuition is somehow inferior to more empirical methods of text analysis. Neither are they mutually exclusive (Scott and Tribble 4). As I soon explain, they are in fact mutually dependent.
} 
(the node) within a specified range (the span)" (59). Christopher Gledhill, who distinguishes between three types of collocation, calls this the "statistical-textual" definition; he observes that this type of collocation is useful for analysts looking for "examples of typical style" (8). Words have an increased collocation when the probability of a words co-occuring with a node in a certain span is greater than the probability of the node occurring in the corpus generally. Gledhill notes that this increased probability is not a fixed statistical value, but that "from the point of view of many corpus linguists, all that separates collocation from mere word co-occurrence is the statistical level at which the researcher is happy to say that the co-occurrence is not accidental" (8). If we found a high collocation between the node season and the word change, for example, we might have "a heightened expectancy" of finding "change" in the "immediate neighborhood" of any instance of season (Halliday and Mathiessen 59). While this relationship would be unsurprising, it would signal a conceptual and/or lexical connection between the two words - that the noun season carries a sense of cycle or impermanence. We can also compare the relative degree of collocation between change and season with another corpus; perhaps in a second corpus consisting of advertisements, season collocates more highly with holiday. The statistical-textual view discourages thinking of collocations as "disembodied lexical units," like we might think of familiar combinations like "shrug his shoulders" or "strong tea" (rather than powerful tea); instead, collocates gain function from the textual context and may be "motivated or triggered by other phrases which appear to be at some distance" (Gledhill 8). A statistical pattern of collocation allows the analyst to identify with confidence simple patterns of topic, emphasis, or style. 
Of course, the identification of collocation patterns in a corpus does not necessarily yield useful insights, especially for a project, like this one, grounded in rhetorical theory. And while Gledhill describes a "discoursal-rhetorical” view of collocation (14), his definition is quite limited in its application and focused on "performance" or pragmatics in a local textual context. ${ }^{13}$ In contrast, my analysis will study collocation patterns with attention paid to latent expressions of power, scientific authority, and stance. In this way, my work coincides with the goals of Critical Discourse Analysis (CDA), which "analyz[es] linguistic/semiotic details in light of the larger social and political contexts in which those texts circulate" (Huckin, Andrus, and Clary-Lemon 107). As Huckin, Andrus, and Clary-Lemon argue, CDA can helpfully inform inquiry in Rhetoric and Composition by, in part, "provid[ing] a lens with which the researcher can coordinate the analysis of larger (macro) political/rhetorical purposes with the (micro) details of language" (111). In an article tying together Rhetoric and Composition with Disability Studies, Margaret Price argues for the usefulness of critical discourse analysis for "its ability to uncover the micro-shifts in language that signal larger critical shifts" (63).

In sum, the interdisciplinary approach of this chapter can be elucidated and justified in this way: corpus methods provide tools (computer programs) and pattern types (collocation) that make a large set of texts available for precise analysis; SFL, through its emphasis on the social function of lexis and grammar, provides a frame for explicating technical and vernacular taxonomies as well as categorizing word-level

\footnotetext{
${ }^{13}$ Gledhill writes that, "from this perspective, idioms such as to get the sack, to be fired can be contrasted stylistically with less marked expressions: to be dismissed, to lose one's job" (14). The difference in "markedness" is linked to the speaker/writer's interpersonal objective but not to a method of persuasion or a larger socio-political context.
} 
differences in discussions of mental health; CDA links these linguistic details with a political context of power and inequality; and rhetorical theory, especially via medical rhetoric, connects these varying insights by identifying persuasive moves made in writing and their significance for the writers and audiences involved.

\section{Linguistic Analysis of Corpora}

In this section, I present the results of an analysis of my corpus of online conversations around mental health, and comparison of that corpus with a representative corpus, COCA. As described in Chapter 1, my corpus consists of conversations gathered from three separate discussion boards devoted to either autism/ASD or PTSD, spanning the years 2009-2015 and totaling 200,000 words. The texts that make up COCA total more than 520 million words dated from 1990-2015 and "equally divided among spoken, fiction, popular magazines, newspapers, and academic texts" (“COCA" par. 3). By comparing collocations with key terms in my study between my corpus and COCA, I demonstrate how the topical focus, interpersonal quality, and treatment on technical terms differ between typical American discourse and the conversations happening online between people diagnosed or self-identifying with autism/ASD and PTSD. I begin with a collocation analysis of three key terms — diagnosis, autism, and PTSD — that fit within the technical taxonomy (as described earlier in this chapter) of biomedical psychiatry.

Diagnosis

When comparing the collocates of the node diagnosis ${ }^{14}$ between my corpus and COCA, I noticed a strong contrast in the topical words, expressions of certainty

\footnotetext{
${ }^{14}$ When searching for each node, I have used a root with a wild card marker (i.e., diagn*, where * returns any ending of the root) in order to cast the widest lexical net. Thus, diagn* will return results for "diagnosis" and also "diagnosed," "diagnostic,"
} 
(modality), and depiction of actors; below, I examine and illustrate these patterns. In my own corpus, the distribution of collocates of diagnosis fits with the genre of the discussion board—shorter, less formal words are more common, as well as personal language referring to the writer; COCA collocates are, however, much more likely to be related medical practice.

The most remarkable contrast between my corpus and COCA regarding diagnosis collocates was the frequency of words related to medicine. In doing this count, I included not only recognizably "medical" terms like syndrome or therapeutic but also words that referred to a medical process of some kind, like treatment, or a descriptor that refers to medicine, like clinical. In my corpus, the most frequent collocates linked to medicine explain what kind of diagnosis—professional/professionally, official/officially, medical— and tend to precede diagnosis. Writing to another person with PTSD, study participant Joanna says, "I too have been waiting $25+$ years for the official diagnoses of CSA related chronic-complex PTSD” (OC). Todd, a study participant and writer on autism forums, discusses the value of "professional diagnosis" in comparison with "self-diagnosis":

Not every individual with an ASD needs the stamp of approval that a professional diagnosis provides. Many, including myself, find satisfaction in screening tests. ... Unless an individual needs certain benefits or supports that only a professional diagnosis provides, the only other difference between a professional diagnosis and a self diagnosis based on a screening test is the cost and time involved with a professional.

Other collocates like valid and criteria refer to the diagnosis and evaluation process.

However, these words collate with diagnosis less frequently than references to people (as described below).

"diagnosing," etc. The COCA database and the AntConc software used to analyze my corpus use identical extra-textual markers. 
In the COCA database, words related to medicine take up more than half of the first 150 collocates with eighty-two (see Figure 1 for an illustration). These words vary widely but, while they include different word types, they are dominated by nouns (treatment, disease, disorder, manual, tests) and adjectives (clinical, differential, psychiatric, chronic). The heavy collocation with words related to medicine in COCA suggests that diagnosis is typically framed, however predictably, as a medical event; the overwhelming proportion of medicine-related collocates suggests that diagnosis is considered almost exclusively medical in nature, and that a diagnostic situation calls people to assume roles specific to medical contexts (I comment further on social roles below). At the appearance of diagnosis, one might say, medicine becomes the primary lens through which we can describe ourselves, our bodies, and our conditions.

One might object that since the COCA, as a representative "mega-corpus," covers so many topics and situations, its tendency toward medical collocates for diagnosis relates to a focus on traditional medicine rather than the psychiatric diagnoses that are the focus of this dissertation. The COCA collocate list reveals, however, a number of psychiatric and neurological conditions alongside bodily diseases like cancer, diabetes, or AIDS (see Table 1). The two conditions addressed in this study, autism/ASD and PTSD, are among the hundred most collocated words with diagnosis, and nearly half $(n=9)$ of the named conditions in Table 1 are either psychiatric or closely related to cognitive function. This relationship suggests that the medical predisposition observed in the previous paragraph is not disconnected from psychiatry or coincidental; in fact, 
discussions of psychiatry share a great deal of language with discussions of general medicine. $^{15}$

\footnotetext{
${ }^{15}$ The connection between psychiatry and medicine seen in the COCA database seems to reflect a broad public acceptance of psychiatry's sustained argument to be considered a medical subfield, as described in Chapters 1 and 4.
} 


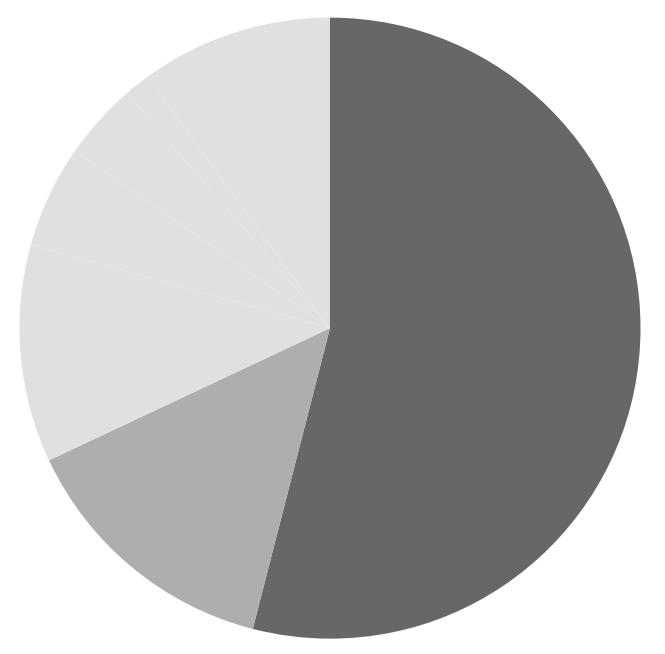

Medical Diagnostic label Other

Figure 1. Collocates of diagn* in COCA by selected categories. 


\begin{tabular}{|c|c|}
\hline $\begin{array}{c}\text { Rank } \\
\text { (by freq.) }\end{array}$ & Collocate \\
\hline 1 & Cancer \\
\hline 22 & Diabetes \\
\hline 25 & ADHD \\
\hline 30 & Depression \\
\hline 32 & Autism \\
\hline 36 & AIDS \\
\hline 44 & Asthma \\
\hline 46 & HIV \\
\hline 53 & Schizophrenia \\
\hline 61 & Bipolar \\
\hline 64 & Alzheimer \\
\hline 74 & Leukemia \\
\hline 75 & LD (learning disability) \\
\hline 100 & PTSD \\
\hline 101 & TB (Tuberculosis, 142) \\
\hline 109 & Sclerosis \\
\hline 122 & Lymphoma \\
\hline 130 & Dementia \\
\hline 146 & Melanoma \\
\hline 147 & Pneumonia \\
\hline
\end{tabular}

Table 1. Collocates of diagn* in COCA, condition names. Psychiatric or neurological conditions in bold. 
The close association of diagnosis with medicine in COCA is also reflected in expressions of certainty (termed "epistemic modality" in systemic functional linguistics) within the word's collocate list. (See Figure 2 for a comparison between COCA and the study corpus.) The COCA collocate list (top 150) for diagnosis contains seventeen words with positive modalization, such as accurate/accuracy, confirmed, specific, definitive, correct, and proper. While such terms must not be used as truth-markers in context (there could be a "doubt of accuracy"), the overwhelming presence of these positive modalizations suggests a belief in the possibility of objective judgment - that there $i$ an "accurate" or "proper" diagnosis even if it is not yet found. Even the few words in the COCA list that might be characterized as expressing doubt or negative modalization, like failure, still suppose a situation where "right" and "wrong" can be identified or measured. In my corpus, on the other hand, the proportion is flipped: very few positive modalizations and many expressions of uncertainty. The words ( 3 total) used by the writers in my corpus when expressing certainty, valid, know, and definition, are outnumbered by modalizations ( 7 total) that qualify information (though, but, if, could) and knowledge verbs that qualify certainty (believe, think, feel). For the writers in these forums, such qualifying language can point to the historically unstable nature of psychiatric diagnosis, its dependence on people and contexts, and its connections with self-identity as well as the characterizations of others.

While expressions of uncertainty might imply the actions of particular people, another category of word type states the actions of others explicitly. The depiction of actors, and their relative presence, varied between my corpus and the results from COCA. Of the 150 most frequent collocates in my corpus, ten are personal pronouns and six are 
what I will call person referents, any term that indexes a person or group (e.g. "person," "people," "individual," "someone," "self"). Five personal pronouns (I, you, they, my, me) and three person referents (self, people, who) occur in the top fifty most frequent collocates. These results suggest that writers in my corpus often conduct discussion around diagnosis with reference to the people involved in giving or receiving - $\mathrm{a}$ conclusion supported by focused readings of the forum conversations as well as participant interviews. In the COCA database, collocates of diagnosis much less frequently represent people: in the top 150 , there are eight person referents, with only four in the top fifty. Significantly, each of the person referents in the COCA collocates are either generic (individuals) or refer to linked social roles (doctor/doctors, physician/physicians, patient/patients, clients). (See Table 2.) In COCA, diagnosis places one squarely in the realm of medical care, where personal interactions are mediated by roles that give power and authority to certain individuals and not others. 
COCA

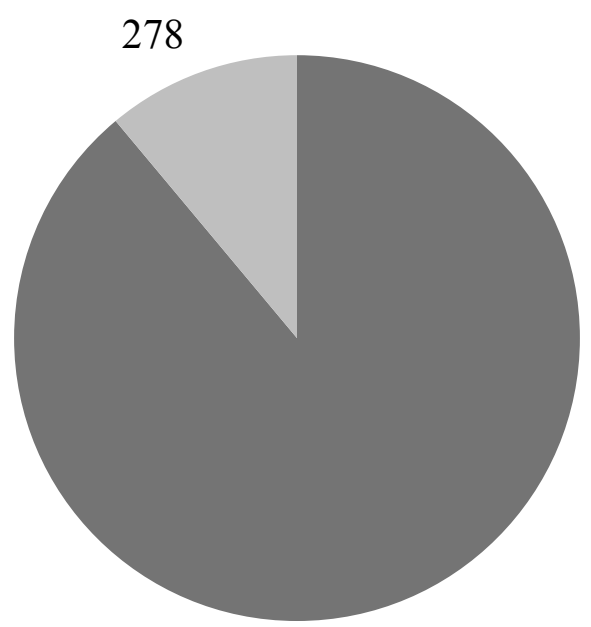

2232

Study Corpus

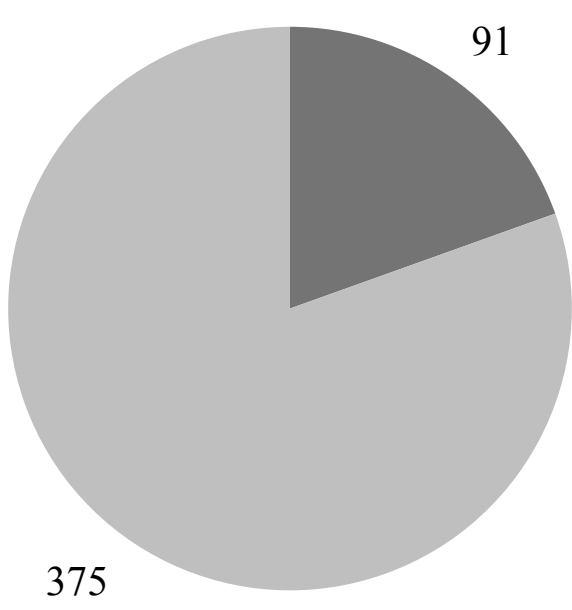

Certainty Uncertainty

- Certainty Uncertainty

Figure 2. Instances of diagn* collocates expressing certainty and uncertainty (modalizations) in COCA and study corpus.

\begin{tabular}{|l|l|}
\hline \multicolumn{1}{|c|}{ COCA } & \multicolumn{1}{c|}{ Study Corpus } \\
\hline Patient(s) & Self \\
\hline Doctor(s) & People \\
\hline Individuals & Person \\
\hline Physician(s) & Someone \\
\hline Clients & Individual \\
\hline
\end{tabular}

Table 2. Person referents collocated with diagn* in COCA and study corpus. 
Autism

As a key term, diagnosis directly points to a process of recognizing particular diseases or conditions, and as evidenced above, its topical context is most often medical despite its common metaphorical use. Additionally, diagnosis is frequently collocated with diagnostic terms for mental disorders and neurological diseases, suggesting a significant portion of conversations around diagnosis involve these conditions. The next two terms studied here are diagnostic terms themselves - autism and PTSD. Both of these terms originated in psychiatric discourse in the twentieth century and were formally tied to sets of behaviors or "symptoms" that clinicians deemed to significantly impact a person's daily life. As cultural artifacts, both of these conditions have seen a surge of interest in public discourse in the past two decades: autism primarily for an increasing rate of childhood diagnosis and PTSD for its widespread incidence among American veterans of the wars in Iraq and Afghanistan. The following sections perform a collocation analysis of the nodes autism and PTSD comparing patterns between this study's corpus of online conversations and COCA.

As in the analysis of diagnosis above, the node autism returned collocation results in the COCA that include a high number of terms related to medicine and medical research: 53 of the first 150 most frequent collocates, compared to 12 of 150 in my corpus. (See Figure 3 for a chart of collocates by word type in both corpora.) Of the medical words found in COCA, many of the most common placed autism in relation to a medical definition or a broader category of conditions (diagnosis/ed, disorder/s, developmental, intellectual, disability/ies, syndrome, neurological, classic [as in "classic autism"]). Other medical collocates in COCA related autism to the context of specialized 
research (research, journal, prevalence, epidemic, evidence-based, risk, criteria, rates, linked). Additionally, some collocates in COCA related to treatments of some kind (intervention/s, treatment/s, therapy, cure, assessment). This broad association between autism and medical words in COCA suggests that conversations about autism usually frame the condition as a medical concern—one that is, and should be, described in the terms given by psychiatry and medicine.

The medical terms collocated with autism in my corpus, less significant than COCA by measures of frequency and proportion, were most often centered around the concept of diagnosis itself (diagnos-is/-ed/-tic/-ing, Asperger/s, symptoms, test). The word official also collocated with autism, most often as an adjective to qualify a type of diagnosis, as discussed in the previous section. These collocation patterns suggest that relating autism to medicine in my corpus occurred within discussions of its identification by clinicians or mental health professionals. The qualitative data I gathered in interviews supports this claim while also framing the issue of diagnosis as contentious- - something that can be disputed rather than a statement of fact. ${ }^{16}$

In a related pattern, the incidence of diagnostic labels in the two corpora differed greatly. In my corpus, only one such label (aside from autism itself) appeared in the collocation list-Aspergers. No other formally defined condition collocated with the node autism in my corpus. In COCA, however, seven diagnostic labels occurred in the list of 150 words most closely collocated with autism (schizophrenia, ADHD, ID [abbreviation for "intellectual disability"], cerebral [palsy], depression, alzheimer, bipolar). The presence of these diagnostic labels as collocates with autism in COCA

\footnotetext{
${ }^{16}$ For an in-depth treatment of this subject, including quotations from study participants, see the section on negotiation of expertise in Chapter 3.
} 
suggests that along with the framing of autism as a medical concern, conversations about autism place it within a constellation of other psychiatric or neurological conditions. When investigating the context of these collocates with autism, the diagnostic labels often occur in a list (e.g., "The FDA approves the use of antipsychotic drugs for adults and teens mostly for diagnoses of autism, bipolar disorder or schizophrenia, but they are legally prescribed for children as young as toddlers for off label use" [Osher and Brown, “Colorado Responds Slowly”]). When bringing up other diagnostic labels, writers and speakers are putting autism in the realm of technical taxonomy-reinforcing the legitimacy of the psychiatric and medical construal of mental difference or disability. While not medical in nature, another related set of terms emerged as frequent collocates of autism in COCA: the language of deficit. Alongside its appraisal of autism as abnormal, psychiatry also describes the characteristics of autism in terms of a lack or absence; for example, the first listed symptom of ASD listed in the DSM is "persistent deficits in social communication and social interaction across multiple contexts" (APA 50). Autistic self-advocates and their allies have consistently challenged the use of deficit language in descriptions of autism for its explicit devaluation of behaviors and traits they claim as part of the spectrum of humanity variance. In COCA at least nine words that connote deficit or a deficit mindset are frequent collocates of autism (high-/functioning, severe/ly, mild, impairment/s, retard-ation/-ed, mild, nonverbal). The deficit-related words work to assess autism according to a scale of normality presumed in most psychiatric diagnoses; even terms like high-functioning and mild, which seem relatively positive, assume that individuals can be classified according to certain measures of normality in relation to social interaction or intellectual ability. In my corpus, by contrast, 
the only deficit-related collocate of autism in the first 150 most frequent is functioning. Review of the corpus's conversations show that the word is not universally rejectedsome writers describe themselves or others as having particular areas of normality by using functioning, and the label high-functioning autism/HFA also appears. The much higher number of deficit-related collocates in COCA, however, suggests a preoccupation with rating the "severity" of the condition in terms familiar in psychiatry and medicine.

The COCA collocates of autism also included a number of words related to a social institution separate from medicine — education. When investigating the context of these terms in the database, conversations about autism often turned to its treatment in schools and related programs - how autism is "dealt with" in those contexts. These twelve frequent collocates of autism in COCA include education/-al, programs, teach/ing, school-based, preschool/-ers, instruction, classroom, curriculum, and enrollment. No terms related to education were closely collated with autism in my corpus. ${ }^{17}$ The words related to education point to a concern with how students with autism are included in systems of public education, especially in early childhood.

The trend toward discussing autism in relation to childhood is reflected in the person referents present in the list of frequent collocates of autism in COCA. While there are similar counts in both corpora (19 of 150 in COCA, 17 of 150 in my corpus), the specific words used vary in significant ways. Most evident in COCA is the construction of autism as a childhood concern: a majority of the person referents in the collocate list for autism refer to children, youth, or parents. (See Table 3.) One other word, adult,

\footnotetext{
${ }^{17}$ Review of the conversations in my corpus does reveal a number of references to school life, special education, and treatment by teachers, but without the statistical frequency suggested in the COCA data.
} 
occurs in COCA but with significantly lower frequency. ${ }^{18}$ The references to childhood present in the COCA autism collocates point to conversations about autism framing the condition as one that affects children and their families. In their article "Infantilizing Autism," Stevenson, Harp, and Gernsbacher recognize the association of autism with children across a number of contexts and point to its deleterious effects: "society's overwhelming proclivity for depicting autism as a disability of childhood poses a formidable barrier to the dignity and well-being of autistic people of all ages" (n.p.). The COCA collocation results confirm this trend to be present in general American discourse. In addition to the trend toward relating autism with childhood, two words in the COCA collocate list point back to the earlier connection with medicine and its practices: researchers and experts. The typical cast of characters in the autism drama, as constructed in COCA, is a family with an autistic child who is under the care and surveillance of psychiatric or medical professionals.

The person referents frequently collocated with autism in my corpus suggest a different picture where individuals are not relegated to the stereotypical roles represented in the COCA list. The vast majority of the person referents listed in the list from my corpus are personal pronouns of some kind, including three in first person: I, my, we, me. These first-person pronouns present autism in relation to the writer rather than an unknown or unfamiliar third party. While the person referent collocates from my corpus do reflect the context of autism-related discussion boards, they also show that

\footnotetext{
${ }^{18}$ Another interesting aspect of the collocation of adult with the node autism is a chronological trend: adult increases in frequency over time, finding its highest collocation in COCA for the years 2010-2015. This result suggests the success of neurodiversity advocates in bringing the concerns of autistic adults forward in public conversations about autism.
} 


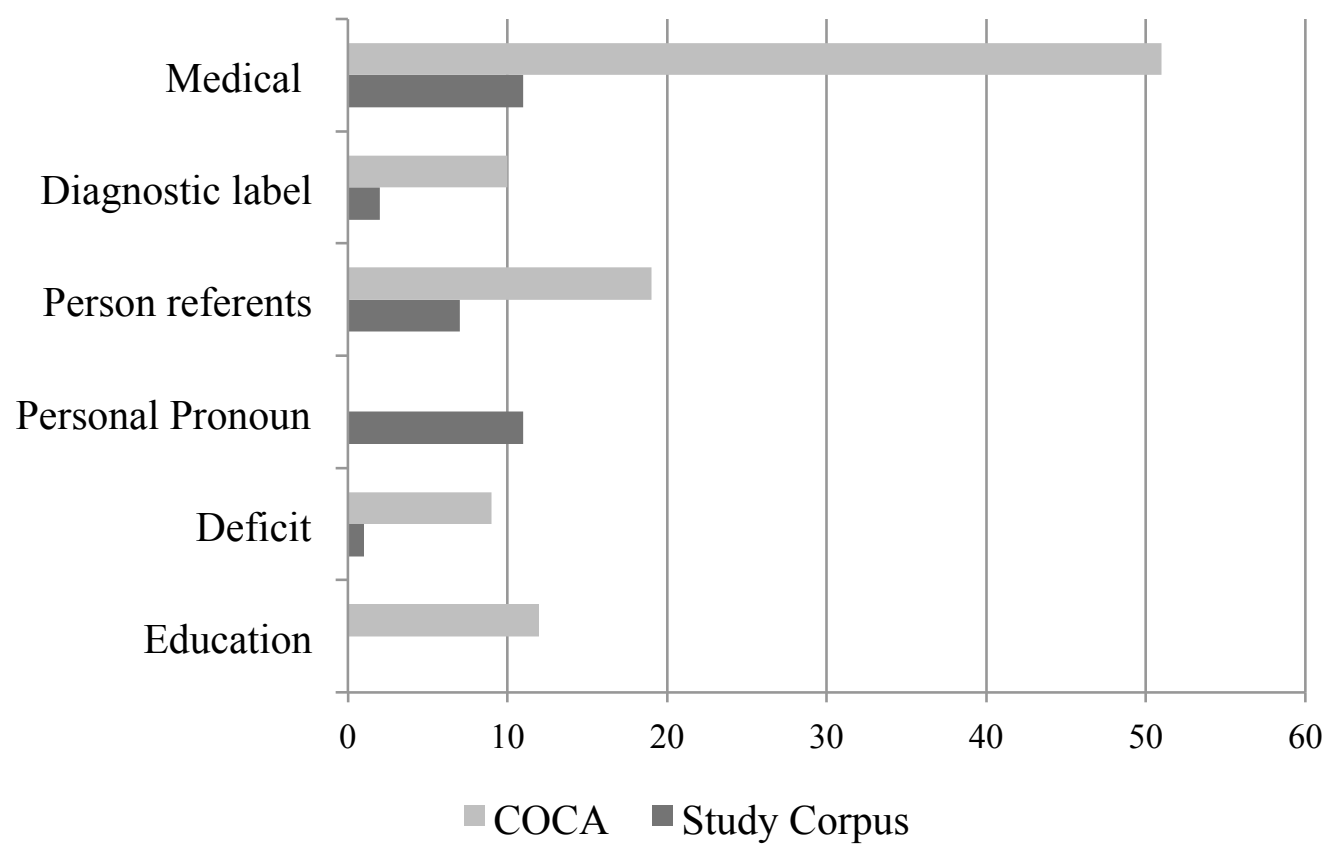

Figure 3. Frequent collocates of node autism by word type in study corpus and COCA.

\begin{tabular}{|l|l|}
\hline \multicolumn{1}{|c|}{ COCA } & \multicolumn{1}{c|}{ Study Corpus } \\
\hline $\begin{array}{l}\text { Children, Child, Kids, Boy, } \\
\text { Adolescents }\end{array}$ & I, My, Me, We \\
\hline Students & They, Their, Them, Themselves \\
\hline Son, Brother, Daughter, Siblings & People, Person \\
\hline Parent(s), Families & You \\
\hline Adult(s) & Self \\
\hline Individuals & He, His \\
\hline Researchers, Experts & Someone, Anyone \\
\hline Peers & Child \\
\hline
\end{tabular}

Table 3. Frequent collocates of autism in study corpus and COCA, category of person referents. Words listed by rank according to frequency in corpus. 
conversations about autism most often focus on the perspective of autistic people.

Further, the person referents common in my corpus place autism in a vernacular environment, over against the technical environment constructed by the collocates found in COCA. The technical taxonomy of psychiatry and related specialized knowledge are secondary and subordinate to the experiences of autistic people.

PTSD

The comparative results of collocation analysis of node PTSD between the study corpus and COCA bear great similarity to the results for node autism. (See Figure 4 for a chart of collocates by word type in both corpora.) For words related to medicine and medical knowledge, the analysis for PTSD revealed 51 of 150 in COCA and 8 of 150 in the study corpus. (See Table 4 for a full list of these words.) The medical words found in the COCA collocation list for node PTSD included many related to:

- diagnosis and description (diagnos-e/-ed/-es/-is/-tic, checklist-civilian/PCL-C [a diagnostic test], DSM-III, criteria, symptom/-s/-atology),

- research practices and measures (epidemic, prevalence, rate/-s, reported, risk/-s, sample, variables), and

- treatment (treat/-ed/-ing/-ment/ments, untreated, follow-up, therapy, psychotherapy).

Measures of the condition's "severity," parallel to the language of "functioning" in the discourse around autism, included major, mild, sever/-e/-ity. The list of medical words in the study corpus is much smaller, but with similar emphases: diagnosis (diagnos-ed/-is, official, symptoms) and treatment (EMDR [Eye Movement Desensitization and Reprocessing, a type of therapy], symptoms, treat/-ment). The wide numerical difference between the two corpora, however, is striking. The size and tone of the COCA collocate list for PTSD suggests that, like the results found for autism, conversations about PTSD tend to frame the condition as a medical problem—one that can be identified, measured, 
and treated through specialized medical knowledge. While the now-declining school of thought psychotherapy is in the COCA list, its presence is connected to treatment (EMDR specifically) rather than a philosophy of mental disorder privileging social over biological concerns.

Regarding diagnostic labels, my study corpus showed only one collocate of PTSD that was not the condition itself - depression. (Instances of $c$ - and chronic refer to a type of PTSD not yet recognized in the DSM, and thus reference the same general condition.) In the COCA list, however, one finds depression along with a number of other diagnoses (HIV, TBI [traumatic brain injury], PVS [Post-Vietnam Syndrome], OCD [obsessivecompulsive disorder], bipolar). The context for these diagnostic labels is most often showing connections between PTSD and the development or co-morbidity of other conditions. As a set, the correlation seems distinct from the cluster of diagnoses found collocated with node autism above, which placed autism in relation to a number of other unrelated conditions; instead, this cluster shows the diagnosis PTSD as a kind of common denominator — one that frequently appears alongside others. Addiction, classified as Substance Use Disorders in the DSM, is also implicated in the COCA collocate list by the word substance (occurring linked with abuse).

The COCA collocate list for PTSD also reveals a topical bias toward which people with the condition are represented, an issue parallel to the association of autism with childhood. With regard to PTSD, the COCA list revealed 13 words associating the condition with the military (see Table 4). The study corpus only registered one militaryrelated word, war, in the top 150 collocates - and instances of war referenced the 


\begin{tabular}{|c|c|c|c|}
\hline \multicolumn{3}{|c|}{ COCA } & Study Corpus \\
\hline Biological & DSM-III & Risk & Diagnosed \\
\hline Brain & Epidemic & Risks & Diagnosis \\
\hline Checklist-Civilian & Exposure & Sample & D \\
\hline Clinical & Follow-up & Secondary & Livinat \\
\hline Clusters & Illness & Severe & Official \\
\hline Comorbid & Major & Severity & Severe \\
\hline Condition & Mild & Symptom & Symptoms \\
\hline Criteria & PCL-C [Diagnostic test] & Symptomatology & The t \\
\hline Diagnose & Prevalence & Symptoms & \\
\hline Diagnosed & Psychiatric & Therapy & Treatment \\
\hline Diagnoses & Psychiatry & Treat & \\
\hline Diagnosing & Psychological & Treated & \\
\hline Diagnosis & Psychotherapy & Treating & \\
\hline Diagnostic & Rate & Treatment & \\
\hline Disorder & Rates & Treatments & \\
\hline Disorders & Reported & Untreated & \\
\hline Dissociation & Revised & Variables & \\
\hline
\end{tabular}

Table 4. Words related to biomedicine in the 150 most frequent collocates of PTSD, excluding diagnostic labels. 


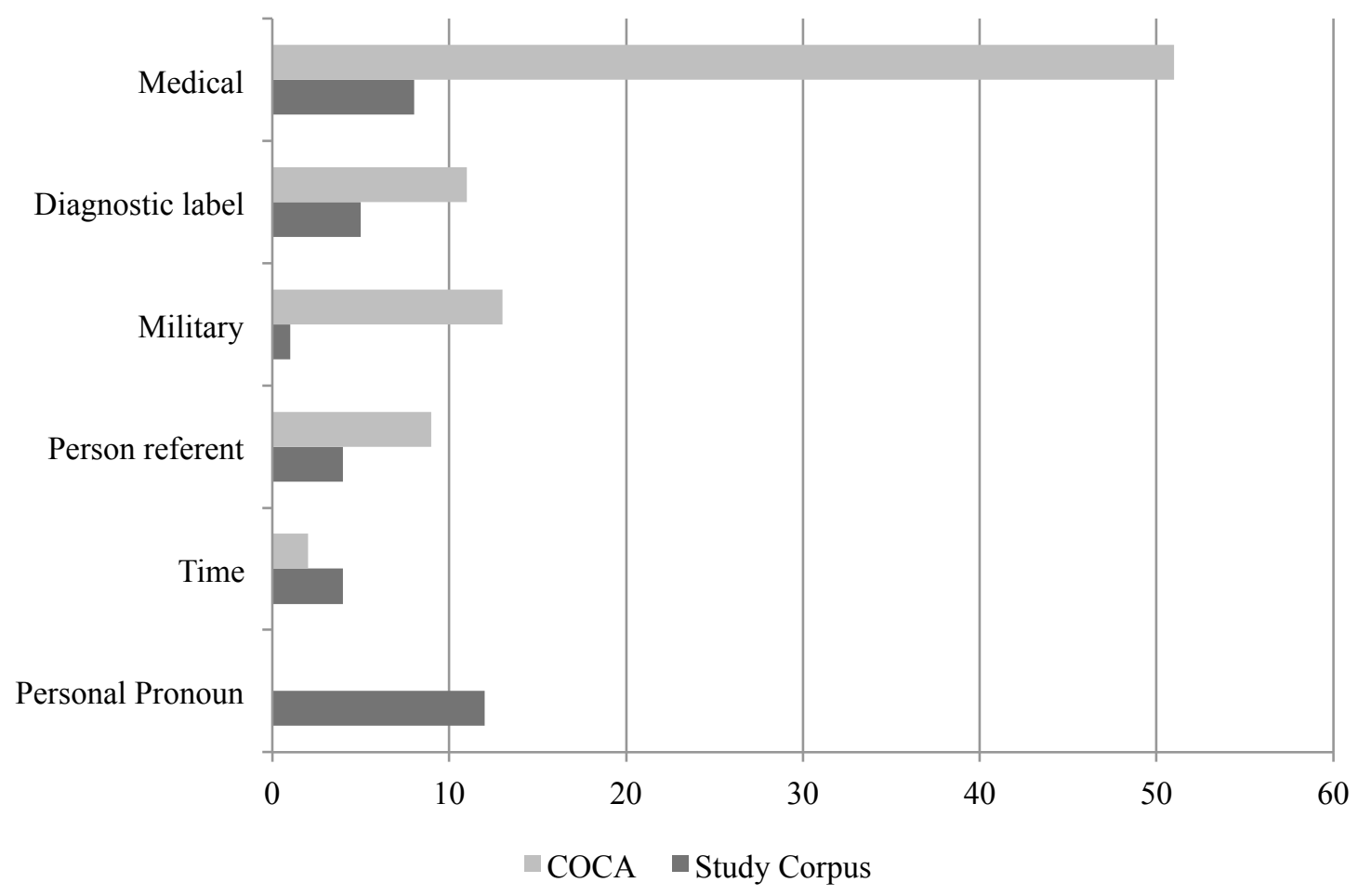

Figure 4. Word types in the 150 most frequent collocates of PTSD.

\begin{tabular}{|l|l|}
\hline \multicolumn{1}{|c|}{ COCA } & \multicolumn{1}{|c|}{ Study Corpus } \\
\hline Afghanistan & War \\
CF [Canadian forces] & \\
Civilians* & \\
Combat, Combat-related & \\
Personnel, Soldiers & \\
VA (Veterans Administration) & \\
Vet, Vets, Veteran, Veterans & \\
Vietnam & \\
\hline
\end{tabular}

Table 5. Military-related words in the 150 most frequent collocates of PTSD. *Usually referring to former military, as in "soldiers' new lives as civilians." 
differing benefits for veterans, not the military experiences of the writers themselves. ${ }^{19}$ The COCA collocate list for PTSD also includes references to specific warsAfghanistan and Vietnam. These correlations in the COCA list point to the cultural tendency to think of PTSD as a soldier's condition, spawned by trauma and violence in the battlefield. The only other word indexing a possible cause of PTSD in the COCA list—abuse - is just as likely to occur as "substance abuse" as physical or sexual abuse, despite the high proportion of PTSD cases that result from child abuse, sexual abuse, and domestic abuse.

Finally, the kinds of person referents present in the study corpus and COCA collocate lists for PTSD, like those for autism above, show a difference in the people represented in connection with the condition (see Table 5). In the COCA list, person referents are connected to specific roles in medical treatment and research (patients, therapists, participants, respondents) or cast the person with PTSD as an object of pity (sufferers, survivors, victims). The COCA list includes no personal pronouns. In one representative example from COCA, an author writes that

PTSD sufferers respond to the traumatic event with intense fear, helplessness and horror. Symptoms include persistent re-experiencing of the traumatic event, persistent avoidance of stimuli associated with the trauma, general unresponsiveness, and persistent symptoms of increased arousal. (Eagan Chamberlain)

Viewing these person referents alongside the host of medical words found in the COCA, few social roles are apparent beyond the twin roles of victim or patient with PTSD and the expert who identifies and treats the condition.

\footnotetext{
${ }^{19}$ As one significant caveat for the lack of military talk in the study corpus, I should note that discussion boards for combat-related PTSD are largely segregated from other boards. No combat-related PTSD boards are part of the study corpus.
} 
The study corpus list includes some similar person referents (therapist, sufferers, expert) but these are outnumbered by personal pronouns (I, me, my, she, their, them, they, us, we, you, your). The greater number and frequency of personal pronouns in the study corpus suggests a focus on the perspective of the people who have or are affected by the PTSD diagnosis. Indeed the instances of person referents therapist and expert in the study corpus are in the context of a writer explaining treatment from the recipient's point of view. ${ }^{20}$

Overall, the study corpus shows less evidence of resistance to psychiatry and medicine in relation to PTSD than to autism—a difference that seems to be reflected in the broader advocacy and writing from communities of people with the condition. Yet the COCA collocate list for PTSD demonstrates society's unrelenting presentation of the condition as a medical and military concern.

\begin{tabular}{|l|ll|}
\hline \multicolumn{1}{|c|}{ COCA } & \multicolumn{2}{|c|}{ Study Corpus } \\
\hline Participants & Anyone & She \\
Patients & Expert & Their \\
Respondents & People & Them \\
Sufferers & Sufferers & They \\
Survivors & Therapist & Us \\
Therapists & I & We \\
Victims & Me & You \\
& My & Your \\
\hline
\end{tabular}

Table 6. Person referents in the 150 most frequent collocates of PTSD.

${ }^{20}$ Posts related to personal experience of treatment also account for the high collocation of EMDR with PTSD in the study corpus. 


\section{Collocation Patterns and Medical Ideology}

Across the collocation analyses of diagnosis, autism, and PTSD, one finds a pattern of illness and disability framed in medical terminology, with patterns related to mental disability no different. The collocation patterns signal a strong alignment between general conversations about mental disabilities and the medical and psychiatric institutions that define them. Such a connection might seem like a given, considering the wide acceptance of these conditions as medical issues, yet the discussion board conversations of people diagnosed with or self-identifying with autism or PTSD reveal another possible angle of attention - the perspective of the person affected by medical language and her interests and desires.

The conversations in the study corpus show people diagnosed with or selfidentifying with autism or PTSD putting their conditions in a particular context, one that ties together medical terms and descriptions with personal experiences and perceptions. For these writers, the diagnosis is not a "thing" to be studied and measured across a population, something that can be essentialized apart from the people living under its description; instead, the diagnosis is one lens, among others, through which to view their own social and mental experiences. As such, the people diagnosed with or selfidentifying with mental disabilities writing in discussion boards break with cultural stereotypes of their condition, rejecting the characterization of autism as a childhood concern or voicing causes of PTSD other than military trauma. While the writers are not actively engaged in resisting the medical institutions that control the descriptions of their conditions, they deviate in significant ways from the narrative of mental disability constructed and perpetuated by those institutions. 
Of course, the effects of their differing narratives are likely to be limited to the discussion boards in which they are written-because of the cultural and political power of medicine and psychiatry, not because of their individuality or "irrationality." Across social and political institutions, medicine holds a monopoly on identifying and describing "legitimate" mental disabilities. The stakes of this monopoly are clear for people diagnosed with or self-identifying with mental disabilities: medications, support services, and accommodations are only available by claiming the medical description and fulfilling the gatekeeper's criteria for impairment or deficit. 


\section{CHAPTER III}

\section{INHABITING BIOLOGICAL PRIMACY WITH CHIASMIC RHETORIC IN}

\section{MENTAL HEALTH FORUMS}

We are seeing this somatic ethic gradually extending from the body to the embodied mind - the brain. ...And it is in the name of improving the well-being of our societies that each of us is now urged to develop a reflexive understanding of the powers of these nonconscious determinants of our choices, our affections, our commitments: in doing so, we will no longer be passive subjects of those determinants, but learn the techniques to act on them in order to live a responsible life. Once more, now in neural form, we are obliged to take responsibility for our biology, to manage our brains in order to bear the responsibilities of freedom. (Rose and Abi-Rached, Neuro 22-23)

The larger issue is medicalizing others. This is done to invent a false narrative that presents beliefs as having more justification than they really do. The belief is that certain categories of people (usually queer or disabled) have something inherently wrong with them. The supposed justification is that their identity is really a medical condition. (Daniel, IR) ${ }^{21}$

\section{Biological Primacy and the Rise of Brain Science}

As I outlined in chapter 1, numerous scholars have traced the increasing cultural authority of biomedical research and other sciences of the body in recent decades. The cultural authority accrued by biomedicine should be measured in rhetorical terms, in its ability to persuade and its frequency of use, since it may not coincide with a proportional growth in wealth or political power. That is, even if physicians' salaries are stagnant and their once monopolized institutional activity spreading to other professionals like registered nurses, the power of the medical concepts that mark their field of study and

\footnotetext{
${ }^{21}$ In this chapter, three different modes of participant writing will be coded: "OC" for statements in discussion forum conversations from my corpus; "DM" for direct messages, including emails; and "IR" for interview responses.
} 
intervention may continue to increase in visibility and acceptance. For this chapter, the most important development in terms of biomedical authority is the steady increase in the "somaticization" of the brain: the perception that brain processes—whether average, optimal, disordered, or dysfunctional—must be explained first, and primarily, in terms of biology and chemistry.

The effects of this growing perception can be seen in the neurological focus of psychiatric research, popular science articles profiling the "autism gene" and the "love chemical," pharmaceutical advertisements describing dysfunctions of neural function in people with depression, and appeals for the benefits of meditation based on brain imaging. Initially, one might attribute these trends and arguments to the growth of scientific knowledge regarding the brain — that as technology improves, scientists are able to make more, and more precise, observations about how the brain works. Such an attribution relies on the assumption that science "discovers" the world as it is via technology that represents objective reality. The propensity for viewing mental states and behavior in terms of neurobiology represents only part of a philosophy of life as a biological phenomenon best understood through scientific knowledge. In many ways, this perspective on life is an extension of a broader ideology of science, one that describes scientific knowledge as objective, universal, and free from any social bias. It is a few short steps to connect the scientific view of life with the achievements of medicine and knowledge that represents the human body as, at its basis, a biological being. When we view ourselves primarily in this light, we are "somatic individuals," as termed by sociologist Nikolas Rose, "beings whose individuality is...grounded" within bodies and "who experience, articulate, judge, and act upon ourselves in part in the language of 
biomedicine" (Politics 25). In The Politics of Life Itself, Rose demonstrates an array of trends in social, political, economic, and private spheres that coalesce around this somatic view of humanity. Rose's more recent volume Neuro: The New Brain Sciences and the Management of the Mind, coauthored with Joelle M. Abi-Rached, focuses on the way that somatic ideologies are applied to the brain in particular. While Rose and Abi-Rached do not think that older forms of conceptualizing the mind and human behavior, such as psychology or spirituality, are disappearing, "it seems that these other ways of thinking of ourselves... are being reshaped. They must now be grounded in one organ of our bodiesthat spongy mass of the human brain" (1).

Of course, this trend is met with happy acceptance by biomedical psychiatry's institutions and actors. Since it marries processes of the body and brain, the somatic ideology fits squarely with the psychiatry's self-conception as a branch of medicine rather than a "social" science. The phrase "psychiatric disorders are brain disorders" has been repeated by many psychiatrists over the past fifty years, but never has the field been more closely aligned with, or the public more receptive to, the idea that all behaviors, emotions, and mental states have a biological origin. In its research, diagnostics, and practices, psychiatry calls us to understand ourselves by understanding the brain organ.

Even so, the sense of self-understanding being "grounded" in the brain need not always lead to the fatalist conclusion that biology is destiny—a related fallacy that scientists are quick to bat down. For instance, at least since the failure of the Human Genome project to confirm a vision of DNA as simple code, the scientific community has acknowledged and investigated epigenetic factors that influence genetic function, varying from environmental stimuli to cumulative effects of mutations. Medical research often 
qualifies the explanatory power of biology on the body in terms of risk-asserting an association, rather than cause and effect, between biological factors and pathology. The relation between family history or genetics and the development of Type 2 Diabetes is one common example of such claims of association - the "person at risk" may stave off the pathologized condition, but she may still considered predisposed to it. In discussions of mental health and psychiatry, conditions like schizophrenia, considered to have an unequivocal biological basis, are distinguished from "less biological" ones like depression. But as one psychiatrist distinguishes, the notion of neuroses as separate from brain diseases is not the absence of biology: "the point is that there is a biological background, as there is in every psychological manifestation of our life, but it is not different from the one lying under normal psychological phenomena" (Lopez-Ibor et al. xi).

The biological basis of mental states, even when separated from a naive determinism, is ever-present. While biological factors may be more or less relevant to the presentation of particular conditions, from this perspective they underly every mental state, normal or abnormal, and thus deserve attention from scientists researching the brain and psychiatric conditions. The repudiation of naive biological determinism may, for some, quell the sense of danger in biomedical approaches to mental health.

For the purposes of this study, however, the most pertinent effect of the somatic perspective on cultural views of mental health is not that biology could be seen as determinative. Rather, my interest is that biology is often constructed as primary in that word's many senses: biology is the first factor to be considered, the most elemental of behavioral causes, the most frequent target of psychiatric intervention (via 
pharmacology), and, literally and symbolically, the most interior of psychiatric dysfunctions.

The writers in online conversations studied in this dissertation, while not uniformly rejecting the somatic perspective of the brain, engage with the growing biological primacy in discussions of mental health by presenting varied and complex accounts of their own experience that undercut simplistic biological accounts of their conditions. In doing so, these writers — sometimes in a single paragraph—show negotiations between different ways of conceptualizing mental disability and difference, including those from neuroscience, psychiatry, psychology, spirituality, and social science, as well as arguments originating from disability and neurodiversity activism. The online conversations explored in this chapter suggest that writers diagnosed or selfidentified with a mental disability "make sense" of their own differences and struggles (and, less often, apparent "normality") by taking up multiple discourses of mental health. The rhetorical act of taking up multiple discourses is here both private and public: private, in the sense that the writers communicate their personal experience, often with a personal "payoff" or resolution; public, in that they frequently acknowledge or engage broad cultural discourses of mental health and, in many cases, offer counterpoints to them.

In the sections below, I describe and analyze a variety of common topics in online conversations that connect mental health and expert knowledge of the brain. I will argue that this connection of mental experience and brain science constitutes a chiasmic rhetoric, a rhetoric of crossing in which discourses often separate, or even opposed, are combined in novel ways. Chiasma, in ancient Greek meaning "to mark with a chi $(\chi)$," 
has multiple meanings in biological discourse. A chiasma can be an anatomical location where two elements cross, like the intersection of optic nerves in the brain; in genetics, a chiasma is a point at which two chromosomes cross over one another and sometimes exchange genetic information. I imagine chiasmic rhetoric as a crossing of discourses, a point of rhetorical exchange that produces new lines of persuasion distinct from the original.

Chiasmic rhetoric seems a necessity in the mental health forums I study in this dissertation. If these writers are to leverage the expertise of experience and maintain a communal sense of scientific credibility, they must (re)combine the discourse of biomedicine and the discourse of human rights, in particular the right of selfdetermination, in a way that acknowledges some epistemic authority in biomedical research but resists the construction of mental disabilities as diseases, dysfunctions, or disorders in that same research. I find that, in these conversations, writers frequently take up a biological view of the brain in a similar way to what is seen in many popular venues; that is, that differences in cognition and behavior can be reliably considered differences in brain structure, development, or chemistry. When arguing for support related to their conditions, however, the writers diffuse that knowledge into a range of personal, social, and political actions rather than only seeking the clinical interventions a medicalization model implies. In this way, the writers in these forums acknowledge and accept much of the claims of medicine and neuroscience regarding the brain but, uniquely, work to divide that knowledge from the path of normativity and optimization that medicalization scholars have shown is the most common conclusion. In so doing, these writers are embarking on a rhetorical reconstruction of medical(ized) knowledge - a 
chiasmic rhetoric - that separates scientific observations from the exaggerated applications often peddled in popular reporting of science.

- In "Biology, Medicalization, and Mental Health," I continue to explore the ways that biology is constructed as the primary way to view mental health and disability, and then connect this perspective to the process of medicalization.

- In "Linguistic Analysis of Study Corpus," I discuss the different ways that writers use key words to refer to their mental experience, with "brain," "mind," and "neuro-," finding that their usage mirrors other rhetorical patterns and goals on the forums.

- In "Naming and Complicating the Biological Brain," I describe how many writers display their partial acceptance of biomedical conceptions of mental difference and disability by naming their own brains as different in some physical way. Following this summary, I show how these writers also complicate the biomedical perspective by placing the biological brain in conversation with other dimensions of experience like emotion, perception, spirituality, and narrative.

- In "Medicalization and Negotiating Expertise," I illustrate how forum writers interact with expert communities, in what I call a "negotiation of expertise": conceding a certain amount of authority to experts while also critically evaluating methods and assumptions, challenging expert knowledge with personal experience, and demarcating the appropriate scope of the experts' jurisdiction.

- Finally, in "Medicalization, Chiasmic Rhetoric, and Activism," I conclude the chapter by reflecting on how these complications of medical(ized) knowledge relate to activism in the ASD and PTSD communities. The rhetorical processes present in the forum conversations could translate into broader public arguments about the applications of medicine and the treatment of people with mental disabilities.

\section{Biology, Medicalization, and Mental Health}

Nursing scholar Emily Jenkins discusses the "hegemony of biological knowledge" in the study of mental and psychiatric disabilities, where biomedicine and its advances "[come] at a cost; other mechanisms underlying illness and disease, such as social, economic or psychological factors, are not adequately explored" (4). The primacy of biological approaches in medicine and mental health "is limiting health professionals' abilities to effectively address mental illness" and instead sometimes leads to "significant adverse consequences" (Jenkins 5), including an increase in social stigma toward people 
with mental and psychiatric disabilities (Jenkins 7). In this way, Jenkins points to ways the primacy of biology in constructing mental health reaches past the domains of research and healthcare into the popular imagination. That biomedical views of mental health effect the public is no surprise, however: representatives of both neuroscience and biomedical psychiatry use the narrative of scientific discovery, and its attending senses of wonder and authority, to publicize their research and lobby for funding essential to such work. Compared with the high-tech imagery of drugs regulating neurons, electrodes stimulating brain regions, and fMRI scans revealing involuntary reactions, interpersonal and social approaches to mental health seem slow, inexact, old-fashioned. Thus the most exciting and, as Nikolas Rose and Carlos Novas propose, hopeful interventions are those associated with biological functions - for both the scientists investigating the brain and the culture at large.

The evolution of myths about autism serves as an instructive example of the move toward biological primacy in cultural views of mental health. ${ }^{22}$ First described in the 1940s, autism was initially seen as a combination of interpersonal distance and specific mental aptitude, with symptoms first manifesting in childhood. One early myth about the condition's origin was the "refrigerator mother," whose distance and lack of affection had extensive effects on her child, resulting in the development of autism. The refrigerator mother narrative fit with common views of psychology and psychiatry of the midtwentieth century, where one's family of origin was considered the primary source of neurotic behavior; this view is closely tied to the tenets of psychoanalysis, the dominant form of theory and treatment at the time. Over time, however, the maternal (well, in

${ }^{22}$ See Jordynn Jack's Autism and Gender for an explication of autism myths from the perspective of gender and sexuality. 
terms of affectionate behavior ${ }^{23}$ ) origin of autism lost its persuasiveness, in part due to the growth of writing by mothers of children with autism describing their lives. Another myth took the refrigerator mother's place, however, and one biological in nature:

vaccines. The vaccine theory of autism asserts that the condition develops rapidly after some children receive routine vaccines, including MMR, and mercury or thimerosal is often the mechanism blamed. This theory dates from the late 1980s, but it was boosted to international prominence in 1998 with the controversy over Andrew Wakefield's infamous and now-retracted Lancet article asserting a vaccine-autism connection in a small set of research subjects. People who believe in the vaccine theory of autism, sometimes termed "anti-vaxxers," continue to make their case in the U.S. and elsewhere; their actions have gained increased scrutiny with a resurgence in vaccine-preventable illness outbreaks. While it thrives on the suspicion of medical conspiracy, of course, the vaccine theory of autism also posits a biological origin for the condition - and this characteristic is a strong factor in its continued persuasiveness. ${ }^{24}$ People opposing vaccines point not to a social condition or interpersonal behavior but rather a biological mechanism for their proof, and in current conversations around mental health, such mechanisms carry great persuasive power.

${ }^{23}$ As we see in a moment, the development of autism continues to be tied to the actions of the mother.

${ }^{24}$ We may also note that the decision to vaccinate a child is often attributed to the mother in conversations around anti-vaccination politics - and on both sides of the debate. Mothers who vaccinate are risking their child's mental health with a potentially dangerous treatment; mothers who do not vaccinate endanger their own children and others with the risk of transmitting preventable diseases. In this way, as scholars like Jonathan Metzl describe, the evolving narratives of mental disorder tend to place responsibility on the same parties. 
Biological arguments undergird a number of controversial treatments for autism, as well. Special "autism diets" are frequent topics on parental discussion boards and autism parenting blogs; one of the more popular variations, the gluten-free casein-free (GFCF) diet, ties behaviors associated with autism to levels of particular proteins in the body. Proponents of the GFCF diet posit that excess gluten and casein absorbed in the digestive systems of people with autism ("leaky gut syndrome") causes their symptomatic behaviors; by eliminating gluten and casein from the autistic individual's diet, these behaviors are reduced. In some more sensational endorsements, GFCF is touted as an autism "cure." The persuasive power of the GFCF diet argument lies in its supposed biological mechanism; it parallels the popular gluten explanation of intestinal dysfunction that led to an explosion of demand for gluten-free products in the last decade. A similar logic of biological contamination can be found in the justification for "toxin removal" treatments for autism, in which an autistic individual undergoes blood treatments to remove heavy metals that are assumed to be a cause of symptomatic behaviors. In both the GFCF diet and the more extreme toxin removal treatments, proponents connect autistic behaviors with a dysfunction or abnormality in the biological equilibrium of the body; if one can restore the body's biology to normality, behavior will be restored to normality as well. The physical, biological, somatic state greatly influences, or even determines, the behavioral or psychological outcome.

As cultural views of bodies and minds move in a somatic direction, the myriad causes of these trends and arguments can be debated. It is undeniable, however, that their prevalence has significantly affected the way that we understand and discuss mental difference and disorder in the twenty-first century. And when public and private 
dialogues arise around mental disorder, or even common states of anxiety or sadness, rhetors take up the lens of brain science to make their cases regardless of what position they advocate.

A separate but closely related trend to biological primacy is the increasing rate of medicalization. Medicalization might be broadly defined as "the processes through which aspects of life previously outside the jurisdiction of medicine come to be construed as medical problems" (Clarke et al. 161). Competing academic accounts of medicalization differ in their estimates of its current extent and recent growth; its causes and relevant contexts; its connection to culture, social institutions, governments, and medical industries; and its relationship to technology. However, scholars seem to agree that medicalization has increased in the last six decades, that advances in medical care and research have promoted that increase, and that its growth can be attributed to an array of social groups rather than just doctors. For this study, medicalization is relevant as a social phenomenon with significant implications for how people - whether diagnosed with a condition or not—understand minds, brains, and the mechanisms of mental difference. And for the study participants, who are diagnosed or self-identify with a particular mental disability, medicalization influences how they think and write about their conditions, their bodies, and their lived experience.

And the effects of medicalization are not limited to the hospital, the clinic, or the therapist's office. By definition, the process gathers more of human experience into what we deem medical and, with each new annexation, casts a shadow over a host of other aspects of life currently beyond its reach. 
Each new step perpetuates the momentum of medicalization, but two central notions have played a role in pushing the medical far past the boundaries of what medicine, as a social institution, can currently hope to treat—health and risk. As Adele E. Clarke et al. argue, the last two decades have seen "the extension of medical jurisdiction over health itself (in addition to illness, disease, and injury)" (162). In practical terms, the medicalization of health radically broadens the authority of specialized medical knowledge. Once the authority on repair or healing, the physician is now an expert on not just the body itself, sick or well, but the appropriate use of that body. Now, people seek out the physician's word, not just on how to relieve pain or treat an infection, but also how and when to exercise, what foods to eat and in what portions, how much to sleep, how much sex to have, which chair to buy for good posture... and the list goes on.

While one might read a number of moral implications in such questions, my concern (for now) is simply that people often think about their furniture, for example, in medical terms - and objects that were once designed according to other values (aesthetic, functional, vocational, cultural) now also must be seen in relation to the ideal body, the healthy body. Medicine does not just heal the diseased body; it encourages health in the average body. In terms of mental health, the same principles apply: where psychiatrists once primarily treated conditions associated with more severe impairments, common emotions and behaviors are now under their purview, from grief over a loved one's death to procrastination in the classroom and workplace (Conrad; Horwitz and Wakefield).

The new abilities of biomedicine to not just restore health but to improve it leads to a category of actions that Nikolas Rose calls "optimization": "interventions [that] seek to act in the present in order to secure the best possible future for those who are their 
subjects" (Politics 6). To draw an example from psychiatry and mental health: the sometimes controversial diagnosis of Attention Deficit Disorder (ADD), and later Attention Deficit Hyperactivity Disorder (ADHD), was created to describe a lack of attention - the inability of a child (or later, adult) to focus on the task at hand. Interventions or treatments—-most commonly stimulant drugs like Ritalin and Adderall— was meant to give the patient an average attention span "like everyone else." Optimization, however, might the "average" state as a starting point rather than a goal— if such a treatment is possible, why not improve the attention spans of whomever might want it? Currently the use of Adderall outside the realm of psychiatric treatment is considered illicit (though widespread among college students). Yet with the success of Prozac and Paxil in treating vast numbers of people with minor depression or anxiety to feel "better than well," to use Peter Kramer's phrase, why stop short of using Adderall for people with "minor" or "situational" attention deficits—or who simply desire superhuman focus?

The important thing for this study in the trend toward medicalizing everyday health is the ease with which medical authority supersedes or overshadows other concerns. And this is where we see biological primacy and medicalization working in tandem: the growing self-understanding of body and mind as biological paves the way for an acceptance of medical interventions that mediate the body's biological processes. In turn, the widening jurisdiction of medical knowledge spurs research into new subjects for biological investigation - as when newly recognized ADHD adults were folded into neuroscientific studies. The two processes buoy one another, affirm one another, and both gain implicit credibility from the overwhelming trust in the authority of science. The twin 
conception of illness, or abnormality, as at once a biological and medical phenomenon seems to push out other ways of understanding the variance we find within humanity and nature. Certainly the biological-medical perspective can cause us to lose sight of the social function of many medical treatments, particularly in psychiatry-the purpose of restoring normativity to the patient.

Intertwined with the medicalization of health is attention to medical risk. As more parts of life come under the "jurisdiction of medicine" (Clarke et al. 161), they become objects of medical categorization and statistical analysis. As obesity has become increasingly medicalized, for instance, it is discussed in terms of "prevalence" in a population, of geographic and chronological trends, and co-occurrence or association with other "morbidities." While it might at first seem to collectivize, by pulling people into a common identification, this statistical perspective in fact targets the individual in its assignment of responsibility and agency through the concept of risk:

...health itself and the proper management of chronic illnesses are becoming individual moral responsibilities to be fulfilled through improved access to knowledge, self-surveillance, prevention, risk assessment, the treatment of risk, and the consumption of appropriate self-help/biomedical goods and services. (Clarke et al. 162)

From the medicalized, somaticized perspective, individuals are the ultimate objects of medicine, since they possess and manifest disease and abnormality. Thus, the prevalence of obesity must boil down to the lives of individuals; and solutions, as well, must be deployed on this level. As Clarke et al. observe, the onus is placed on individuals to monitor and control their own health — their own bodily normativity. The responsibility is individualized, I would argue, in large part because of the primacy of bio/physiology as a means of diagnosis and treatment: that, ultimately, biological factors in the body will be 
the measure of health, as well as the first target of intervention (i.e. through medications, surgeries, etc.).

As dominant conceptions of psychiatric disabilities and mental health more generally become more medicalized, the trends described above apply there as well. The psychiatric standards of normativity that were once conceived in terms of behaviors and emotions are re-construed toward the anatomy and chemistry of the brain.

Individualization in psychiatry now extends beyond personal responsibility to innate genetic and chemical differences. And the logic of risk inheres for mental as well as bodily health ${ }^{25}$ : one must self-monitor behavior and mood, and deviations from normativity should be treated with medication.

\section{Linguistic Analysis of Study Corpus}

The powerful notion of mental disability as a biological phenomenon is the background for many conversations in online forums devoted to mental health conditions. Writers in these spaces must work rhetorically to negotiate their experiences with biomedical assumptions, which they encounter throughout their lives—not only in the clinic, but at school, with their families, and in the online forums themselves. Below, I describe how this rhetorical work happens and the common moves and topics that writers use to facilitate their own understanding of self, of mental health, and of life with a mental disability.

My initial window into this complicated situation is quite simple: how writers employ the words mind and brain for different functions and purposes. My findings here demonstrate that writers in my corpus (conversations gathered from the forums studied

${ }^{25}$ In many cases, mental health is framed as bodily health. 
for this dissertation, totaling 192,000 words) divided their usage of mind and brain according to the connotations commonly associated with each one-of brain as an organ of the body characterized by biological processes, and mind as a representation of consciousness, subjectivity, or emotion tied to one's sense of self. Other differences in usage of mind and brain proved more surprising, as I explain later, such as the connection between mind and a sense of agency, largely absent in the usage of brain.

In the subsections below, I outline the results of a quantitive linguistic analysis of my corpus for the words mind and brain as well as the prefix neuro- with attention paid to the connotative and functional differences in writers' usage of the terms. Unlike the analysis in Chapter 2, I will not be comparing the usage in my corpus to the Corpus of Contemporary American English (COCA). I have forgone that analysis primarily because a fine-grained local analysis of usage in the much larger COCA is not feasible for a study of this scope. Secondly, my purpose here is not comparative; rather, I aim to document in more detail the usage of these particular communities.

As in other chapters, the text available for quotation here is limited by the small proportion of my participants in relation to the number of writers involved in the whole conversation. Long quotations (greater than a few words) are all taken from and attributed to participants in my study; small phrases are anonymized and only used when they cannot lead to the identification of the author.

My primary coding categories for this analysis were emergent from the data as I assessed the purpose or topic related to each word's usage in context. I separated each instance into one of five categories: 
- Science/Medicine: Word used in reference to a scientific or medical topic, study, or procedure. May be constructed as object of research or recipient/owner of pathology.

- Vernacular: Word used to reflect a personalized or idiosyncratic account of mental experience.

- Psychology: Word used in reference to concepts in psychology or popular psychology (e.g. "subconscious mind") without scientific connotations.

- Activism: Word used in reference to mental health activism (primarily related to "neurodiversity").

- Other

With some exceptions, usages coded Science/Medicine fit the frame of medicalization described earlier in this chapter: the brain seems to be imagined as an object of scientific observation that can be characterized according to biological and chemical processes. Usages coded Psychology similar reference a particular frame for identifying mental processes and experiences, but one that does not imply biological localization even while it may suppose pathology. Usages coded Activism were all related to the concept of neurodiversity, which asserts that people with conditions like autism are neurologically distinct from those who represent the "norm," who are termed "neurotypical" or "NT." Usages coded Vernacular were various and incongruent, and seemed to make no reference to a particular frame for understanding mental experiences.

Of course, my ad hoc categories to describe vocabulary related to mental health have some overlap. For instance, psychology as a discipline takes up many medical and scientific terms to produce arguments about cognition and behavior. Terms growing out of vernacular descriptions of the experience of mental disability have been taken up by activist groups to support their cause. For my purposes, however, these individual words and phrases should be treated as indexical—-they point to a particular way of thinking about mental health, even if the writer is not "endorsing" it. One might observe that 
vernacular conversations around mental health incorporate terms from the other categories: as public understanding and usage increases, medical terms, for example, circulate far outside the expert communities from which they originated. For my purposes, however, the medical terms remain such precisely because of that origin: as I explain in Chapter 2, those terms are consonant with particular ways of viewing the body and mind, and they retain the connotations of medicine even when taken up elsewhere. The phrase "brain scan," then, is placed in the Science/Medicine category even though a wide range of non-expert usages might be found in popular discourse.

\section{Brain}

As might be expected given its formal definition, the usage of brain in my corpus generally consists of references to the bodily organ and related scientific or medical processes. Throughout my corpus, I found a total of 70 instances of the word brain. Of these, forty-eight (68.5\%) coded for Science/Medicine, fourteen (20\%) for Vernacular, five (7.1\%) for Psychology, and three (4.2\%) for Other. (See Figure 6.)

Of the instances of brain coded for Science/Medicine, a significant portion (thirty-one or $44 \%$ ) contained the term paired with another where brain is a modifier (usually adjective) rather than a noun. The following brain phrases were present in my corpus:

- brain activity (2)

- brain cells

- brain chemistry

- brain damage (3)

- brain function (3)

- brain growth
- brain profile

- brain scan (7)

- brain science (2)

- brain studies

- brain tumor (5)

- brain wiring (2) 


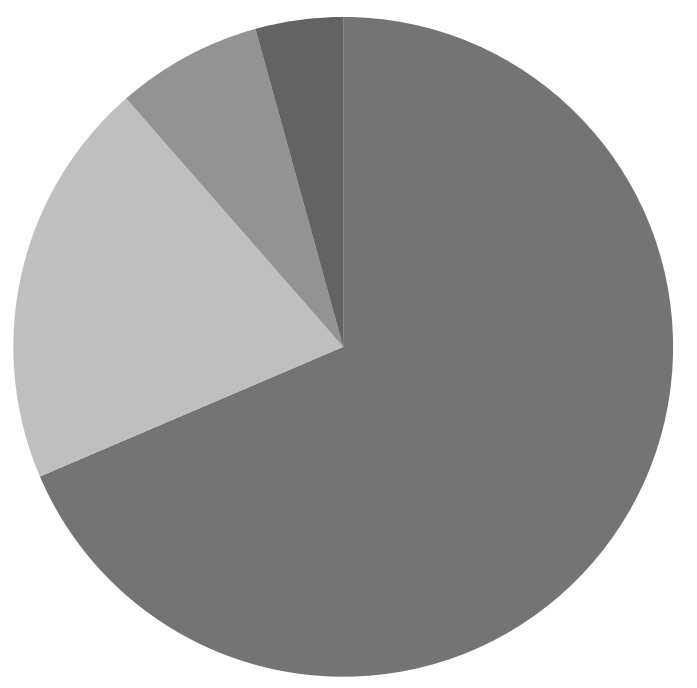

- Science/Medicine

- Vernacular

- Psychology

Other

Figure 6. Instances of brain in study corpus by category. Science/Medicine is the most populated category. 
Many of these combinations point to the tendency in the Science/Medicine category toward using brain as an object of study that can be measured. "Brain science" and "brain studies" represent formal projects to study the brain, and these fields are seen as the origin of knowledge about the brain as an organ - measurements like "brain activity," "brain chemistry," "brain function," and the metaphor "brain wiring." Phrases like "brain cells" and "brain chemistry" refer to ways that the brain can be viewed as a unity of constituent parts.

Interestingly, the most common brain phrase is "brain scan," the visual representation ubiquitous in popular accounts of mental health and a strong factor in the public's sense that brains with mental disabilities are "of a different kind" (Thachuck 149). In popular media, brain scans are often used as proof of a particular brain state or diagnosis, or less directly, as visual reminders of one of neuroscience's flagship technologies. In my corpus, however, the phrase comes up not as evidence of a difference but as an absence of it: writers refer to the fact that brain scans cannot be used to diagnose particular conditions. The writers do not disbelieve the scans or doubt their scientific value, but they do place that value in context—what does a brain scan actually tell us? As these writers argue, the brain scan may visualize electrical activity or chemical changes, but it does not represent a particular condition like autism.

Of the fourteen (20\%) instances of brain coded Vernacular, usage was varied. In this small category, brain was most often mentioned as a possession of the writer (i.e. "my brain") rather than an impersonal object (nine of fourteen instances). 
Mind

Of the 106 instances of mind found in my corpus, the vast majority (ninety-four, or $88 \%$ ) fit into the Vernacular category. Since mind is a word with more variable meaning than brain, including its idiomatic and metaphorical functions, ${ }^{26}$ one might expect greater Vernacular usage than Science/Medicine or even Psychology. (See Figure 7.) Distinguishing between different usages within the Vernacular category is difficult, but I trace some recurrent themes in paragraphs below.

One general pattern worth noting is that in the majority of cases, Vernacular instances of mind were preceded by the word my. The phrase "my mind" accounted for fifty-two (55\%) of the Vernacular instances; across all 106 instances of mind in all categories, fifty-six (53\%) were in the phrase "my mind." The pattern of using "my mind" first distinguishes the use of mind in my corpus from the use of brain (comparatively, nine [13\%] instances were in the phrase "my brain"). The word mind (versus brain) signals a highly personal as well as less "scientific" posture toward one's mental experience. Secondly, the frequency of "my mind" mirrors the concern with explaining personal experience that I noted in Chapter 2 in relation to the usage of personal pronouns near diagnostic labels. In that section, I observed that instances of diagnostic terms like autism or PTSD were likely to be collocated with personal pronouns in the conversations within my corpus, while in the general COCA corpus, such pairing was nearly nonexistent. In a similar fashion, the writers in online forums analyzed here tend to use the word mind in relation to their own sense of self or in describing their own

\footnotetext{
${ }^{26}$ When coding the instances of mind in my corpus, I separated any idiomatic usages that did not reference a mental experience. For instance, phrases like "I don't mind" or "mind you" were not included in the total 106 instances of mind I analyze here.
} 


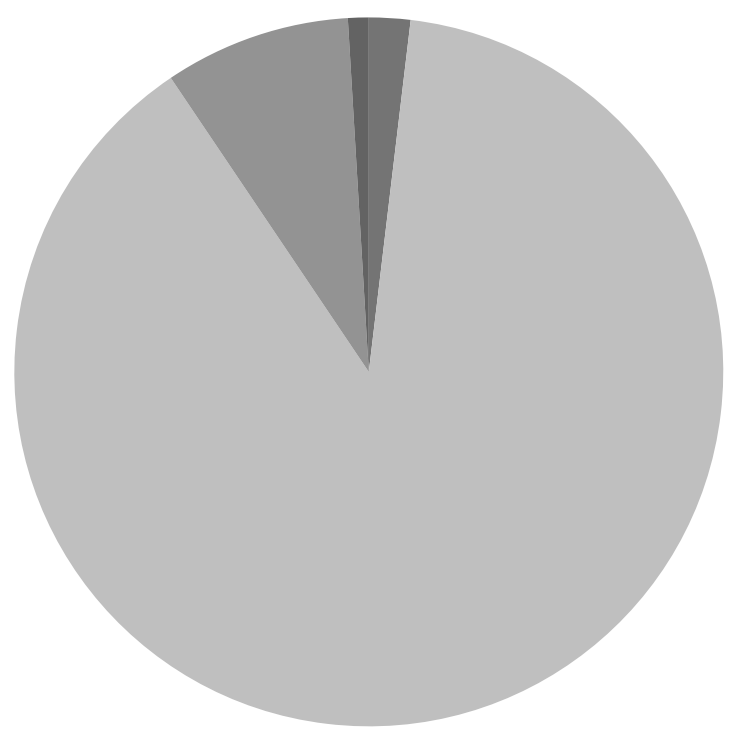

Science/Medicine

Vernacular

- Psychology

- Other

Figure 7. Instances of mind in study corpus by category. Vernacular is by far the most populated category.

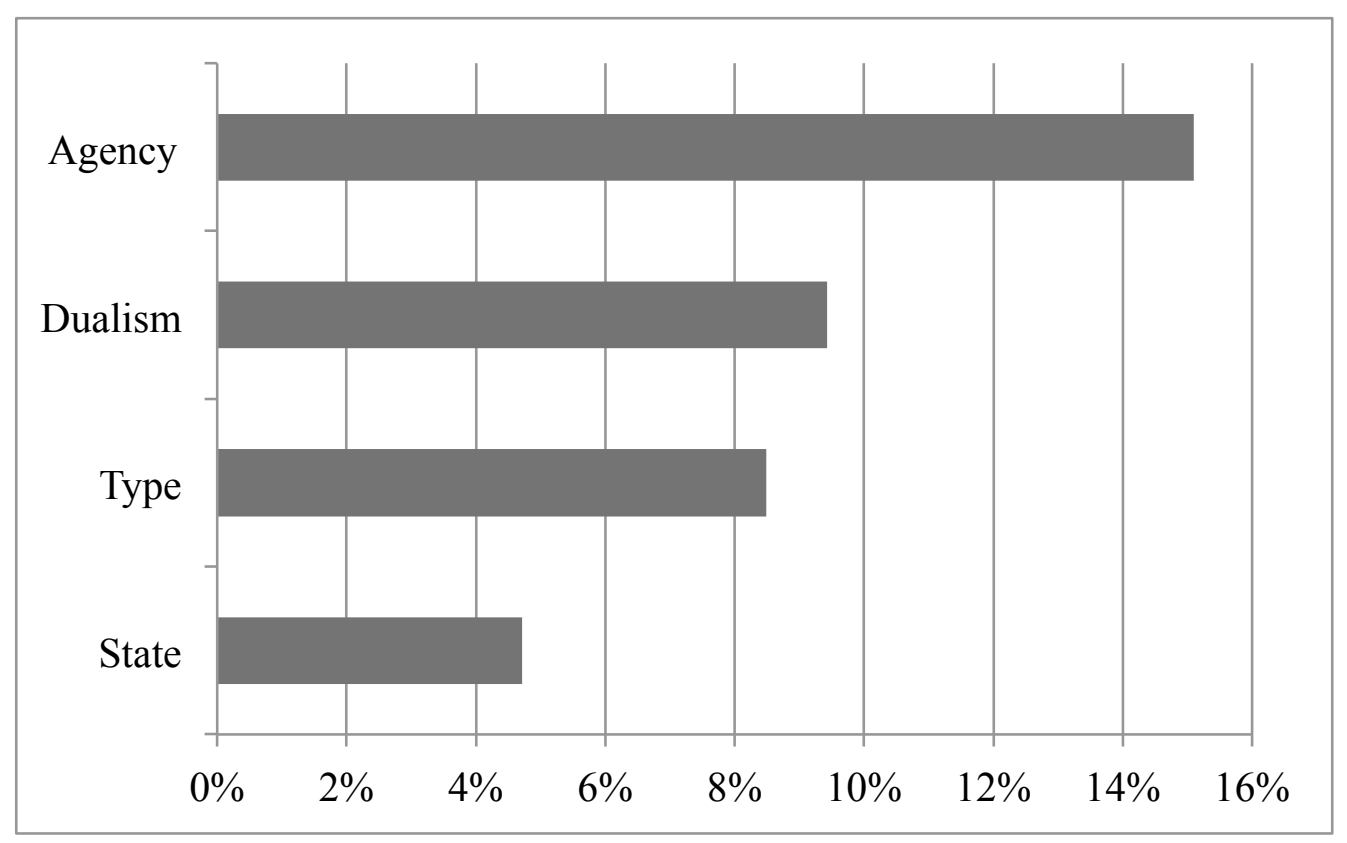

Figure 8. Percentage of total instances of mind in study corpus by theme. 
experience. If you include the instances that use the personal pronoun your, as in "your mind," the proportion rises to $70 \%$ of all instances of mind. ${ }^{27}$

The other coding categories garnered far fewer instances: of 106 total instances of mind, nine (8.5\%) were coded for Psychology, two (1.8\%) for Science/Medicine, and one $(0.9 \%)$ for Other. Of the instances coded for Psychology, four denoted a level of consciousness (e.g. "subconscious mind") typical of popular psychology and three referenced a level of quality (e.g. "healthy mind").

The Vernacular category is certainly overwhelming in this case, with $88 \%$ of the total instances of mind, and yet its content is not uniform. I applied the category Vernacular in part because these instances of mind do not seem to fit an existing cognitive framing like the frames of medicine, science, or psychology. The phrase " the schizophrenic mind" implies a number of contextualizing assumptions about mental health: that individual minds can be "identified" with a diagnosis, that diagnosis categories are unique and exclusive, and that people with this diagnosis can be grouped regardless of social factors like race, gender, or socioeconomic status. In contrast, the instances coded as Vernacular are not clearly connected to a particular frame for thinking about mental experience; in this sense, each of these instances is more idiosyncratic.

Within the total set of instances of mind in my corpus, a small group of themes came up that can illuminate patterns of talking about mind that are not necessarily tied to an overarching frame. Of 106 total instances, sixteen (15.1\%) talked about mind as having a kind of agency; ten (9.4\%) contrasted mind with body in a dualistic way; nine (8.5\%) specified a particular type of mind; and, finally, five (4.7\%) referenced a state of

${ }^{27}$ Instances of "your mind" added to seventeen (16\%) of the total 106 instances of mind. 
mind. These themes are not categories in addition to the five described at the beginning of this section (page \#\#\#); most but not all instances of the themes were coded in the Vernacular category.

The theme of agency appeared when the writer gave mind some kind of choice or action, whether literal or metaphorical. For example, the writer might describe the mind as initiating an action ("my mind decided...," "my mind blocked out..."). When writers use the theme of agency, they seem to imagine the mind as having its own volition or instinct — senses that act most often in a person's best interest. In the PTSD forums in particular, the theme of agency was used to conceptualize feelings of dissociation or gaps in memory: the mind erases painful memories, puts up defenses against strong emotions, works to calm bodily reactions, and even "shuts down" to protect the individual from psychological harm. In these variations of psychomachia, mind plays a strong protective role in the drama of mental distress. In a smaller number of instances, mind seems to act independently of a person's intentions with ill effect, fixating on a memory, thought, or emotion.

The theme of dualism arose when writers worked to separate their mental experience from bodily feelings, properties, or states. If paired with the theme of agency, the mind and body have separate and sometimes conflicting drives; the person benefits if mind and body are "in unison," as a few writers describe. One of my participants, Stephen, writes about different treatments that help his PTSD symptoms in terms of body and mind: the practice of Reiki (a method of Japanese alternative medicine) "somehow helps my mind" and that "aromatherapy massage is good for my body" (Stephen, OC). 
By separating the locus of each treatment's effectiveness, Stephen gestures toward his holistic view of coping with mental distress related to his diagnosis.

The theme of mind type allowed writers to generalize about how particular qualities tend to cluster in a recognizable whole. A number of writers used the phrase "autistic mind" to mark common ways that they felt their experiences were different from people with "neurotypical" minds. The concept of the "autistic mind" helped unify the group of people diagnosed with the condition despite the range of ways that autism is expressed in their lives. Another writer, on a PTSD forum, affiliated herself with gender norms by saying she has a "female mind."

Finally, writers used the theme of mind state to describe who their mind seems to be functioning at a certain moment. For instance, writers said that their minds felt "hazy," "clouded," "freaked up," or "a mess." These descriptors of mind state helped writers to contextualize their posts, how they are feeling at the moment, or to explain how they felt during past events they recall in their writing.

Neuro-

The prefix neuro- ${ }^{28}$ appeared in my corpus a total of ninety-two times, and nearly all of them occurred in the ASD forums (two instances were in PTSD forums). Most of the instances of neuro fit into either the Science/Medicine or Activism categories; fortythree (46.7\%) were coded for Activism, and forty-one (44.6\%) for Science/Medicine. In the other categories, six (6.5\%) were coded for Psychology and two (2.2\%) for Other. (See Figure 9.)

${ }^{28}$ As explained in Chapter 2 regarding diagnosis, the linguistic analysis software allows the user to find all instances of a term, no matter its ending, by using an asterisk. Thus, searching for neuro* will return "neuron," "neurologist," and "neurodiversity.". 


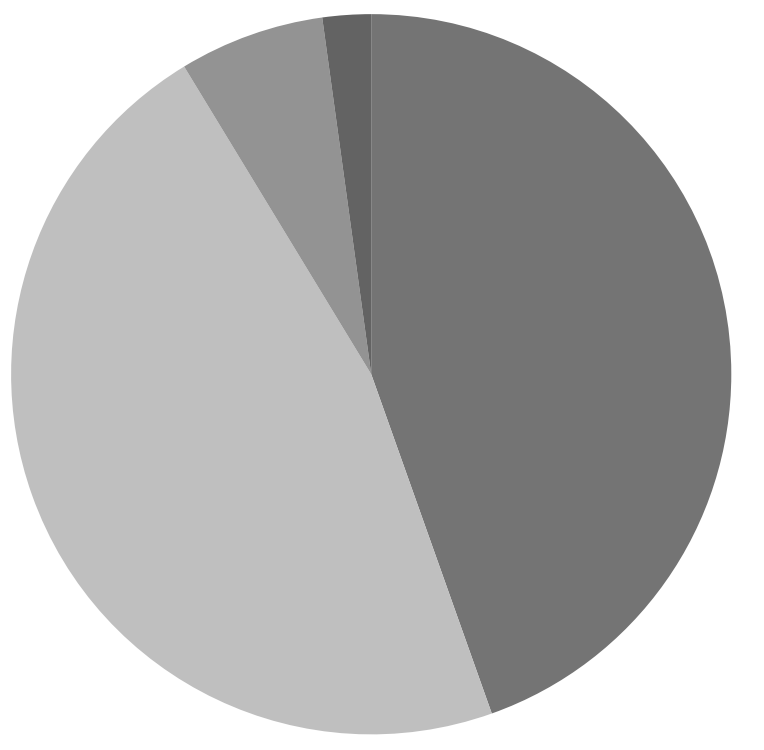

- Science/Medicine

Activism

- Psychology

Other

Figure 9. Instances of neuro- in study corpus by category. Science/Medicine and Activism are represented in near equal number. 
All of the instances of neuro- coded for Activism related to the neurodiversity movement (explained in Chapter 1, page \#\#\#). On the ASD forums, the concept of neurodiversity is often a unifying force, met with broad agreement of its value, even if the details of its application can be contested. Forms of the word "neurodiversity" accounted for about half (twenty-one) of the instances coded for Activism in my corpus. The word "neurotypical" accounted for another large portion (eighteen) of the Activism category for neuro. On the ASD forums, "normal" people are referred to as neurotypical to distinguish them from people with autism or other mental disabilities; "neurotypical" can also be a derogatory reference to mainstream ways of viewing autism negatively. A few instances (four) in this category were a derivative of neurodiversity, the word "neurotype" as a way to denote a particular type of mental experience; extending the idea of autism as neurological variation, these writers called each different variation a neurotype (thus, autistics are one neurotype, ADHD another, and neurotypicals another).

The frequency of references to neurodiversity in my corpus reflects the commitment of many writers in the ASD forums to the concept as a central way of understanding both their personal experience of autism and how to conceptualize autism as part of society. Writers' descriptions of "neurotypical" behavior help the community to build a collective identity distinct from other ways of being while also valuing autistic traits that are derided in other contexts.

The other category with most instances of neuro- was Science/Medicine, with forty-one of the total ninety-two. The words in this category varied in their type and reference. Twenty-one instances, more than half of this category, were the adjectives "neurological" and "neurodevelopmental"; these words modified nouns like "condition," 
"disorder," and "difference." Like the medical terms covered in Chapter 2, "neurological" and "neurodevelopmental" signal a particular framing of autism as an object of neuroscience and psychiatry. A significant number in this category (eight) named a practitioner or physician with the words "neurologist" or "neuroscientist." Another eight instances used neuro- to name a discipline or field of study, with "neurology," "neuroscience," and "neuropsychiatry." Finally, in four instances, writers used the word "neurons" in descriptions of brain function.

The nearly equal numbers of instances in the Activism and Science/Medicine categories suggests that writers in my corpus, while concerned with scientific assessments of autism, also seek to place their experiences in a new frame- one that has been developed within autism communities rather than outside of them. The ways that neuro- in used in the Science/Medicine category are unsurprising, given the prefix's origin in scientific terminology. Even so, their frequency in my corpus suggests an engagement with scientific/medical institutions and knowledge-making; this suggestion is confirmed in my interview data and close readings of conversations later in this chapter and in Chapter 4. Further, the frequency of Activism instances shows that writers are not reliant upon scientific assessments to communicate about their experiences and conceptions of autism. In fact, the concept of neurodiversity runs counter to the mainstream medico-scientific conception of autism as an abnormality, dysfunction, and pathology. Writers in the forums do not simply converse about neurodiversity, however, but put its central tenets in dialogue with mainstream views of autism, often with a goal of promoting cultural understanding. 
While few instances of neuro- were coded for Psychology, all were variations of the psychological term "neurosis." Four of those instances constructed "neurosis" as a kind of diagnosis or type (as when one writer asks if she is "bipolar" or "neurotic"), and two referred to "neuroticism" as one of the Big Five personality traits (openness to experience, conscientiousness, extraversion, agreeableness, neuroticism).

\section{Naming and Complicating the Biological Brain with a Mental Disability}

The powerful notion of mental disability as a biological phenomenon is the background of many conversations in online forums devoted to mental health conditions. Writers in these spaces must work rhetorically to negotiate their experiences with biomedical assumptions, which they encounter throughout their lives—not only in the clinic, but at school, with their families, and in the online forums themselves. As noted earlier in this chapter, many of these writers accept scientific claims about brain biology and, further, the biological or chemical aspects of mental disability. This limited acceptance is not the end of the thread, however. These writers continue to investigate their experiences in light of such knowledge rather than simply following medicalization's parallel logic — a medical problem needs a medical solution. In this way, writers are engaged in creating a chiasmic rhetoric that combines scientific knowledge with personal experience. Neither that knowledge or experience is lost or subjugated in the process, but rather they are (re)configured in a way that disrupts the typical conclusions of medical research.

Below, I begin by describing how many writers display their partial acceptance of biomedical conceptions of mental difference and disability by naming their own brains as different in some biological or physical way. Afterward, I show how these writers also 
complicate the biomedical perspective by placing the biological brain in conversation with other dimensions of experience like emotion, perception, spirituality, and narrative. Accepting Biological Factors

For many writers in the forums devoted to autism, the biological differences between the brains of neurotypical (NT) people and autistics is an essential part of understanding autism itself. As Daniel describes in one conversation, "You are autistic... if you have the type of brain that is autism" (OC). For writers like Daniel, autism is a trait (or set of traits) that is carried in, and recognized by, the individual. When asked what role that biology plays in his mental experience, Daniel replied, "the brain is a biological object, so all of it" (IR). While opinions diverge between writers on the forums about how to conceptualize autism, I found a consistent adherence in the conversations I studied to this kind of scientific materialism with regard to the brain: the differences in thought, behavior, and cognition that one might associate with autism are assumed to have originated from a difference in the brain itself. As another writer states, autism is a "neurological condition" that "has always been there... and it's not going anywhere!"

In a similar fashion, another writer valorizes what she calls "the spectrum mind" and frames autistics' "exceptional brains" as distinct from neurotypical brains (Susan, OC). Susan is careful to make this distinction without medicalizing it, though, encouraging another writer that autistic experiences can be recognized as "lovely once you understand it's not pathological" (OC). For Susan, and many other writers in these forums, it is important to separate credible neuroscience from its more subjective cousins in psychiatry and psychology. Susan references different kinds of structures in the brain 
to describe what's happening, writing about "the frontal lobe (i.e. the CEO of the brain)" and "new neurons"; in one metaphor, she calls brain science "the driver's manual" (OC) ${ }^{29}$ Her acceptance of these terms - and the biological view of the brain they implydoes not, however, signal an acceptance of mental disability as a medical issue, and she argues against such an interpretation at other points in the conversation. In Susan's view, "the mainstream" has a medicalized response to autism, even if it has "all the best intentions"; the negative effects of that medicalization can be observed in "ABA ${ }^{30}$-abuse" and "chemical restraints" through overmedication (OC).

Writers in the PTSD forums I studied construct the role of brain biology in relation to mental disability in a different manner than writers in autism forums, but the pattern of acceptance was similar. By definition, PTSD results from traumatic life experiences, rather than being an innate condition as the writers above describe autism. Writers in PTSD forums frequently use biology to describe the reality of their condition, and they may see differences in brain chemistry or physiological reactions as the basis of their distinction from people without PTSD. "Normal" brain chemistry is often referenced, for example, in discussions about the efficacy of certain medications the writers have been prescribed; the writers name their own "abnormal" brain chemistry that needs to be modified by medication to reach a more "normal" state.

The connection between PTSD and a person's biology raises some controversy, though, when writers tease out the differences between stress, trauma, mental disorder,

\footnotetext{
${ }^{29}$ As shown in other quotations from Susan, she sees the science behind autism and other mental disabilities as valuable but not the full picture. She follows the "driver's manual" comment by stating that "one needs to learn to manage the mind akin to driving a high performance vehicle."

${ }^{30}$ Applied Behavior Analysis, the most common type of therapy prescribed for children with autism.
} 
and mental illness. As a large body of sociological and humanistic research indicates, people use differing terms to describe illnesses, disabilities, and other conditions according to the cultural connotations associated with them (see, for example, . If someone feels that having a "mental illness" is permanent and consistent, for instance, she might characterize her own experience of mental disability as a temporary dysfunction or a situational condition. One writer in the PTSD forums writes that having a mental illness means that something is "biologically wrong" with an individual, while PTSD can be considered a "natural" response to "distressing events" (OC). A writer responds in agreement, distinguishing between a person whose "[brain] struggle[s]" with trauma and someone with "biological issues" like "chemical imbalances" that cause mental illness. Another writer relies on how experts classify the condition: he argues that a person seeing a friend killed could cause depression, and since depression is "classed as" a mental illness that person is mentally ill. He says that mental illness can occur "at any age" and is not necessarily a lifelong "biological inbalance [sic]." The negotiation of terms here—deciding what constitutes "mental illness" and whether PTSD qualifiesmirrors similar conversations about psychiatric expertise in the next section. The conversation is conducted, though, with an acknowledgement that at least some mental disabilities have a biological component and, importantly, that certain terms carry more social stigma than others.

In conversations about autism and PTSD, writers in my corpus adopted some of the language of biology that characterizes popular discourses about the brain. While no writers in my corpus reduce their condition to only biological differences, many writers discuss issues of mental disability in relation to brain biology, chemistry, and anatomy. In 
the ASD forums, writers commonly reference the importance of family histories and the important genetic factors in the expression of autism; writers in these forums also imply, or sometimes argue directly, that people with autism have a distinct type of brain from the rest of the population. Both of these claims have become central to the furtherance of the concept of neurodiversity, which asserts that the differences we now call autism were always present in humanity and that they are generally lifelong and cannot be "cured" (though individuals often learn to cope or "pass"). In PTSD forums, the role of biology in mental disability is framed in different terms, usually in reference to brain (dys)function and the effects of particular medications. Further, writers in the PTSD forums place that biological role in a social context and wrestle, whether explicitly or not, with the social stigma attached to mental disability.

Connecting the Condition with Experience, Emotion, and Psychology

The biological perspective of the comments above do not characterize the full picture of mental disability experience that the writers in my corpus present, however. Very few, if any, writers talked about their experiences of ASD or PTSD solely in biological terms; even when discussing brain science or biology directly, writers situated that knowledge in a social context and put it into dialogue with other ontologies and epistemologies. While the precise way this contextualization occurred varied widely in my corpus, many writers sought to soften the sharp boundaries of biomedical thought with assertions and observations that they felt accurately reflected their own experience.

In the ASD forums, the most common rhetorical move of this type was to observe that diagnoses and symptoms related to autism are derived from behavior rather than 
biology.${ }^{31}$ For instance, one of my study participants, Bethany, consistently reminds her readers that ASD diagnosis is performed by a practitioner observing behavior. While Bethany, a graduate student in neuroscience, is a staunch and, to a degree, outspoken defender of autism research on the forum, she puts that research in a context of limited but constantly growing expert knowledge about the condition. ${ }^{32}$ Future tools may allow autism to be defined "by cognition and brain function," but "autism is currently defined mostly through behavior and diagnosed based on behavior and impairments" (Bethany, $\mathrm{OC})$.

The behavior/cognition/brain profile of HFA [high-functioning autism] is a continuum into the general population, so it is the people who have more and stronger traits to cause impairments who would be diagnosed for support and accommodations instead of people who have less and milder traits who don't have impairments. (OC)

Bethany describes the current process of diagnosing autism as part of a "progress of science" narrative (Fahnestock) that assumes future study will result in more precise measurement-based means of making a diagnosis: she writes that current work in the genetics of autism "are too shaky to apply to individuals" but that testing according to "brain/cognition is more likely" and that "more specific definitions/subtyping...can be made using brain function instead of behavior" (Bethany, OC). In her arguments, despite her defense of the albeit limited scientific knowledge about autism, Bethany writes that autism can only be diagnosed by someone else (usually a professional) because it is

\footnotetext{
${ }^{31}$ This observation is also central to the writers' negotiation of expertise described in the following section of this chapter.

${ }^{32}$ I report on and analyze more of Bethany's arguments in Chapter 4.
} 
defined according to observations of behavior. ${ }^{33}$ Bethany's writing reveals, implicitly, the limits of biomedical knowledge regarding autism and its current reliance on the judgment of a professional rather than technological measurement of the body/brain.

Another ASD forum writer, Frank, places autism as at an intersection of different intellectual fields, implying that no one field can claim a monopoly on knowledge about autism. He says that "autism lies in that vague zone... within a Venn Diagram [sic] which depicts the disciplines of neurology, psychology, and medicine" (OC). For Frank, each of these distinct dimensions of experience and knowledge-making must be taken into account to "understand" autism; the claims of professionals in any one field will not be independently authoritative. Frank sees self-knowledge of autism as vitally important as well, and he suggests that individual experiences should be used to informed conversations around diagnosis. While diagnosis itself may be more complicated than self-identifying with the condition, Frank writes that "I think presenting anecdotal accounts within this thread [about self-diagnosis] would be useful" because they "would illustrate the journeys that people took to obtain their diagnosis of autism" (OC).

One of the writers on the PTSD forums, Joanna, speaks of her experience in a similar way to Frank. Joanna does not feel that PTSD can be reduced to biological, or any other, explanation, but must be understood in connection with other dimensions of life. In the conversation I quote in this section, Joanna is responding to another writer who is having difficulty with multiple diagnoses of PTSD, OCD, and anorexia and has reached out asking for help from others on the forum. Joanna opens a long post with these two

\footnotetext{
${ }^{33}$ This point is also important for Bethany's argument against what some in the forums call "self-diagnosis," where someone states that they have the condition without an external or professional diagnosis.
} 
sentences, and the description of her recovery process that follows bears out her interconnected conception of PTSD: "PTSD seems very unspecific to me as it encompasses so many area's of health, mind, spirit and body. The parts are connected and all part of the PTSD, forcing oneself to work on only one area before another I really think is near impossible" (OC). Joanna explains that in her experience, separating out different kinds of needs — physical, psychological, emotional—can keep one from finding relief from the distressing effects of trauma. She relates how the "monstrously intense" emotions she felt were "a million piece jigsaw puzzle" began to be reconciled in her mind:

I found once my subconscious mind was strong enough it allowed myself to remember the emotional memories. At the time even though it was terrifying, I thought I was going crazy, would never get better etc. all the symptoms or other conditions with my physical health and mental health seemed so very different when in fact they were all interconnected. (OC)

For Joanna, the "emotional memories" are different from simply knowing what happened to her; she worked through a long process of "accepting what the trauma's done to me" (OC). She encourages the person who made the original post in the conversation to "take it in baby steps, even if it's years of baby steps" and to "work on what you can...with or without your therapist's help" (OC). Since the nature of the trauma and of recovery are interconnected with "health, mind, spirit, and body," Joanna did not find a solution in the kinds of sequential treatment plans common in biomedical treatment of mental disability: 
There was no one thing, then the next, methodically planned out, or schedules by docs and therapists, it was my mind going willingly into the gateway, into that intensely emotional and behavioral roller coaster, remembering it all, constantly twisting, turning, so many ups and downs. It was true acceptance of myself in whole including all the bits I had locked away. (Joanna, OC)

While her account of recovery may seem quite distant from a medical approach, Joanna sees medical research as valuable and potentially transformative. She writes that "brain imaging is not used enough in psychiatry," and she is "excited about the latest genetic marker discovery in schizophrenia" as well as "neuroimplants that are being developed to help in memory centers of TBI patients and patients with Alzheimer's and dementia" (Joanna, IR). Even so, she sees psychiatry as "biologically driven, still in need of reform" and states that it could benefit from "inclusivity of more comprehensive treatments and alternative treatments" (Joanna, IR). Thus, in the interviews, Joanna shows that her view of PTSD and mental disability more generally is informed by scientific and medical knowledge; at the same time, she acknowledges the limits of that knowledge and, when helping others, encourages a holistic rather than simply biological view.

Another one of my participants from the PTSD forums, Stephen, writes about the connection he feels between his experiences and his body. Earlier in this chapter, I showed how Stephen used the dualism theme when writing about "mind" to reference his holistic view of recovery. Stephen works to separate the location and effects of his condition in order to better understand for himself what is happening and how to move 
forward. In one conversation, Stephen describes the force of his flashback experiences by relating their physiological effects:

I have tried to confront my traumas head on but this is not the right approach as I just get stuck in it. and despite what they say about the flashbacks 'not really happening now' and all in the past, my own flashbacks are so physically painful that I can feel the electric shocks wracking through me, I know that I need to get through these to find my way to the other side. (OC)

As he explains in other conversations, Stephen was involuntarily subjected to electroshock therapy as a young man, and these experiences, along with witnessing the death of a close friend, represent much of the trauma that led to his diagnosis of PTSD. In his treatment in therapy over the years, he has been encouraged to think of the flashbacks as temporary and based in memories of the past; his account above, however, shows that he is not just remembering but re-experiencing past trauma, even down to physical sensations. Speaking to another writer on the forum, he writes that this cycle is "the nature of PTSD": "I have been returning endlessly to the point where it started...we are being traumatised again and again by our pasts" (OC). To help conceptualize his experiences, he uses "body," "mind," and "brain" in unusual ways, creating the idea of "body memories":

Body memories....are the only way I can fathom out what has happened to me. Body memories cannot lie. Body memories are not kept in the body but somewhere in the brain. I think broken synapses sever the recall of the traumatic memories until they reform in some way and release the information to my body which reminds my mind what was actually going on. (OC) 
In some ways, Stephen's “body memories” recall biomedical ways of understanding the brain — t synapses that can be functional or "broken," lines of communication between the brain and the body. Clearly, though, Stephen does not rely on a biomedical frame, and his way of describing "body memories" seems to impart some kind of agency to the processes in his mind that protect him from the trauma. It seems unnecessary, as well, to try and explain the biological means by which his brain can "release the information to my body," which then communicates with "my mind," even if that understanding would be central to a biomedical explanation. Whatever knowledge or concepts he borrows from biomedicine, Stephen will connect them—and adapt or modify them — to fit with his experience of PTSD. While the pressure of medicalization may cause some to reframe their experiences to fit a biomedical explanation, Stephen and other writers like him on the PTSD forums understand biomedical ideas to be tools for understanding that can only reveal a part of the whole experience.

As illustrated in this section, writers in the ASD and PTSD forums I studied may accept the medicalization of some parts of their condition, but they also adapt, modify, and supplement biomedical explanations in ways that reflect their personal experiences. The differences between biomedical accounts of mental disability and what I found on the forums reflect broader rhetorical purposes for writing — writers in my corpus do not just want to know what is happening in their bodies/brain, but are also concerned with how to understand their personal and social experiences, to manage or cope with relevant effects and impairments, to support others on the forums with these same goals, and finally to educate people outside the community about the condition. 


\section{Medicalization and Negotiation of Expertise}

At constant issue in these conversations is the status of psychiatry--and expert judgment in particular--as a science. Writers in the forums broach the topic from several directions, but in each case the debate lingers around the veracity and appropriateness of psychiatric practice. I frame these conversations as a negotiation of expertise, since the writers offer a variety of arguments, with corresponding evidence, that assess how much psychiatrists and related professionals can be considered the authority on the conditions they treat. In response to the growing medicalization of their conditions in popular discourse, writers in the forums adjudicate the limits of a physician's and researcher's knowledge claims and suggest ways that people living under the diagnosis can contribute to the production of knowledge as well as improve clinical interactions.

In this section, I divide the negotiation of expertise into two common debates that arise in the forums used in this study. First, writers evaluate knowledge and practice in psychiatry against a standard of "true science." When discussing the credibility of psychiatry, writers frequently invoke the social context of the DSM and other diagnostic tools. Second, writers parse out the roles of different parties in mental health treatment and the type of authority each should be given in a situation - including the patient or client herself. To emphasize the importance of people with mental disabilities advocating for their interests, writers present evidence of expert resistance, from doctors or others, to a patient's own knowledge and judgment.

\section{Psychiatry as a (Pseudo)Science}

As I explain in Chapters 2 and 4, writers in the forums I studied do not typically make wholesale judgments of medical practice, positioning themselves as pro- or anti- 
science. When discussing psychiatry, many writers instead couch their opinions within a certain theory of how medicine could construct their condition and its relation to biology.

Given the negative clinical treatment of people with autism, the legitimacy of psychiatry is sometimes questioned in conversations from both ASD and PTSD forums. A few refuse to defend psychiatry as a "hard" science but still explain how it is still, in its own way, reliable and accountable to scientific processes. One writer [non-participant] calls psychiatry a soft science, with results that can be considered "accurate" but have different standards of proof from fields like physics or chemistry (OC). Yet such a characterization is not vindicating: this writer later claims a great difference between "science" and "autism research" (OC). Another writer [non-participant] identically distinguishes the methods of psychiatry and physics, but says that the distinction is not a reason to disregard psychiatry—especially if that disregard leads people to think that mental disabilities are not "real" (OC). She goes on to write that it's a mischaracterization to portray psychiatry as solely driven by the influence of the pharmaceutical industry, writing that she knows of many who are "sincere" and work to help their clients live better lives (OC). In another conversation, a writer [non-participant] challenges the supposedly sincere motives of medical researchers, arguing that genetic studies of autism, whatever their stated purposes, always have a "goal" of developing a test for "prenatal diagnosis"; he derisively asks if a certain study is funded by Autism Speaks, which supports an extensive genetic autism study called the "10K Autism Genome Project" (OC).

The most cynical views toward psychiatry can be illustrated by statements from study participant Benjamin, a writer in ASD forums, in his interviews for this 
dissertation. When asked in what types of conversations he chooses to participate, Benjamin at first lists general topics: "Aspie behaviours/traits, issues, coping strategies. Political" (IR). He then cites a category of conversation he calls "don't trust the 'experts' discussions," where he likes to debate the "validity of self or doctor diagnosis" as well as "labels which medical psychological science is flailing around to make up as we go along, while they call it certainty" (IR). Benjamin sees psychiatrists as part of an academic cycle that reinforces dogmatism and prevents researchers from admitting mistakes for fear of professional censure. Instead of building scientific knowledge with research, each generation of psychiatrists sticks with its own theories; Benjamin believes this is why"it takes decades to change anything rather than years" and shifts in psychiatric though only occur when "that generation dies out then the new generation comes in" (IR). In one forum conversation about diagnosis, Benjamin makes an attempt to temper his skepticism:

But I suppose that it is important for me to agree, just to be clear, that I do believe most professionals ARE probably genuinely trying hard and motives must ultimately mostly be altruistic for all my criticism....ie not bad people, however they may well be misguided and tied to the mast of redundant theory of the latest status quo as the cutting edge is usually 10 years ahead ahead of current usage. (OC)

It seems that for Benjamin, good motives and altruism only go so far; the professionals are still beholden to a system beyond their control and limited by current applications of knowledge.

Benjamin sees the "latest psychiatric model" as "fit the person in the box," a "made up" method where the psychiatrist "draw[s] boundary lines where there are only 
overlapping textures of experience" (IR). Psychiatry's "boundary lines" and "labels" have affected Benjamin's judgment of himself; the idea of having a mental illness has a "negative connotation" and "I am trying to overcome with positive labelling....and occasionally succeeding" (Benjamin, IR). Benjamin calls himself an "Aspie" because it "sounds non medical and friendly"; instead of claiming a condition or illness, Benjamin says that "I 'think differently' and I have 'social or communication problems/struggles" (IR).

Susan, another writer on ASD forums, affirms Benjamin's view of psychiatry as a field dominated by people clinging to tradition and "academic pride" (IR) when she writes about the American Psychiatric Association's (APA) terminology on personality. When characterizing tendencies and behaviors, Susan "prefer[s] an approach such as the Myers \& Briggs non-judgmental 16 personalities" (IR). Susan believes the "APA is appalled that Myers \& Briggs were not formally educated and reject their work" and instead "promotes the useless 5 questions" (i.e., the "Big Five" personality traits of Openness, Conscientiousness, Extroversion, Agreeableness, and Neuroticism). ${ }^{34}$ Susan sees the Myers-Briggs model as identifying "strengths and weaknesses that make me valuable" while the APA marks deficits to uphold its view of certain behaviors as signs of mental illness.

By positioning their arguments as matters of personal experience as well as academic inquiry, the forum writers quoted above create a chiasmic rhetoric of exchange

\footnotetext{
${ }^{34}$ Neither Katharine Cook Briggs or daughter Isabel Briggs Myers received formal training in psychology, though Myers was a college graduate. The Myers-Briggs test is based on the typological approach of Carl Jung. Critiques of the Myers-Briggs from within the fields psychology and psychiatry test often focus on the test's use of reductive dichotomies (Extraversion vs. Introversion) and its low reliability across time (Pittenger).
} 
between the separated, observational gaze of the professional and the perspective of one under the power of that gaze. At first glance, there may not seem to be much to call "chiasmic" in these arguments from writers on ASD forums, no exchange or cross-over between discourses; psychiatry is being pilloried for its insistence on using particular models of mental disorder and the reductive nature of the labelling system outlined in the DSM. The arguments described above have much in common with critiques of psychiatry that have risen in the last five decades, as described in Chapter 1 (cf. Frances; Horwitz; Kirschner; Lafrance and McKenzie-Mohr; McLaren). However, the personal nature of the arguments sets the forum critiques apart from academic critiques: the conceptual and social dimensions of psychiatry the forum writers criticize are situated within the experience of mental disability. Benjamin, for example, says the current labelling system is problematic because, first, it neglects the "overlapping textures of experience"-his experience as someone identifying with Asperger's Syndrome, if we view the comment as phenomenological. Benjamin also connects the labels to his personal identity and social interactions, where he chooses the "non medical" name to avoid the derogatory connotations of the biomedical label of "mental illness." Susan's discussion of personality traits does reference what she sees as short-sighted professionalism in rejecting the Myers-Briggs model; her evidence, though, is tied not to formal evaluations of the comparative validity between personality tests but rather her experience of MyersBriggs as "non-judgmental." For Susan, it is a matter of dignity and self-determination that her autistic traits be seen as a group of "strengths and weaknesses" rather than a medicalized disorder. Susan concludes her discussion by asserting the importance of her autistic identity and experience in describing the condition: "the APA does not consider 
an autistic a reliable source of information about autism," she writes, "But they do not describe me" (IR).

A similar dynamic arises when forum writers discuss the social context of psychiatric diagnosis - both its abstract formulation and application to individuals. Susan voices one of the most common critiques of psychiatric descriptions of autism: that it cannot be described without the help of autistics themselves. ${ }^{35}$ Responding to an interview question about his appraisal of accounts of autism from medical professionals, Benjamin writes that such professional "can list symptoms" but asks, "can they explain them?" (IR). Benjamin questions the authority of someone who doesn't experience the world "as an Aspie" to write about his condition; "If they are not fellows on the journey, how do they know what it's like?" (IR). Another ASD forum writer [non-participant] writes about his co-diagnosis of paranoid schizophrenia, saying that people should use diagnostic labels if they are "helpful," but cautions that psychiatric terms and labels are "highly subjective" and have more utility for medical treatment than self-understanding; this writer often thinks his psychiatric label to be "utter nonsense" (OC).

The forum writers rarely see this "nonsense" as neutral, though, and write about the subjugation of patient voices in psychiatric history (as well as the present). One PTSD forum writer [non-participant] connects the very existence of her diagnosis to historical gender inequity. When the effects of trauma were typically recognized in women, it was labelled as "hyseteria"; once trauma became "a male problem," however, with the return of U.S. veterans from foreign wars, she points out that PTSD was "suddenly...a

\footnotetext{
${ }^{35}$ Not all writers share this view, of course. Bethany, an ASD forum writer and graduate student in neuroscience, argues that an autism diagnosis is by definition made through outside observation; as such, she does not support "self-diagnosis," a common topic on the forums studied in this dissertation.
} 
recognized condition" (OC). Similarly, writers on ASD forums sometimes write about figures in the history of autism study. Many prefer Hans Asperger's (1944) clinical descriptions as more sympathetic to people with autism, as opposed to Leo Kanner's (1943) deficit-laden language. Asperger can more easily be seen as a champion for the proper treatment of autistics, and some on the forums even speculate that Asperger himself was "on the spectrum.” ASD forum writers criticize Ole Ivar Lovaas, who was instrumental in developing Applied Behavioral Analysis therapy for children with autism, for his intense and explicit goal of normalizing autistic behavior, as well as the therapy's original purpose of encouraging gender conformity. Like the above quotations about diagnosis, forum writers place the history of psychiatry in relation to their experience as someone diagnosed or identifying with a certain label. For these writers, the stops and starts in the development of psychiatric treatment are sources of personal suffering and social stigma; and, it goes without saying, there is more work to be done.

\section{Professional Roles and Authority}

The discussions around psychiatry in the forums I studied extended to its routine practice, as well, and the roles of different parties in the mental health system, including patients. In negotiating their own role in the delivery of mental health care, forum writers find it necessary to advocate for their interests with different individuals and organizations; in the seemingly endless cycle, people with mental disabilities are challenged about knowledge of their own experience and must explain, again, how their needs may not fit the paradigm of biomedical diagnosis and treatment.

On one PTSD forum that is hosted in the United Kingdom, writers often talk about the process of getting care through the National Health Service (NHS). One writer 
calls the NHS mental health services "ridiculous" and criticizes the short-term nature of covered treatment; she is flabbergasted that they will only provide eight weeks of therapy for PTSD. Stephen, one of my study participants, gives advice to other forum writers about how much (or how little) to expect in support from the NHS for mental health; in one forum conversation, he describes arguing with multiple practitioners about his diagnosis and what treatment will be helpful. As described in more detail in Chapter 4, Stephen identifies his diagnosis as Complex PTSD, a variant that is described in some psychiatric literature but not yet included in the DSM. Stephen feels that some psychiatrists and psychiatric nurses hold on to limited views of PTSD; they assume "that I have been in a train crash or the army or something" (IR), traumas that are more commonly the cause of PTSD. "They cannot relate to the fact that I have just got it from being tortured 38 years ago," he writes, "for something I appeared to have volunteered for" (IR). In the 1970s, Stephen underwent electro-shock therapy at a religious institution in a program that was intended to make his behavior heteronormative. Since Stephen's situation does not fit the typical presentation of PTSD, he finds it more difficult to get the long-term support he needs. At one point, he writes with frustration, "I seem to have had all the help I am going to get off the NHS. Is that it then? Am I cured?" (OC). Stephen knows that "I can't do it on my own," though, and so he will "go on bothering the NHS mental people until I get help" (OC).

Writers also give each other advice on navigating issues related to diagnosis and getting necessary care. One writer on an ASD forum, Sam, [non-participant] encouraged another to seek more opinions after a doctor and therapist disagreed over diagnosis. The doctor in this situation said that he could not be both autistic and bipolar. Sam advised 
this person to talk with another doctor to help process the "conflicting information" he was getting from the therapist and doctor. Sam's advice mirrors the process that Joanna, a study participant from a PTSD forum, described in her path toward diagnosis (her story is covered in greater detail in Chapter 4). Faced with skepticism from a number of doctors and therapists, Joanna researched her trauma-related issues and learned about PTSD. It took some time to find a professional who would recognize that diagnosis, however; like Stephen, her circumstances (years of child abuse rather than a single traumatic event) did not fit the typical presentation of PTSD as it was understood at the time.

For Bethany, an ASD forum writer, negotiating expertise in psychiatry involves judging its usefulness for different tasks. As stated above, Bethany is a graduate student in neuroscience. She says that "my research projects have the most influence on how I think about mental and social experience," and her reading about autism has included mostly "scientific rather than clinical or medical" sources (IR). Bethany sees value in the work of psychiatry for individuals, and states that it is "good for recognizing problematic or maladaptive ways of thinking or acting, and helping people adopt healthy mental states that improve their general well-being" (IR). She says that psychiatry's methods for diagnosis are less useful: "there are too many vague psychiatric criteria for disorders, too much subjective judgement of clinician, and too much drug prescription as a solution to life's problems" (IR). The clinical assessments Bethany read seemed to be "accurate" in their "descriptions of outwards behavior" but "some of the speculations about mental states seemed inaccurate" (IR). While Bethany is an outspoken critic of self-diagnosis, her views here seem to correlate with other forum writers' critiques of psychiatry: even if psychiatrists are able to describe the behavior of someone with autism, they are still 
"speculat[ing]" about that person's experience, and without his or her input runs the risk of misunderstanding what the condition is like for the individual.

\section{Medicalization, Chiasmic Rhetoric, and Activism}

One of the defining features of medicalization is that it seems to procede in one direction; like fluid passing through a one-way valve, aspects of life can move toward medicalization, but the valve resists any movement in the other direction. Once shyness, anxiety, and sadness have been medicalized, it becomes more difficult to view them outside of the biomedical terms with which they are commonly described in science and health writing. However, the chiasmic rhetoric illustrated in this chapter could initiate action against medicalization by parsing the limits of authority for medicine and psychiatry in a novel way: using the experiential knowledge they have gained as people "living under a diagnosis" (Martin), the writers studied in this dissertation bridge a gap between epistemologies that strengthens, rather than weakens, both their confidence in scientific processes and the conviction of the right to self-determination. By separating medical and psychiatric knowledge from the unspoken sense of objectivity attributed to science, and building new conceptual connections between science and experience, these writers offer a conception of mental disability that maintains scientific literacy while remaining politically charged and committed. 


\section{CHAPTER IV}

\section{CLASSIFIED CONVERSATIONS:}

PSYCHIATRY AND TECHNICAL COMMUNICATION IN ONLINE SPACES

\section{Introduction $^{36}$}

Building on the linguistic and closer-reading analyses of Chapters 2 and 3, in this chapter I examine the practices of my dissertation research participants in online mental health discussion forums conversations as they interpret technical documents, including American psychiatry's “charter document," the Diagnostic and Statistical Manual of Mental Disorders (DSM). The analysis in this chapter brings the archive of data created for this dissertation into conversation with theories of technical communication and studies of reception, with particular attention paid to how medical descriptions of psychiatry are received and transformed in online forums.

In his $T C Q$ article introducing the concept of "tactical technical communication," Miles Kimball writes that the field's "focus on the organization has kept us from appreciating the growing amount of technical communication produced outside of (or in spite of) organizations" (68). While research in technical communication often centers around the "strategic" work of institutions, Kimball exhorts us to "ask not just how to improve technical communication, but what technical communication and other

\footnotetext{
${ }^{36}$ A version of this chapter is published under the same title in Technical Communication Quarterly, vol. 26, no. 1, pp. 8-24.
} 
technologies mean to users culturally, as well as how user-producers make further meaning through these cultural materials" (84).

As described in earlier chapters, participants in the forums I have chosen to study have received, or identify with, a particular psychiatric diagnosis; those included in this study have written in forums dedicated to either autism spectrum disorders (ASD) or post-traumatic stress disorders (PTSD). This communal identification, along with each venue's relative privacy, leads to candid conversations about experiences with social and psychological distress, behavioral differences, and medical interventions. Users in these forums are both extra- and intra-institutional actors: they discuss documents like the DSM outside of its official applications but are also subject to the decisions and descriptions of mental health professionals and thoroughly enmeshed within institutional practices.

The actions of these mental health forum participants, however, may be invisible to relevant institutions and organizations that act in strategies rather than tactics. As Michel de Certeau distinguishes, institutions enact strategies that impose order or conformity. The institution and its representatives may fail to notice, or consciously disregard, the actions of people under their direction, like the shop manager who ignores a worker "borrowing" company tools for personal purposes (25). However, tactics put into use by the worker, the consumer, the subject, or the medical patient can reveal a strategy's limits: tactics "show the extent to which intelligence [i.e., knowledge] is inseparable from the everyday struggles and pleasures that it articulates" (de Certeau xx). Though they are described by documents like the DSM, the discussion forum participants in this chapter reveal "everyday struggles and pleasures" that deviate from, contradict, or 
make tactical use of institutional knowledge about their conditions and, indeed, their lives.

When viewing technical communication in mental health contexts through the lens of tactics, I suggest that the two disciplinary purposes Kimball mentions above—of improving technical communication and studying how users interpret and use that technical communication - could be imagined as working together in a dynamic cycle of revision: documents used in mental health organizations might be improved precisely by listening to the people such documents describe, categorize, and control. (See the concluding section for more detail on this process.) And though users in online mental health discussion forums have been engaged in the work of interpreting medical documents for at least two decades, their voices have been largely absent from conversations where diagnoses and treatments are constructed and revised—including those happening in technical communication and rhetoric and composition. ${ }^{37}$

Writers in online mental health discussion forums take up and transform the clinical, descriptive language of medical documents to more accurately reflect their own experiences of difference. At the intersection of medical discourse, popular science, and personal narrative, these tactical technical communicators reveal the ways in which the biomedical language of mainstream psychiatry inflects individuals' descriptions of mental and social experience. The practices of writers in these forums provide significant insight into the circulation of scientific knowledge in everyday contexts, especially in the rhetorical moves writers make to construct their ideas and create identifications between users. Hence, the writing of those affected by mental health documents can contribute to

\footnotetext{
${ }^{37}$ Notable exceptions include Prendergast, "On the Rhetorics"; Heilker \& King; Duffy \& Yergeau; Heilker \& Yergeau; Price; Yergeau; Jack, Autism; and Molloy.
} 
reception studies, helping our field continue to widen its view of technical communication's role outside of institutions and organizations.

More importantly, including the voices of people affected by medical and mental health documents, like those represented in this chapter, can spur the development of ethical practices in the production of technical communication. For decades, the discipline has incorporated the thoughts and purposes of people not involved in design through the lens of usability; more recently, that lens has been expanded to include usefulness (Mirel; Simmons and Zoetewey) and repurposing (Kimball, Bellwoar). Building on the spirit of these expansions, those working in technical communication have an opportunity to promote social justice as allies to marginalized and underrepresented groups whose views are ignored, or even maligned, by institutions and organizations that significantly affect their lives.

- In the next section, "Medical Discourse and Mental Health," I review scholarship related to medical discourse in mental health from the fields of rhetoric, technical communication, and disability studies, followed by a brief description of the methods used to gather the data in this chapter.

- Next, in the key analysis section, "Medical Discourse in Online Communities," I detail four salient forms of the manipulation of medical discourse in online communities: (a) demonstrating ethos through scientific literacy, (b) "unpacking" a diagnosis, (c) navigating medical care and support services, and (d) changing diagnostic language to benefit the community.

- In my final concluding section, I explain how these insights can inform academic study of writing in mental health contexts and transform the content and 
application of medical and technical texts. Finally, I describe how teachers of writing and technical communication can adopt inclusive practices that highlight the voices of marginalized and underrepresented groups.

\section{Medical Discourse in Mental Health}

Current medical discourse tends to classify, explain, and define (technically and bureaucratically) bodily phenomena in terms that privilege biological over social factors of disease (Rose and Novas; Rose; Conrad; Karkasis). As referenced in Chapter 3, the scientific and medical advances of the mid-twentieth century led people to think of themselves as "somatic individuals"; in the practices of medicine, health and sickness, like life, are "envisage[d]... at the molecular level" (Rose, Politics 6). The shift toward conceptualizing all life, including its "abnormal" varieties, in terms of (micro)biology affirms and encourages medicine's pursuit of biological and chemical interventionstreatments that target the body's smallest components to heal the whole. This "biomedical" approach focuses the physician's gaze on visible signs of microcosmic mechanics. Biomedicine must be constantly redirected into considering people as social and experiential beings; if the pathological mechanism is microscopic, only a microscopic intervention can be effective, and other factors influence the situation in only minor ways. The biological focus is not limited to treatments, however: the molecular and the physiological are also rhetorical arbiters of medical truth. As Katrina Karkasis details in Fixing Sex, for physicians the proper definition of intersex conditions must be based upon the (microscopic) chromosomal status of the individual over all other factors - even in the face of evidence that cultural gender roles dictated their most 
common interventions in those cases. The relevant - and persuasive - knowledge is the physiological, the molecular, the biological.

Psychiatry is an exceptionally contentious field in this regard, since its primary scope covers behavioral phenomena appearing in complex social contexts. Regarding itself as an equal branch of medicine (Compton \& Guze) with other specialties, psychiatry has gained cultural and intellectual capital in the last forty years by focusing its diagnostic and treatment practices on biological and neurochemical factors. This approach precipitated the meteoric rise in prescriptions of psychopharmaceuticals, including antidepressants and antipsychotics. Additionally, research into psychiatric conditions has gravitated toward similar markers of difference, and features like blood flow, levels of neurochemicals, or the relative size of parts of the brain come to represent the abnormalities in behavior - again, the molecular and physiological are messengers of psychiatric truth. Critiques of the biomedical turn in psychiatry have arisen from within the field itself (Wilson; Horwitz; McLaren; Lewis, Moving; Metzl, Prozac and Protest; Frances) as well as a number of academic fields (Gaines; Crowe; Moncrieff; Kirschner; Lafrance and McKenzie-Mohr). Given the range of criticisms from scholarly and popular sources, some psychiatrists have engaged the topic directly, defending the "medical model" in psychiatry and its bio/physiological focus (Compton and Guze; Shah and Mountain).

Though not always explicit, the biomedical approach is embodied in the central technical document of American psychiatry, the DSM. While the DSM lists mental disorder diagnoses within a taxonomy that serves a number of institutional actors, including psychiatrists, general physicians, nurses, therapists, and insurers, its form 
reflects the efforts toward medical professionalization made in the field of psychiatry since the 1970s. While the previously dominant mode of psychiatry emphasized personal etiology, social ills, and the importance of case studies, the field currently privileges clinical trials, generalizable diagnoses, and pharmaceutical intervention-all practices that are shared with general medicine and reflect its biological focus. The DSM aims to provide observation-based descriptions of discrete mental disorders to facilitate and standardize individual treatments. The consistent focus on neurobiology and brain imaging in psychiatric research mirrors the clinical stance.

In rhetoric and technical communication, research on psychiatry often focuses on the rhetorical nature of diagnosis and its application. In "Revising Psychiatry's Charter Document DSM-IV," Lucille McCarthy and Joan Gerring suggest that the emergence of new psychiatric diagnoses results from the interaction of medical research in the field and the individual observations (and personalities) of psychiatrists. McCarthy and Gerring demonstrate that diagnoses are produced not simply by "crunching numbers" but by using multiple persuasion strategies. Of particular importance were the "contingent repertoire account," in which earlier versions of the DSM are presented as "flawed" by "various contingent and nonscientific factors like personal and professional biases" (McCarthy and Gerring 164), and the "progress of science account," which asserts that the different editions of the DSM can be trusted for their rigorous method and “impersonality" (McCarthy and Gerring 166). Carol Berkenkotter's research in psychiatry shifts the focus from the production of classifications to their use in medical practice. In the discursive record, a client's narrated experience is "recontextualiz[ed]" into the language of dominant psychiatry by the practictioner, a process that leads to a 
formal diagnosis (Berkenkotter and Ravotas 271). In a later study, Berkenkotter reiterates these claims with respect to the genre of the case history: in case histories "the patient's 'story'...is subsumed into the narrative pattern and thought-style of clinical psychiatry" (2). Though case histories are no longer considered to have independent scientific validity, they can serve to maintain the validity of DSM categories or more abstract quantitative data (Berkenkotter 143). Taking up another example of applied medical discourse, Susan L. Popham and Sage Lambert Graham analyze the use of electronic charts in a juvenile mental health facility. As with Berkenkotter and Ravotas's "recontextualization," Popham and Graham found that "the structure of the chart both reflects and determines the structure of thought about patients and may ultimately influence decisions about their care" (170).

Some recent studies in technical communication move out of the professional context to find out how patients receive and interpret medical knowledge. Hannah Bellwoar argues that the "active reception of health-related texts" she describes should reframe the cultural practices of people seeking information about health, who can be "considered as tactical and perceptive rather than passive or noncompliant" (325). This conceptual reframing allows researchers to "approach literate activity from the perspective of users' intentions and motives for technology use in their own worlds" rather than privileging the perspective of organizations or institutions; further, Bellwoar argues that many users of medical documents demonstrate "not only...the way they inhabit the made world of medicine but also how they remake this world for their own purposes" (343). A step further from medical documents, Cathryn Molloy studied the discursive moves of people diagnosed with mental illnesses in one clubhouse institution. 
These speakers combated the stigma of their diagnoses with "recuperative ethos" by demonstrating characteristics assumed to be lacking, such as social awareness, intelligence, and strong relationships. With an abundance of examples, Molloy convincingly charts the rhetorical means by which these individuals are able to distance themselves from a diagnostic stereotype.

Historically, however, scholarship that explicitly privileges the patient's point of view has more often come from disability studies, where the person affected by medical discourses is a usually a protagonist rather than a passive subject. Disability studies scholars give much attention to narratives of the experience of disability and assert the value of such narratives as more than a "supplement" to expert knowledge in medicine and science. Moving from the individual to social experience, another core focus within disability studies is the construction of disability and illness - and the people who "have" those conditions - by cultures and institutions that, in Lennard Davis's phrase, "enforce normalcy" of body and mind. As Davis argues, "the very term that permeates our contemporary life — the normal—is a configuration that arises in a particular historical moment" in which particular scientific and cultural discourses made it possible to conceptualize (12). In “A Mad Fight," Bradley Lewis relates the approach of disability studies, and disability rights more generally, to the "Mad Pride" movement, whose activism seeks more equitable and socially-minded mental health treatment. The enforced normalcy of the body also extends to the mind: "the binary between normal and abnormal shores up this psychiatrization by providing tremendous social and psychological pressure to stay on the side of normality, or sanity" (“A Mad Fight” 340). When addressing the negative effects of psychiatry, Lewis emphasizes the importance of 
diagnosis, which he calls an "expressly biomedical [assignment] of impairment" that works through "a direct and specific diagnosis and treatment process" ("A Mad Fight" 341). Building on foundational disability studies texts, other scholars have studied different conceptions of mental health and disorder through the critique of psychiatric discourses and practices, analysis of the representation of mental disabilities in popular culture, offering their voices in the DSM-5 revision process, and, of course, the description and analysis of individual accounts of the experience of mental disability.

In this chapter, I aim to bring together the powerful critique of normativity exemplified in disability studies scholarship with the text- and discourse-based analysis of work in rhetoric and technical communication. Building on Bellwoar's argument that patients may "not only... inhabit the made world of medicine but also...remake this world for their own purposes" (343), this chapter will analyze the uptake of medical and psychiatric texts in online environments and explicate the strategies used by tactical technical communicators to craft representations of their own lives and minds.

\section{Background of Discussion Boards}

In this study, I examine conversations at three online discussion boards around issues of mental health diagnosis and treatment; one of these boards focuses on PTSD, and two focus on ASD and autism-spectrum conditions. While users of the forums are not screened for a documented diagnosis, each one of those writing identify with the condition indicated. Intended to connect people with similar experiences, the boards discourage "mental health expert" respondents such as psychiatrists or counselors, and none of the conversations included in this project had explicit contributions from such professionals. Moderators in these forums typically intervene only to ensure the safety of 
the community and its members, removing antagonistic responses or experience descriptions that could cause serious negative reactions or relapses in other members.

While conversations like the ones studied here certainly occur in offline spaces, the online context is significant for its ability to immediately connect people from distant locations. Like many medical and disability-related groups, people with ASD and PTSD can easily find others with similar conditions or experiences online though few may be present in local communities. Online spaces were pivotal in the development of the neurodiversity movement in the 1990s, where people with autism or Asperger's Syndrome built arguments against the "deficit" model and framed their behaviors as different rather than abnormal. Further, the discussion boards studied here afford deep communal identification and candid life description specifically for the lack of supervision or interjection from mental health experts. Writers feel free to explain their situations and opinions without fear of judgment from people without first-hand experience of their conditions. As such, the discussion boards become fertile spaces for tactical communication—spaces writers can challenge common ideologies of mental health and devise ways to act toward their own goals despite constraining institutional or cultural pressures.

\section{Medical Discourse in Online Communities}

In this section, I demonstrate how writers in particular online spaces use their experiences of interaction with medical texts and practitioners to seek appropriate treatment, critique psychiatric philosophies and practices, build self-understanding, and support others with similar conditions. My analysis of discussion board conversations and interviews has revealed four common tactics that participants use to navigate technical 
and medical documents related to mental health: (a) demonstrating ethos through scientific literacy, (b) "unpacking" a diagnosis, (c) navigating medical care and support services, and (d) changing diagnostic language to benefit the community. While these moves are not all unique to this research context, the rhetorical situation in which these moves take place is distinct from most similar scholarship in crucial ways. First, these mental health discussion boards create non-hierarchical, parallel social roles between participants who each identify or have been diagnosed with the condition under discussion. ${ }^{38}$ This situation of parallel social roles is distinct from the most commonly studied interactions in medical settings, between a doctor/practitioner and patient/client, where people fulfill certain social "duties" accorded to their role or title and power is unequal between parties (Berkenkotter and Ravotas; Barton, "Further Contributions"). These studies also include research into documents used in medical settings to mediate behavior between different parties (Hyde, "Medicine"; Barton, "Interactional Practices"; Keränen, “'Cause Someday”). Secondly, this study focuses on interactions between private individuals rather than between people and (representatives of) organizations or public texts, as when a person interacts with a hospital, insurance company, government agency, or health website (Popham and Graham; Keränen, “"Cause Someday”;

Bellwoar).

In the sections below, three different modes of participant writing will be coded: "OC" for statements in discussion forum conversations from my corpus; "DM" for direct messages, including emails; and "IR" for interview responses.

\footnotetext{
${ }^{38}$ The non-hierarchical social situation is similar to other types of special interest or support groups, such as Emily Martin's accounts of bipolar disorder group meetings in Bipolar Expeditions.
} 


\section{Demonstrating Ethos through Scientific Literacy}

Many conversations on these discussion boards may look, at first glance, to be highly skeptical or even antagonistic toward science and medical research. Participants question the motives of mental health researchers, blame "biological" views of mental illness for stigma, and recall moments of failure in medical systems, as when a prescribed medication causes a severe adverse reaction. Often, open contempt is shown for psychiatry: one interviewee from an autism discussion board, who chose the pseudonym Daniel, wrote that "psychiatry on the whole is an industry of violence" (IR); another participant, H. W., thinks psychiatry "is slowly coming out of the dark ages" (IR). In other cases, writers lament the seemingly limitless flow of reporting, in popular media and scientific discourse, on supposed connections between mental disorders and a variety of bodily and environmental phenomena, such as genes, food, or "toxins." Science, to some degree, seemed to be constantly stacked against them: as people diagnosed with psychiatric conditions, their lives are the source of problems that medical research seeks to "solve" by understanding a cause or developing "cures."

Most often, however, these writers do not take an anti-science stance even as they might critique medical treatments of mental health. In fact, participants displayed, both in discussion board posts and interviews, an effort toward demonstrating ethos in the community through scientific literacy in their interactions with medical documents and issues related to medicine and psychiatry. Knowledge of scientific concepts and processes carries significant cache in conversations and sometimes functions, implicitly, 
as a rare area of consensus - even more frequently than any particular view of the condition that serves to organize the discussion forum in the first place. Even when criticizing a medical or scientific claim or practice, the writers' conversations resolve in the direction of the most appropriate or accurate application of science rather than a rejection of its authority in the topic at hand.

Conversations about psychiatry on the studied discussion boards often referred to the $D S M$ as a source for diagnostic information and medical studies of various kinds to support particular views of how to conceive of a condition. Several of my participants expressed interest in academic and medical research. For many on these discussion boards, their psychiatric diagnosis was the beginning of an intensive and continual process of research into the condition, and medical documents like the $D S M$, because of its ubiquitous use in psychiatric and psychological practice, are among the first consulted. Bethany reads "diagnostic manuals" and "scientific journal articles related to neuroscience" (IR). Erik looks at "medical websites" and "publications for the EU" on mental health; and though he "object[s] to the medical model in the peer reviewed papers" he reads them "because they are the best source on the physical science" (IR). Another writer, Donald, will “occasionally read newly publish[ed] studies about Asperger's or HFA [high-functioning autism]" and has "looked at various sections in both DSM-IV and DSM-V" (IR). Though he is a "patient," Donald writes that "both my diagnosing Psychologist and clinical Psychologist commented on me knowing the DSM better than they do" (IR). A few writers also reported looking to historical medical documents, such as Leo Kanner's seminal descriptions of autism (Bethany, Jacob) and technical descriptions from the 1960s and 1970s of psychiatric interventions for 
homosexuality (Stephen). This background of scientific knowledge, while usually not certified with formal education, appears in the online conversations through brief references, detailed explanations, or citations of sources - all of which tend to hold up to the scrutiny of fellow writers and stimulate further discussion.

One particular conversation, centered around the concept of "self-diagnosis," on an ASD-related forum provides a concrete example of such actions. The definition of autism - including who can assert a definition, how, and where — is a frequent topic on this forum. Often divisions appear between those who want autism to serve as an identity and those who consider it a medical diagnosis or neurological condition, as well as between those who are optimistic about the motives of physicians and psychiatrists and those who are skeptical. As described above, however, these divisions do not correlate with pro- and anti-science stances; instead, scientific knowledge works as a powerful persuasive tool. In one particular case, participant Bethany consistently brings her scientific literacy to bear in clarifying research practices and defending her claim that "self-diagnosis is not ok, it is invalid, and a bad thing" (OC). The word "invalid" is key here, since Bethany situates autism as a purely diagnostic label—something medical professionals use to describe certain individuals: "Autism is defined from the outside by behavior, not by introspection from first-person perspective" (OC). To draw a line between the subjective self-knowledge of autistic people and scientific investigation, she explains how an individual cannot apply medical research to themselves:

However, I don't think that reading research studies is directly applicable to selfdiagnosis, as I said before. Some autistic group's fMRI activation pattern will not help someone self-diagnose, since they don't know their fMRI pattern. Behavioral measurements will not help, as they can't measure their behaviors the way the researchers did. Some behavioral coding result will not help, as their behavior was 
not coded by a professional according to certain guidelines that involve large manuals and months of training. (Bethany, OC)

Bethany references many of the hallmarks of specialized knowledge: complex and expensive technologies (fMRI), technical taxonomies ("coding"), education and certification ("professional," "training"), standards of validity ("guidelines"), and fieldspecific texts ("studies," "manuals"). Later in the conversation, one writer implies that diagnoses of autism, and related research, are based solely upon screening tests and selfreporting in "quizzes," as they are often referred to informally. Bethany responds with a list of tools that scientists use to study autism:

EEG, MEG, fMRI, all kinds of cameras, custom-built gloves for motor measurements, computerized behavioral tasks, standard sets of stimuli, strict procedures, actors/actresses, and all the analysis code/math to process/compute results from numerical measurements. Autism research studies are much more than screening tests. (OC)

Though she doesn't explicitly identify herself as such in the conversation, Bethany is speaking from a place of knowledge as a graduate student in neuroscience herself. Surprisingly, other writers in the conversation do not challenge the relevance of the tools she mentions (e.g., "one cannot know autism by doing brain scans"). Perhaps this is because, in other posts, Bethany has established herself as someone with the interests of the autism community in mind. Toward the end of the conversation when one writer mentions the term broad autism phenotype (BAP), she makes a more direct statement about the politics surrounding autism labels and self-diagnosis, writing that "In my opinion, ASD the medical diagnosis and medical label can't be applied in a selfdiagnosis, it doesn't make sense. BAP can be applied in a self-identification, while ASD can be applied in a medical diagnosis... For identity reasons, I suggest BAP instead of ASD” (OC). 
Participants also voiced concern about the accuracy of information posted to the discussion board and the sources people use to justify their claims about mental health. For writers like Joanna, the effort put into reading about a condition—she has been researching PTSD for over 20 years and "keep[s] up with most international journals of medicine and psychiatry to the best of my ability" (IR) — leads to persistent fact-checking in discussion board conversations. As a moderator and safety staff member, Joanna always "tr[ies] to be as accurate as possible" (IR) and uses the scientific authority of medical research to make her case against what she sees as negative forces in conversations. When speaking about encountering differing views on the discussion board, she writes:

...there is a lot of argument from the off med activists [people opposed to using pharmaceuticals in treating PTSD or other mental health conditions]. I feel it's dangerous to those dependent on medication to function and will post recognized medical studies to support my views often. (IR)

After such a post, the "off med activists" might see Joanna as naively following the drugcentered practices of mainstream psychiatry without question. Yet she describes psychiatry as "biologically driven, still in need of reform" and needing "inclusivity of more comprehensive treatments and alternative treatments in many areas" (IR)—clearly not an attitude of simply trusting the experts. Joanna tactically uses the medical studies to support her position and perform a protective act toward others in the conversation.

\section{Unpacking a Diagnosis}

As mentioned above, many writers on these discussion boards do a great deal of research after receiving a psychiatric diagnosis, and the first information they have is likely medical and descriptive in nature. A diagnosis in the $D S M$, for example, will list a number of traits or behaviors and state that a certain number must be present for 
diagnosis; a practitioner also evaluates the "severity" of the traits as part of an assessment. Reading this kind of detached description can be an emotional experience for people receiving the diagnosis: Donald writes, "the first time I read the [diagnostic] assessment, I was both shocked and saddened. The clinical psychologist described someone I didn't want to be" (IR). Following such moments, the participants in my study sought information and clarity on discussion boards where others with the same diagnosis met online. In these spaces that "were made for and by neurodivergent people (as opposed to parents, therapists)" (Quinn, IR), writers "unpack" diagnostic descriptions and debate how to best describe the condition in the everyday lives of people with the diagnosis, all outside of the intervention of outside medical or institutional authority.

Significantly, the movement from diagnosis to life experience in these forums reverses a pattern identified by Berkenkotter and Ravotas in which the psychiatrist or therapist translates the patient's personal account into their field's specialized terms and categories. As a result, "the client's richly descriptive narrative is lost, the result of the therapist's use of rhetorical and linguistic strategies that lend credence to her diagnosis, the primary practice for which she is billable" (Berkenkotter and Ravotas 271). The types of discussion board conversations described here allow the individual to unpack the technical language of the $D S M$, psychological assessments, and research articles and then place that language within a larger, coherent narrative of their own lives. For many writers, this process of reclamation produces a new sense of control and independence and plays a key role in self-definition after a psychiatric diagnosis.

Since many people first visit these discussion boards after a medical evaluation, writers often work with newcomers to "unpack" a recent diagnosis and see how the 
medical language they encountered might apply (or not) to their lives. For some, medical descriptions are unhelpful or even confusing: Daniel writes that, when researching autism, "I mostly rely on secondary sources, because documents that are directly from scientists tend to use inaccessible language" (IR). Donald describes how, after his initial diagnosis, the discussion board gave him a space to discuss how to interpret a psychiatric diagnosis in relation to his life:

I worried (sometimes obsessively) about the diagnosis being incorrect. Or, maybe the diagnostician didn't user the conduct the proper test (after all, she only spent 6 total hours with me). And during that time, she administered a bunch of tests. How on earth can she made a determination from that? ... And, it went on from there. I used [the forum] as a tool to understand how much of me is related to the diagnosis. (IR)

In this case, the discussion board is functioning as a tool for interpreting an array of texts that describe mental health from a particular-biomedical — point of view. Through this process, Donald is able to use the diagnostic tools not as an unequivocal judgment but as a lens for viewing experiences of mental and behavioral difference.

Participants also reported seeking examples of "real people" with the relevant diagnosis or identification. One participant, Todd, recounted that he sought out one forum "firstly for advice and information about the diagnostic processes for autism; and secondly, for the described experiences from others of being autistic"; he says, "autobiographical books by autistic individuals put lives to the research data," and he gives Steve Silberman's recent book Neurotribes as example (IR). Similarly, Bethany wrote that in visiting the discussion board she "was looking for information about autistic traits, like how other people experience them" (IR). On many discussion boards related to specific mental health conditions, identification through experience creates an environment of mutual vulnerability where candid life descriptions and self-assessments 
are common; writers encourage, advise, and empathize through bridging a psychiatric diagnosis with major life events and everyday details.

The conversations on mental health discussion boards allow participants to situate themselves in relation to a diagnosis outside the scope of its technical (medical) application. The diagnosis manual is written by clinicians and researchers for institutional use, but these writers apply its terms in ways that emphasize individual experience over the impersonal and generalized traits listed in the DSM. As discussion board writer Erik explains, "in general I think people should pay more attention to their story, as a description of what they have been through, rather than a label. It is more complete and nuanced, while a label is only a shorthand used by medical staff' (IR). Erik's comment reveals the limits of medical diagnostic language, especially when describing "abnormalities" of mental health, by placing the DSM in its social context as a tool to efficiently generalize and categorize across large populations.

Moving away from an exclusive focus on diagnostic language, which medical offices seem to use for the sake of standardization, can give the writers in these forums a way to look at a condition they share with others from their own point of view. While the $D S M$ works centripetally, rallying around commonalities, discussion forum conversations often parse out the differences between individuals and their experience of the condition or topic at hand. As a common saying in the autism community goes, "If you've met one autistic, then you've met one autistic." In a conversation on self-diagnosis, Donald emphasizes that readers on the forum should foster "introspection" when thinking about their own embodiment of autism in order to "understand and accept who you are as an individual" (OC): 
It's important to understand that it's OK to be different. That it's OK to be you. You don't need a diagnosis (professional or otherwise) for this. Then, you need to identify the areas where you are "inside your comfort zone" and those where you are "outside your comfort zone". And, then simply gravitate towards those situations where you are inside your zone and avoid those situations where you are outside your zone. (OC)

Such a perspective clearly shifts the agency from the practitioner who diagnoses and treats to the individual who assesses her own needs and perceptions. Berkenkotter and Ravotas, among others, recognize the depersonalizing effect of medical language in diagnosis and in therapist notes; these writers re-personalize their experiences through dialogue and storytelling and invite new forum participants to do the same. Collectively, their conversations are a powerful comment on, if not rejoinder to, to the medical encounters, personal and textual, that preceded their initial visit to the forum.

\section{Navigating Medical Institutions and Support Services}

As evidenced in Erik's comment above that "a label is only a shorthand used by medical staff," many writers in these forums are keenly aware of the institutional practices related to their diagnosis or condition: he sees the diagnostic label as a "shorthand" that allows "medical staff" to do their work, rather than a comprehensive description. The insights into institutional practices - in relation to medicine, insurance, and government — offered by the discussion board's elders is another reason participants visit these particular forums. H. W. writes that she visited a discussion board because she "hoped to find autistic people living close to me who could advise me how to best use the support systems available" (IR). In addition to "discuss[ing] my experiences," Erik wanted to "find practical information from users of my medication" (IR). After leaving the online forum for a time, Joanna returned when her sons were diagnosed with schizophrenia — an event that precipitated relapses in her experiences of PTSD as well. 
Each of these writers sought help in putting institutional resources to use in managing their lives with a particular condition.

Some forum posts regarding support services perform an analogous function to the "re-personalizing" process mentioned above in relation to diagnosis: to describe how each person's experience of medical and social services has been affected by a variety of circumstantial factors. What might otherwise seem like a standardized process is disrupted by the differing, and sometimes competing, roles of individuals involved in the service system. In one forum conversation, Todd (who speaks to mistrust of clinicians above) tells a story illustrating exactly why he mistrusts some clinicians. As the conversation turned to the topic of screening tests for ASDs, he recounts how one clinician seemed to have ignored some diagnostic tools in favor of another: "Her answers to my leading questions about any review of my [screening test] scores made it clear to me that she hadn't read any of them or my detailed list of lifelong characteristics; but relied solely on the Personality Assessment Inventory (PAI) multiphasic test." As a result of this focus on the PAI test, the clinician "concluded from the test results and conversation alone that I was diagnosable as having GAD and OCD" but "declined" from diagnosing Asperger Syndrome or ASD (OC).

The behavior of this clinician, Todd reasons, may have been influenced by her context. To begin, she was part of a "counseling corporation" that seems to have limited services and inflexible policies. Todd remembers the receptionist "reading from a script that described the overall abilities of the corporation" upon arrival, reflecting what might be described generously as a concern for consistency. After checking in, Todd—a man in his $50 \mathrm{~s}$ - was "randomly 'assigned' to the children's autism clinic" rather than a part of 
the office that routinely interacted with adults. The environment was off-putting and infantilizing: Todd writes, "Seriously, the whole office was knee-deep in play-therapy toys when I arrived. I knew immediately that I had made a mistake in agreeing to attend this office" (OC). The clinician herself was "genuinely pleasant and humorous," but Todd felt like she "couldn't see the bigger forest for the trees" and that she might be "restricted" by "corporate guidelines" (OC). His latter suspicion seemed to be confirmed when she said, half-jokingly, "we always just diagnose people with anxiety if they come in for something specific" (OC). Ultimately, Todd's diagnostic session left him feeling frustrated and misunderstood; it would take more time before he felt that he could recognize autism as part of his identity in a way that allowed him to build selfunderstanding and avoid pitfalls in his past. (He later received a diagnosis from a professional at a large university autism research center.) The details of his narrative reveal a situation far removed from the disinterested (disembodied) categories of the $D S M$ description of ASDs. He was affected not only by a single clinician's choices and biases but also the "efficiency" of corporate medical care and its standardizing of practice. Todd even encountered, in this clinical space, the broad cultural association of autism with childhood — an ideology that strikes many autistic adults as shortsighted and insulting. ${ }^{39}$ The retelling of this clinical encounter demonstrates for others on the discussion forum how medical texts are always applied in particular circumstances, and that one may encounter barriers even to this critical first step toward receiving support services of any kind - a diagnosis.

${ }^{39}$ For an insightful description of this trend, see Stevenson, Harp, and Gernsbacher. 
Conversations spawned from similar questions often reveal "insider" knowledge that a psychiatrist, nurse, or therapist cannot provide—especially knowledge of moving between institutions and service organizations. Joanna describes how different specialists disagreed on her diagnosis when she first sought treatment:

At the time my GP [general physician] was dismissive of me having MH [mental health issues] and the Psychiatrist I was seeing didn't acknowledge PTSD as a disorder as was common back then. I started by contacting university professors by email first, and utilizing library resources which at the time were very limited. [It] was easy at the dawn of the internet to do so, contact university professors personally and ask them the criteria for PTSD and how it related to SA [sexual assault] and CSA [child sexual abuse] survivors. (IR)

When medical gatekeepers would not recognize her distress, Joanna sought knowledge and assistance from other authorities. Other participants reported similar frustrations: Stephen was diagnosed with PTSD in medical documents after a "mental breakdown," yet only found this out when diagnosed again twelve years later in a different medical context (IR); Todd was "(mis)diagnosed with depression disorders no less than five times between ages 15 and 20" and denied a diagnosis of ASD years later (IR). After his experiences, Todd expresses "serious doubts" about how "diagnostic criteria, comorbids ${ }^{40}$ and characteristics are...implemented by clinicians in their day-to-day work" (IR). These narratives of (inter-)institutional dissonance and failure serve the discussion board community by letting others know they are not the only ones in such situations and, perhaps, offering motivation for persistence in their work to receive an accurate diagnosis and find appropriate supportive services.

${ }^{40}$ Other diagnoses or conditions beyond one's "main" diagnosis, as when an autistic person also experiences depression. 


\section{Changing Diagnostic Language to Benefit the Community}

Inconsistencies, disruptions, and silences like those experienced by Joanna, Stephen, and Todd highlight the rhetorical nature of medical documents like the DSM: despite its ambition toward order and objectivity, the text must be applied in complex situations to fit a number user purposes. The text may even find itself transformed as it moves from one context the next. The participants in this project are cognizant of the malleability of technical documents as they discuss the evolution of diagnoses in mental health and debate which diagnostic language would best serve the community.

For some participants, the language of a diagnosis could be changed to better reflect the population it is meant to describe. Joanna recalls how the gradual acceptance of PTSD was a personal "vindication": "I met with a lot of opposition in the early years. When the medical community finally accepted non military PTSD as an official diagnosis it was a huge relief" (IR). Many writers in the PTSD forum I studied mentioned a relatively new diagnosis, chronic post-traumatic stress disorder (C-PTSD), that is not yet universally recognized. C-PTSD covers types of trauma that occur consistently over time rather than in a single or small number of events, broadening the range of people who might receive a PTSD diagnosis. For those advocating the adoption of C-PTSD, this addition to a technical document like the $D S M$ would support, not undermine, the credibility of diagnosis because it takes into account the different kinds of trauma people experience. 
Regarding the stance toward diagnosis, the autism community has historically taken a different perspective. ${ }^{41}$ Taking up the model of the disability rights movement (DRM), proponents of "neurodiversity" reject the idea of autism as a disorder that should be cured. The DRM grew significantly in the 1970s with the goals of combating discrimination on the basis of disability, securing equal access for people with disabilities, and fighting the social stigma of disability. For the DRM, one bedrock concept is the social model of disability, which asserts "disability is a situation cause by social conditions" rather than an individual state: "it is society which disables physically impaired people" (UPIAS 3). As such, the social conditions that produce disabilitypolicies, prejudices, environments — should be changed to accept with equity people with differences or impairments. While originally centered around physical disabilities, the DRM later came to include people with various conditions and impairments, and in the 1990s and 2000s, mental/psychiatric/intellectual disabilities were explicitly theorized as a component of disability rights. For many in the autistic community, the neurodiversity model constructs autism and common autistic behaviors as a natural variation in human behavior and cognition, thus providing a strong argument for the acceptance of autistic people of all ages and rejecting interventions that attempt to discipline, "treat," or "cure" autism as a disorder or disease.

One participant, Jacob, advocates for this view, and sees himself in line with other activists "who participate in the Autistic Self-Advocacy Network [ASAN], as well as...the National Autistic Society" (IR). In another conversation, Todd points to the

\footnotetext{
${ }^{41}$ I am not implying that the autism community is homogenous; in fact, writers in the community often point to its broad diversity of personalities, opinions, and idiosyncratic traits. Self-advocacy groups and self-advocates, however, tend to shun the pathologization of autism in medicine and psychiatry.
} 
language $\mathrm{ASAN}^{42}$ suggests as a positive alternative to medicalized conceptions of autism; the organization "often uses the phrases 'self-identify,' 'self-identified' and 'selfidentification' when compared to a professional diagnosis" (OC). ASAN promotes the acceptance of autism by working directly with lawmakers and governments, making public statements about autism and neurodiversity-related issues, employing a legal team to assist in policy writing and legal cases, and, given the recent revision of the DSM, engages medical institutions like the APA to lobby for more inclusive and less harmful diagnostic and treatment guidelines. Unlike many other autism advocacy groups, ASAN is made up of autistics from leaders to volunteers; in comparison, Autism Speaks has only occasionally had a single autistic member in a leadership position. ${ }^{43}$ The conversations I encountered on forums devoted to autism were largely approving of the efforts ASAN has made in policy and culture.

The method and rate of diagnosis is a frequent topic of conversations on discussion boards devoted to autism, and changes to how autism is described are seen as central to making headway against cultural stigmatization. These conversations are full of stories of exclusion and alienation due to that stigma. Daniel writes that, "I had a long period of self-hate and struggling with self-acceptance because of the deficit-based model of autism diagnosis" (IR). Jacob "was told that Autism = stupid, and diseased" (IR). When I used the word "condition" in an interview, Adam politely countered, "Oh... I

\footnotetext{
${ }^{42}$ ASAN "seeks to advance the principles of the disability rights movement with regard to autism... [and] seeks to organize the community of Autistic adults and youth to have our voices heard in the national conversation about us" ("About ASAN" p. 2). By framing their movement as a matter of rights, autistic self-advocates invoke a history of emancipatory political actions to end institutionalized discrimination.

${ }^{43}$ Writer and autistic self-advocate John Elder Robison served within Autism Speaks for a time, but resigned his position in 2013 due to the organization's continued use of "autism epidemic" rhetoric to promote its work.
} 
don't know if I have a 'condition.' I suspect that I may be on the autism spectrum, but I would never say that to anyone I know" (IR). The connotations of "condition" (much like those connected with "disorder," "disability," or "impairment") mark someone as other, as outside the norm, and Adam's response points to the tactics of "passing" used by many autistics to appear more "normal" in social settings—even if they are confident in their autistic identity. Negative conceptions of autism and the social barriers that stigma raises also form a major cause of depression and anxiety in the autistic community, where rates are much higher than the general population.

Many writers on these forums see the critique and reform of medico-psychiatric approaches to autism as a major social issue in the community. The chosen paths of change are quite diverse, however, as are the attitudes toward medical institutions and practices. Daniel contends that professional diagnosis isn't scientific and "has zero relevance" (IR); Klaus disagrees. Donald sought out a diagnosis, after suspecting a range of possible psychiatric conditions, but would not pressure his two daughters to seek an evaluation. When discussing whether young people should "self-diagnose" as autistic, Donald writes about his children:

So, are they autistic? I have no idea. While I have noticed minor autistic traits in everyone, I do not have the first clue about recognizing autism in anyone. But, the moment one of them told me, "I strongly believe I am autistic", I would definitely have them speak to someone to get evaluated. My daughters are of the age, that if they declined my suggestion to be evaluated, I would honor that. But, it would be irresponsible of me not to suggest/encourage it. (IR)

This perspective clearly places some value in diagnosis, but Donald's other posts (such as his advice to use introspection above) do not suggest that the medical view is authoritative or exclusive. Rather, the diagnosis can be a means to an end, whether that end is self-understanding or access to necessary services. In yet another take on the 
matter, while Quinn sees "the pathologization of realms of mental experience both problematic and necessary," she believes people should resist the idea of psychological normality (IR). She argues that even the label "neurotypical," common in neurodiversity circles, actually "reinforces neurotypical privilege by reifying the idea that there is a 'normal' way of thinking/feeling/being" (IR). Thus, the diagnosis of autism-if there is a medical "diagnosis" to be had at all—should observe difference rather than abnormality and cultural practices should encourage acceptance rather than exclusion or change by force.

Whatever their philosophical or semantic preference, the majority of writers in the autism forums argued for greater inclusion and acceptance for autistic people and viewed with utmost significance the language used to construct autism, as disease/epidemic or condition/variation. In their efforts, the writers discussed changes to medical and psychiatric texts like the DSM and patient records, the attitude of psychiatrists and other practitioners, the practices of research scientists, laws and policies in a number of countries, inclusion in public and private education (including higher education), provision of social services - interventions in almost every imaginable area of expertise or professionalization. In each case, the self-advocates voice the need for changes to technical knowledge in the interest of those most affected by its application.

\section{Classified Conversations and Tactical Technical Communication}

The discussion board participants interviewed for this project demonstrate that medical documents can serve important functions beyond those envisioned by the institutions that utilize them in an official capacity. The personal stories of technical (re)interpretation discussed above can complicate our views of genre and authority in 
technical communication, as the tactics employed by discussion board writers elide the institutional boundaries that technical documents often maintain. Reception studies like this one can allow researchers in technical communication to account for unsanctioned cultural practices that use tactics to manipulate, redirect, transform, or resist the institutional strategies for which technical texts were originally designed. Such culturally significant literate actions have the potential to alter our field's understanding of texts-in$u^{4} e^{44}$ while also tracking the ideological effects of technical documents in everyday life. More significantly, acknowledging the successful tactics of users opens opportunities for technical communicators to become allies in the process of reforming institutional practices in the interest of social justice.

The prospect of direct reform is most apparent in the tactic of changing diagnostic language. As the participants described above, the movement to alter psychiatric diagnoses to reflect the diagnosed or self-identifying community's values has been underway for some time, especially with regard to ASDs. The central plank of the autistic self-advocates' reform—disavowing the "deficit" model in favor of neurodiversity—has implications for other mental health conditions that hinge on a clinician's judgment of abnormality. Judy Z. Segal notes that "drugs are advertised to the public...within a rhetoric of permissible pleasures derived from the general virtues of sociability, authenticity, and productivity" ("What" 23); a similar matrix of "virtues" drives some psychiatric diagnoses, where common behaviors are pathologized for their differences of, for example, degree or cause. (As Segal wryly observes, "solitariness is a medical

\footnotetext{
${ }^{44}$ From an activity theory perspective, Russell (1997) and Spinuzzi (2003) refer to many forms and objects, and specifically genres, as "tools-in-use." My phrase here is more limited in scope.
} 
condition" ["What" 19].) Changes to the DSM, which codifies the symptoms of mental disorder, have the potential to push clinical practice as well as cultural ideologies at the macro level toward accepting the voices of people who have received or identify with a psychiatric disability. ${ }^{45}$

In more everyday situations, the documents one encounters in clinics, hospitals, or mental health facilities may also be revised to recognize the contribution of marginalized voices. Technical documents are typically created to serve an organization's purposes, and despite good intentions, may work against users because of constraints like time or funding. Simmons and Zoetewey found that civic websites on environmental concerns were often built according to “the U.S. Environmental Protection Agency's educational mandates" even though the citizens using them had "needs outside that field of vision" (252). The same dynamic is present in medical and mental health contexts, where technical documents are designed seek to meet legal obligations and obtain insurance reimbursement. Further, psychiatric materials for evaluation and documentation reflect institutional purposes and biases. As Bartesaghi found, intake questionnaires, selfreporting inventories, and even therapist conversations have organizational goals that are "inaccessible to clients" and these forms of discourse can "function to replace client accounts with the nosological accounts of institutional psychiatry" (153-154). Even a cursory reading of mental health discussion forums reveals many writers' disregard for the routine clinical accounts of their lives, where their stories and descriptions are appropriated into the language and logic of psychiatry (Berkenkotter and Ravotas; Bartesaghi). Instead of simply housing the practitioner's written observation, these

${ }^{45}$ As J. Johnson and Molloy attest, people with a psychiatric diagnosis are often distrusted, disbelieved, and dismissed as incompetent. 
technical documents could be include a client's own words and reflections as a counterbalance to their inherent institutional, bureaucratic biases. Self-assessment forms could reserve spaces for clients to describe the context of their experiences rather than relying on Likert scales and vague language. Since these imprecise and constraining evaluations are translated into $D S M$ diagnoses and insurance codes, the voice of the client could broaden the scope of information collected and avoid miscommunication between clients, practitioners, and organizations. Such changes to technical documents would afford a place for the disparate, granular accounts of people receiving mental health care in the official record and, perhaps, facilitate the legitimation of their perspectives in local and institutional contexts.

For teachers of technical communication, this study helps emphasize new types of user in the design process: when performing usability studies, for instance, we can take into account not just the primary practitioner or technician but also the groups affected by technology or specialized knowledge. In common assignments like genre studies or analysis of genre systems, for instance, students can be encouraged to incorporate affected groups of stakeholders that lack institutional power; examples might include the perspectives of minors toward education policy, the practices of incarcerated individuals navigating judicial and penitentiary systems, and the work of undocumented, migrant, and refugee groups to meet basic needs in the absence of governmental recognition (or in the face of government oppression). Expanding the scope of technical communication to include these extra-institutional tactics will produce a more accurate and complex portrait of cultural-textual activity and the circulation of specialized knowledge. 


\section{CHAPTER V}

\section{RE-FORMING MENTAL HEALTH:}

\section{RHETORICAL INNOVATION AND THE LANGUAGE OF ADVOCACY}

\section{Introduction}

Like other forms of advocacy, mental health advocacy experiences highs and lows; successes are often incomplete and uneven. Recent media coverage of autism and PTSD reflect such partial successes for self-advocates and their allies, but the undercurrent of popular discourse about the conditions remains largely unchanged. Even though there are myriad differences between autism and PTSD, as well as their cultural connotations and the strategies of their advocacy communities, two of the most recalcitrant associations with mental disability attach to both: first, the powerful stigma felt by people with all kinds of mental disabilities; and second, the high visibility of asyet-unconfirmed biomedical interventions despite underfunding of more routine support (which has been established as effective from decades of mental health research). To illustrate the dynamics of this situation, I'll offer a few representative vignettes of popular media coverage related to autism and PTSD and explain their connection to the rhetoric(s) of mental disability explored in this dissertation.

\section{Autism Coverage}

In many ways, representation of autism in popular media is at a high: in movies, TV shows, documentaries, as well as journalistic outlets, people with autism have become more visible and, increasingly, more faithfully represented. The neurodiversity 
movement has sparked a number of documentaries about adults with autism (Autism in Love, Life Animated, Asperger's Are Us), Steve Silberman's book Neuro Tribes became a best-seller, and an autistic character on the Sherlock Holmes spin-off show Elementary described herself as "neuroatypical." Changes are occurring in media created for children as well, including the introduction of an autistic character on the long-running children's program Sesame Street (Martinelli). Sesame Street created the character in consultation with Julia Bascom, who is executive director of the Autistic Self-Advocacy Network. Bascom and others involved "wanted to focus on making sure that Julia [the autistic Muppet character] had as much agency as possible," and they sought to counter common portrayals of autistic children: “we didn't want to show her as an educational object or an object of pity or a burden on the people around her" (Martinelli).

Awareness of ineffective and dangerous "treatments" for autism have come under greater scrutiny, thankfully, as the anti-vaccine movement has lost some mainstream credibility (despite the claims of our current President). Recently, the FDA posted a warning about fake treatments for autism that are ineffective and dangerous but, sadly, still legal (Preidt). One of these treatments—billed as "toxin removal"—involves dangerous blood treatments meant to remove heavy metals from the person's bloodstream and thus, according to its practitioners, reduce the symptoms of autism caused by those materials. As discussed in Chapter 3, this treatment and others like it rely on the assumption that autism is caused by an excess of toxins or heavy metals in the body; no coincidentally, this is also the logic behind the spurious connection between vaccines containing thimerosal and autism. For many autistic self-advocates, the FDA's announcement is welcome but fails to address the problems with other conventional 
treatments like Applied Behavioral Analysis (ABA) therapy, a major source of reported incidents of trauma and abuse from adults with autism. The same article quoting the FDA warning reports that "antipsychotics such as risperidone (Risperdal) and aripiprazole (Abilify) are prescribed to children to treat irritability associated with autism," without discussing potential side effects or the perspective of children with autism who have been forced to take the drugs (Preidt). Ultimately, autism is still pathologized with ABA's broad acceptance, including the federal government's blessing (see the Autism CARES Act, signed by President Obama in 2014). Significantly, and reflecting the cultural tensions discussed in this dissertation, the idea that autism is a disorder that requires medical treatment is untouched.

As with many other illnesses and disabilities, discussion of autism is often focused on biological factors, even if not the vaccine-blaming heavy metals theory of autism. Both explanations of the condition and means for treatment or support become focused on medico-scientific technology, from brain scans and genetic research to dietary changes and prescription drugs. One highly circulated CNN article from April 2017, "Stem Cells Offer Hope for Autism," reported on a Duke University-sponsored study where autism became the new target of a familiar biotechnology (Drash and Gupta). The authors report on an open-label safety study (not double-blind) in which children with autism had "impressive" improvements in behavior after receiving stem cell treatments. While the autistic child featured in the article says she "doesn't even remember" her past behavior, the authors put much focus on the parents' experience: "when a tantrum intruded on family outings, her mom and dad wished they had T-shirts that said 'My kid has autism' to ward off judgmental stares" (Drash and Gupta). The authors also portray 
the child's autism as a quantifiable drag on the family's routine, asserting that "[Gracie's] parents say the disorder consumed about $75 \%$ of their daily routine. After her participation in the study, that figure has been reduced to a mere 10\%" (Drash and Gupta). With statements like these, the CNN article speaks to a number of intractable ideas related to autism (and other mental disabilities): that people with mental disabilities are violent and unpredictable, that the absence of symptoms heals family life, that the appropriate (and miraculously effective) treatment is biomedical and applied to the individual.

\section{PTSD Coverage}

The environment for PTSD representation in the media is similar. Fictional characters with PTSD are being portrayed more often, and with a more sympathetic eye. The majority of characters in film and television identified as having PTSD are presented as violent, raging criminals (who are typically veterans), even if the audience "understands" their actions; some recent portrayals offer a more realistic picture of life with PTSD, illustrating the effects of symptoms on daily life and relationships. In one illustrative article, Ava Jarvis, a writer who has PTSD, discusses the accurate portrayal of Josh Lyman's PTSD symptoms after a shooting in the television show The West Wing. Jarvis praises the show's writers for giving great attention to how subtle triggers can be for people with PTSD; she also appreciates that Lyman is not "healed instantly" after an enlightening therapy session, staying away from "cure" stereotypes related to mental illness.

In the U.S., reporting on treatments for PTSD tends to go in one of two directions: either lamenting the paucity of support for returning veterans with PTSD through the 
Veterans Administration or heralding new techniques for "fixing" the brains of people with PTSD through medical or biotechnological means. In 2014 and 2015, for example, news outlets reported on military research to develop "brain chips" that would alleviate or erase symptoms of PTSD. Descriptions of the "cybernetic implant" say that it will "record, predict and possibly treat" psychiatric symptoms and compare the technology to a cardiac defibrillator (Tucker). Another wave of stories emerged in early 2017 reporting on a study on the effects of an antibiotic on levels of anxiety. One article, "Scientists Find Common Antibiotic Could Prevent or Treat PTSD," said that people taking this antibiotic had "60 percent lower fear response" because the drug "blocks certain proteins outside nerve cells...which our brains need to form memories" (Kelland). In these constructions of PTSD, as in the examples about autism above, potential treatments available in the popular imagination are biomedical and function at a biological level in an individual. The articles on treatments for mental disabilities, while trumpeting biotechnology and pharmaceuticals, rarely mention decidedly low-tech interventions that have a long track record of success (and which are often favored by communities of people with those disabilities) such as funding for regular therapy, community integration programs, and assistance for living independently.

It is in the midst of these public conversations about their conditions that autistics and people with PTSD come to the discussion boards studied in this dissertation. Popular conceptions of their conditions color the discussion board dialogues, even when the writers are discussing everyday topics. This dissertation seeks to provide a picture of these conversations and place them in a rhetorical context. 
Below, an overview of this dissertation outlines its central contributions for the fields of Rhetoric and Disability Studies. Afterward, I discuss the implications of this research for Rhetoric, the Rhetoric of Health and Medicine, and Disability Studies, alongside recommendations for changes in these fields as well as in disability activism.

\section{Dissertation Overview}

At the beginning of this dissertation, I asked two related questions about the use of medical language in online mental health forums: first, how the influence of biomedical psychiatry affected how people discuss their own experiences; and secondly, what strategies of language use emerge in online communities for interacting with biomedical ideology. Taking scholarship in Disability Studies as a starting point, I suggested that writers with mental disabilities in online forums would make unique and hereto unrecognized contributions to the formation of medical rhetoric outside of medical institutions. My descriptions and claims throughout the preceding chapters attempt to illustrate the diversity of rhetorical strategies present in online mental health forums while also highlighting key unifying moves that act as resistance to the dominant biomedical vision of psychiatry and mental health—often in surprising ways.

The data from corpus analysis, close readings, and interviews each confirmed the existence of tailored rhetorical strategies in the forums I studied, strategies which differ from the popular discourse surrounding Autism Spectrum Disorder (ASD) and PostTraumatic Stress Disorder (PTSD). The corpus analysis in Chapter 2 showed that popular discourse typically frames ASD and PTSD as medical concerns, and the people associated with the diagnoses are either patients or medical professionals. Further, the patterns in popular discourse reflected cultural stereotypes around these conditions- 
PTSD was strongly associated with the military and ASD with children. In contrast, the forum conversations in my corpus had a much lower proportion of medical terms related to the diagnostic labels, and writers more frequently used personal pronouns (predominantly first-person) to refer to people with the diagnoses.

Building on the distant reading of the corpus analysis, I explored forum conversations and participant interviews to investigate how writers in the forums I studied interact with scientific and biological views of mental health and disability. I found that these writers employed a "chiasmic rhetoric" that combined and reconfigured biomedical and disability rights discourses. In particular, forum writers sought to acknowledge and make use of scientific knowledge of the brain as a biological entity while framing analysis in terms of their personal experience of mental disability. Critiques of psychiatry in the forums did not coincide with rejections of science, or medical research, more generally; instead, writers offered nuanced challenges to psychiatric practice informed by their personal experiences.

The writers' interactions with medical and psychiatric documents related to psychiatry reflected similar strategies; technical descriptions were framed in terms of personal experience rather than of clinical observation. In Chapter 4, I described how forum writers "unpack" the diagnosis process in terms of their own diagnosis, inverting a reductive rhetorical process identified by Berkenkotter and Ravotas in therapeutic practice. Forum writers also call for changes to psychiatric and medical descriptions of their conditions, citing specific changes to terminology and treatment to benefit the community of people diagnosed. 


\section{Ethical Concerns}

As I explained in Chapter 1, I have tried to ensure that my research methods will produce wide-ranging, detailed linguistic and textual data while also respecting the privacy, vulnerability, and dignity of my participants. My ethical stance in relation to participants is especially important as I work with people with mental disabilities, who have been exploited as research subjects and disregarded as authorities on their own experience. Taking into account pitfalls identified in similar online research (Galegher et al.; Gajjala), I have avoided privileging the research target (natural talk) over individual consent in this study. My design also set up an intractable dilemma for me as a researcher seeking to validate my claims for an academic audience: how can I respect the privacy of the innumerable writers who did not formally participate in the study, but whose writing formed an essential background for my analysis?

The writing of research non-participants appears throughout this dissertation as part of the vast corpus of online conversations I gathered and analyzed with linguistics software, most frequently in Chapters 2 and 3. The patterns I identified in those chapters were, in part, derived from my analysis of the corpus as a whole; individual pieces of that corpus, however relevant for my purposes, may be from my research participants or, much more likely, from other writers on the forums who did not give individual consent. Those non-participant writers are integral parts of the conversations I use to draw my conclusions, yet the most direct evidence I can provide - quotations of their writing - are not permissible under the research design I have chosen. That is, their writing is accessible to $m e$ in the corpus but not ethically available for quotation in my writing, since the individual writer has not given consent. Further complicating the issue, each of 
my participants was part of a complex conversation with non-participant writers; I could ethically summarize writers' arguments but not include quotations of each "turn" in the conversation.

As I began to draft the dissertation chapters, committee members expressed their concern about the lack of quotations in my analysis. As academic researchers, they rightly expect detailed analysis and evidence to support my claims and conclusions. I felt that I was in an ethical bind: I could either limit my own study to protect non-participants or I could meet the academy's norms of evidence and explanation. If I identified rhetorical strategies, I needed quotations from the conversation to substantiate the observation; yet those strategies were not often exemplified by the writing of my small group of participants. Given the publicly accessible nature of the conversations I studied - none were in private groups or behind paywalls, and all were discoverable to Internet search engines - I found myself tempted to "just quote" the writing, as so many other academics working in the social sciences, humanities, and even rhetoric and composition have done.

My ethical stance in relation to these writers, though, prevented that kind of open quotation (and co-option) of their arguments. While their writing is technically "public," in that it is accessible to anyone with an Internet browser, it is created within a vulnerable space and only read, by appearances, by a very small group of like-minded people.

Writers visiting the forums I studied wrote about personal crisis, troubling events in their past, diagnoses and experiences that they have not revealed even to friends and family. To publicize those words through publication may be acceptable to common academic or IRB-related standards, but it is certainly not ethical when considering the potential effects 
on writers when they engage in personal, vulnerable, and controversial conversations online.

\section{Implications and Recommendations}

Given the variety of frameworks, methods, and means of analysis employed in this dissertation, I am clearly concerned both with dialogue between disciplines in the academy and with connections between the academy and political (health) activism. The fields from which I draw most heavily, the rhetoric of health and medicine (RHM) and disability studies (DS), already cultivate such connections in many ways; however, I suggest here that greater dialogue between the two will result in greater interdisciplinary and activist engagement for both. In this section, I expand on this premise with reference to both RHM and DS and, afterward, make some observations about and suggestions for effective activism in the communities I have studied for this dissertation.

\section{Rhetorical Theory and the Rhetoric of Health and Medicine}

Over the past thirty years, RHM has modeled a range of ways to pursue interdisciplinary research in rhetoric: through intentionally connecting theories and methods from separate disciplines in their writing (cf. Segal, "Interdisciplinarity"); representing rhetorical perspectives in publications centered in other disciplines (Barton, "Construction," "Disability Narratives," contributions to Idalski Carcone et al. and Eggly et al; Derkatch and Segal; Keränen and Scott; Segal, "Strategies," "Rhetoric," and contribution to Young et al.); and directly collaborating with researchers in other disciplines (Berkenkotter and Ravotas; Graham et al.; McCarthy and Gerring) and people in non-academic contexts (Koerber; Potts). ${ }^{46}$

\footnotetext{
${ }^{46}$ See Segal et al. for a cautionary commentary on "missionary" research in Rhetoric.
} 
To sustain this vital trend, scholars in RHM should continue producing interdisciplinary work while cutting paths to fields and social groups less often studied in our research. The practices of connection and collaboration have been important to the growth of RHM yet in the past have skewed toward the social sciences and, to a lesser extent, medicine and health sciences. Ellen Barton, Lucille McCarthy, and Carol Berkenkotter (and many others) have worked with medical professionals to analyze rhetoric and discourse in health-related contexts. RHM collaborations with advocacy groups have been present but less common (Potts; Scott). In the humanities, RHM scholars can collaborate with those working in DS as well as other fields related to minority identities, like Critical Race Studies, Women's and Gender Studies, Queer Studies, and Trans/Multilingual Studies. Conversations in these fields pose essential questions of the function of power in medicine, such as health disparities between populations, institutional discrimination in government and the healthcare and insurance industries, neglected areas of medical research, and institutional, cultural, and social barriers to healthcare access. Further, as I suggest in Chapter 4, RHM scholars can work with marginalized groups to investigate their knowledge-making and writing practices related to health and partner with them to improve medical care and access. In relation to mental disability, RHM scholars can partner with local and national advocacy groups to deepen awareness of arguments that grow from self-advocacy rather than medical intervention; for example, highlighting the experiences and interests of autistic adults. RHM scholarship may also identify the persistence of negative stereotypes of people with mental disabilities and the rhetorical processes by which they affect both popular discourse and medical practice. RHM research with marginalized groups should work to 
amplify the perspectives and concerns of people who have historically been excluded public and academic forums.

RHM can also gain much from common practices that have shaped DS over the past three decades, such as its persistent interrogation of normativity (epitomized by Davis; Garland-Thomson; and, in the field of rhetoric, Brueggemann; Dolmage; Price) and co-authorship with, or publication of writing from, people from the disability or illness community under study (Benham and Kizer; Broderick and Ne'eman; Price and Kerschbaum; and countless others). The topics of RHM — which, by definition, involve ideas of health and wellness - necessarily intertwine with with cultural norms about what bodies count as healthy, well, and whole; and further, ideals of health, wellness, and wholeness that are considered unambiguous goods to be pursued (and, as a result, disability and illness as evils to be avoided or erased). Consistent attention to normativity in RHM research will allow scholars to address issues of social power in medical contexts.

As noted above, DS provides a model for working with disability and illness communities that does not simply position them as research subjects or informants. Instead, people in those communities can inhabit roles as research partners, co-authors, and authors themselves; in these roles, people in disability and illness communities can not only inform RHM about their perceptions and practices but also influence the direction of scholarship in its theoretical stances, content, and political implications. The kinds of connections I am imagining here are nicely illustrated by the 2010 special issue of Disability Studies Quarterly, "Autism and the Concept of Neurodiversity." The academic authors come from a variety of fields, including Rhetoric, Education, 
Psychology, Literary Studies, Occupational Therapy, Information Sciences, and Medicine; there are also autistic authors in peer-reviewed articles as well as cultural commentaries, interviews, creative pieces, and "roundtables." The diversity of theoretical perspectives and life experiences produces an intricate picture of autism in society with an overall theme of increasing acceptance and inclusion for people with autism and other disabilities. Margaret Price demonstrates a similar approach in the final chapter of her book Mad at School. "In/ter/dependent Scholarship" presents Price's analysis alongside interviews with Leah (Phinnia) Meredith, Cal Montgomery, and Tynan Power, scholars who share Price's experience of working within and outside academia with a mental disability. The orientation toward disability communities in the $D S Q$ special issue and Price's book can be taken up fruitfully in RHM, building upon existing interdisciplinary connections and amplifying the voices of people in the disability and illness communities we study.

The concern for individual thought and experience should not just include people with disabilities or illnesses, but anyone who is interacting with notions of wellness, health, and medicine. Future work in RHM should include further detailed studies of the practices of individual writers and their stances toward medical knowledge and health ideologies. Understandably, RHM scholarship often focuses on public conversations surrounding medical practice and treatment, from the study of health discourse to the actions of governments and organizations (Ding; Graham and Herndl; D. Johnson; D. Johnson Thornton, Brain Culture, "Transformations"; Kolodziejki; Segal 2007; Sidler and Jones; Spoel). Studies in Medical Anthropology and Sociology can offer models for small-scale empirical research of this kind that can be adapted for studying rhetorical 
practices. For instance, Roy Richard Grinker and Kyungjin Cho observed and interviewed parents and teachers in South Korea to investigate the idea of "border children," a cultural category used to describe children with "impairments in social communication" that avoids the social stigma of an Autism Spectrum Disorder diagnosis. Grinker and Cho reveal how individuals interpret specific parts of their, and their children's, lives in a culture that highly values social and academic success-including (re)interpreting and reframing medico-psychiatric knowledge to account for specific differences that might mitigate stigma. In such a situation, RHM scholarship could study the interactions between parents, teachers, and school officials in their negotiation of a child's "status" and educational needs. What particular appeals are most common in each group, and what purpose do they seem to serve for the speaker/writer? How is scientific, medical, and psychiatric expertise framed in these conversations? How do the speakers/writers argue for their own credibility from education and/or experience? Hannah Bellwoar's study of one woman's health writing practices, discussed in Chapter 4, is one example of such studies already present in RHM. Cathryn Molloy's research, published in $R S Q$, also follows a similar trajectory: she studied the discursive moves of people diagnosed with mental illnesses in one clubhouse institution and found that these speakers combated the stigma of their diagnoses with "recuperative ethos" by demonstrating characteristics assumed to be lacking, such as social awareness, intelligence, and strong relationships. Both Bellwoar and Molloy show a concern not just for the cultural meanings attached to health and medicine but also the practices of individuals weaving those meanings into the narratives of their lives. 
Finally, RHM can deepen its investigations of the interaction and co-existence of medico-scientific knowledge and popular understandings, especially in relation to disability and health activism. Rather than opposing expert knowledges with popular ideas of health, treating them as distinct and relatively circumscribed, scholars in RHM should analyze the ways that expertise is taken up in public, activist, and everyday settings, as well as how public attitudes and everyday practices influence the study and practice of medicine.

\section{Disability Studies}

My first recommendation for DS echoes the previous one for RHM, but takes a different form because of the field's history. DS scholarship grew out of the disability rights movement, and its arguments have often been critical, activist, and even liberatory. By focusing on the perspective and experience of people with disabilities-typically including the researcher herself-DS challenged medical and academic discourses that sought to exclude them.

Along with continuing this important work, DS scholars can investigate how people with disabilities take up expert discourses, whether they are accepting, supplementing, adapting, altering, or challenging those discourses. The participants in this research project have shown that expert knowledge is not always seen as separate from one's experience of mental disability, and that it sometimes serves to support the individual's sense of self-knowledge. Further, some participants make use of expert knowledge while also acknowledging the ableism present in research practices and academic writing — for example, highlighting the genetic basis of autism to support the idea of neurodiversity while also pointing out the pathologizing language of genetic 
autism studies and the ableist sources of funding for that research (through corporate medical research and the oft-vilified advocacy organization Autism Speaks).

On a related point, DS scholarship can also study the writing and arguments of people with disabilities (PWD) that do not share a disability rights mindset. While it may seem antithetical to the activist stance of DS, researching PWD who are ambivalent or even opposed to the positions of disability rights groups can reveal how ableism manifests itself in different groups and contexts. Many have noted the "hierarchy of disabilities" that marks some as more desirable than others (Dolmage; Grue, Johannessen, and Rasmussen; Mitchell and Snyder; Sieber), and research of the full diversity of perspectives of PWD will help illuminate the mechanisms that produce the hierarchy—essential knowledge when working to dismantle it. Furthermore, such research can provide support to PWD whose pursuit of treatment may be viewed negatively by disability activists. The much-studied distinction between "little d" deaf and "big D" Deaf communities has something of a correlate in mental disability communities, where some may claim "Mad Pride" and forgo biomedical treatments, such as psychopharmaceuticals, while others value psychiatric drugs and their ability to help them cope in the workplace and everyday life. Adapting Alistair Wardrope's argument about critiques of medicalization, I suggest that opposition to the medical model can overlook how sometimes medical knowledge "may not obscure, but rather illuminate, individuals' experiences" and strident opposition to biomedical treatments can "neglect the testimony" of people who find value in them (341).

Last, I suggest that DS build stronger connections with scholars in Rhetoric and Composition and integrate rhetorical theory into analyses of disability and ableism. 
Dialogue and collaboration between DS and Rhetoric and Composition has a long history, exemplified by the pioneering work of Brenda Brueggemann in the 1990s and 2000s. In 1995, Brueggemann published an article in Rhetoric Review on Deaf culture and American Sign Language, followed in 1997 with a resonant personal account of "(almost) passing” and then "“coming out' as a deaf person" and its relation to her teaching of writing in College English. Brueggemann's 1999 book Lend Me Your Ear treated these and other related topics in much greater depth. In one chapter on "the audiologist's authority," she roots the field of audiology in the designation of all hearing loss as pathology and rhetorically analyzes the interpretation of Audiology Reports. In relation to mental disability, the writing of Margaret Price and Melanie Yergeau demonstrate how disability and rhetoric frameworks can be usefully applied.

As I hope to have demonstrated in this dissertation, DS scholars can also find valuable insights and research models in RHM that can be taken up in their field. As RHM builds up more nuanced accounts of the circulation of health discourses and their use in public and private arguments, DS can engage those accounts to extend studies of ableism in society. Rhetorical research can trace the trajectory of particular arguments and their circulation in different contexts; in relation to medicine and disability, RHM has the potential to investigate the means by which ableist arguments circulate and gain credibility in both expert and popular discourse. Further, this same kind of analysis can be applied to disability advocacy and its interactions with other movements and organizations. For example, the high-profile organization Autism Speaks has been central to popular understandings of autism while also serving as a representative for the harmful mainstream misconceptions against which self-advocacy groups build their own 
identities. DS scholars can use rhetorical tools to investigate how particular ideas or arguments related to autism— such as the concept of the "autism epidemic"—-become distributed between audiences and taken up as medical ideology by rhetors from diverse social positions, from doctors and medical researchers to non-profit groups and politicians. Research of this kind is present in DS, yet perhaps because of RHM's short history, RHM scholarship is less frequently utilized than more general rhetorical concepts. I suggest that RHM and DS can work in concert to inform each other's theoretical frameworks and research methods, with reciprocal benefit.

Activism

My recommendations for activism, outlined below, should be taken as extensions of current lines of argument rather than critiques of them. The applicability of the recommendations is contingent on the agreement of (at least some) people in the advocacy communities they invoke and their usefulness to mental disability activism more generally.

First, I suggest that advocacy groups begin to move their model past a "condition" model to something like a overarching "mental disability" model, whatever language they choose to employ for their purposes. Many modern medical advocacy groups engage in what Nikolas Rose and Carlos Novas term "active biological citizenship," a concept which draws upon Paul Rabinow's earlier formulation of biosociality: "a new active consumer-like turn in the strategies of even quite old support groups for those with particular illnesses or disabilities...in which sufferers and carers campaigned for research funding, donated money, tissues and time, and sought to direct research towards cures" (Rose 69). In autism advocacy, the invocation of diagnostic language is one of the key 
ways that "hope is materialized through a range of social practices" (Novas 290) where the connotations of medical disorder drive the perceived need for funds and research. Autism self-advocacy groups have worked to reframe the aim of that hope toward a life of inclusion and acceptance instead of a cure for non-normative behaviors. Their public appeals are most often centered on autism itself, rather than cultural norms that mark autism as pathological, with specific descriptions of the experiences of autistic children and adults and criticism of popular misconceptions of autism. In the future, though, autism self-advocacy groups can highlight the disability rights focus of their work and relate the activism between different diagnoses and conditions. While the writers on ASD and PTSD forums I studied might not see themselves as being "in the same boat," but an umbrella advocacy approach toward mental disability would see their concerns with discrimination, lack of agency, and stigma as intertwined in critical ways. For example, both communities would benefit from reducing the common perception that people with mental disabilities are unpredictable, irrational, and less capable of change; they would also both benefit from greater voice in the process of describing conditions in healthcare, education, and the workforce. If advocacy groups can formulate a coherent model of difference that encompasses multiple mental disabilities, they will be able to push for reforms that affect social systems for the good of all rather than one specific condition.

The move toward an inclusive mental disability model of advocacy mirrors the calls in DS and disability activism to incorporate mental disability with the more commonly cited physical disabilities. Though the disability rights movement grew out of concerns for access and inclusion for people with physical and mobility disabilities, many have argued that current disability advocacy organizations should include 
mental/psychiatric disabilities as well. This call for inclusion has been answered by disability rights organizations, academic publications like Disability Studies Quarterly, and popular disability media like the Disability Visibility Project.

Secondly, I suggest that mental disability advocacy groups work to broaden the meaning and applicability of the concept of neurodiversity to include all people with mental, intellectual, and psychiatric disabilities. Again, from a historical perspective, the neurodiversity movement grew directly out of autism advocacy groups and the term neurodiversity is most commonly used by those groups now. However, as some in DS have argued, the philosophy behind the concept of neurodiversity can be applied to many kinds of conditions; neurodiversity does not seem to imply simply two types, "typical" and "autistic," but rather a wide range that encompasses different behaviors, disability identities, and impairments. While the word is never applied in the PTSD forums that I studied, I would argue that the neurodiversity model can include the participants I interviewed from those forums. Expanding our vision of neurodiversity would mean that the diversity of human minds — like the diversity of disability more generally — would include differences that are:

- categorized in various ways by both medical and disability communities;

- recognized across the life spectrum, from childhood (as is common in people with autism) to adulthood and old age (e.g., schizophrenia and dementia);

- considered unstable in their appearance or permanence;

- borne out of various etiologies (e.g., genetic, environmental, or as a result of trauma)

By expanding the scope of meanings attached to neurodiversity, advocacy groups can achieve multiple goals. First, the broad vision of neurodiversity provides a platform for interaction between groups that are currently working independently (and, as noted 
above, typically in relation to a single condition). Second, the broad vision of neurodiversity works against the biomedical tendency to categorize, rank, and value different conditions and thus give them differential treatment in clinical and institutional/educational contexts. The separation and categorization of conditions too often results in uneven distribution of resources (e.g., the gap of research and treatment funding between breast cancer and other types of cancer) and pits conditions against one another to vie for resources. Third, the broad vision of neurodiversity provides common ground for cultural change in the conception of mental disability. By arguing for the acceptance of mental diversity, rather than the acceptance of a particular condition, advocacy groups might be less reliant upon existing (and harmful) models of disability to make their claims. For example, in different ways, advocacy for autism and schizophrenia have taken up normative biomedical conceptions of mental disability to argue for support. Some in autism advocacy claim that autistics "really are normal" and pitch their ability to hold jobs (and savant stereotypes) as a justification for support-a framework that relies upon normative standards of productivity and cognition that would exclude other mental disabilities. Schizophrenia advocacy, on the contrary, sometimes embraces the biomedical framing of mental illness to argue that schizophrenia is a "real" condition and that it should be treated institutionally like other physical illnesses; the illness framework, as explored elsewhere in this dissertation, is not accepted by many with other kinds of mental disabilities. The broad vision of neurodiversity would encompass both autism and schizophrenia under a disability rights framework, acknowledging their differences but arguing that both should be accepted and supported. 
Whether or not this vision of neurodiversity is taken up by advocacy groups, the tensions highlighted in this dissertation—-between scientific knowledge, medical practice, psychiatric diagnosis, institutional support, mental disability advocates, personal experiences, and the rights of individuals - will remain for scholars in Rhetoric to continue studying. By portraying the unique combinations of information, ideology, and experience present in online mental health discussion boards, this dissertation can serve as a model for other scholars to investigate how diverse rhetorics, even ostensibly competing ones, may be transformed by the creativity of writers parsing out issues of health and medicine. 


\section{REFERENCES}

American Psychiatric Association. Diagnostic and Statistical Manual of Mental Disorders: DSM-5. 5th ed., American Psychiatric Association, 2013.

Aull, Laura L., and Zak Lancaster. "Linguistic Markers of Stance in Early and Advanced Academic Writing: A Corpus-Based Comparison." Written Communication, vol. 31, no. 2, 2014.

@AutismSpeaks. "How has Autism Speaks touched your life? Tell us your story at AS10Years@gmail.com \#AutismSpeaks10.” Twitter, 17 Feb. 2015, 1:09 PM, https://twitter.com/autismspeaks/status/567792978975289344.

Baker, Paul, et al. "A Useful Methodological Synergy? Combining Critical Discourse Analysis and Corpus Linguistics to Examine Discourses of Refugees and Asylum Seekers in the UK Press." Discourse \& Society, vol. 19, no. 3, 2008, pp. 273-306.

Banks, David. The Development of Scientific Writing: Linguistic Features and Historical Context. Equinox, 2009.

Bartesaghi, Mariaelena. "Conversation and Psychotherapy: How Questioning Reveals Institutional Answers." Discourse Studies, vol. 11, no. 2, 2009, pp. 153-177.

Barton, Ellen. "The Construction of Legal Consciousness in Discourse: Rule and Relational Orientations Toward the Law in a Disability Support Group.” Journal of Pragmatics, vol. 36, no. 4, 2004, pp. 603-632. 
---. "Design in Observational Research on the Discourse of Medicine: Toward Disciplined Interdisciplinarity." Journal of Business and Technical Communication, vol. 15, no. 3, 2001, pp. 309-332.

---. "Disability Narratives of the Law: Narratives and Counter-Narratives." Narrative, vol. 15 , no. 1,2007 , pp. $95-112$.

---. "Further Contributions from the Ethical Turn in Composition/Rhetoric: Analyzing Ethics in Interaction." College Composition and Communication, vol. 59, no. 4, 2008, pp. 596-632.

---. "The Interactional Practices of Referrals and Accounts in Medical Discourse: Expertise and Compliance." Discourse Studies, vol. 2, no. 3., 2000, pp. 259-281.

---. "Linguistic Discourse Analysis: How the Language in Texts Works." What Writing Does and How It Does It: An Introduction to Analyzing Texts and Textual Practices, edited by Charles Bazerman and Paul Prior, Lawrence Erlbaum Associates, 2004, pp. 57-82.

Barton, Ellen, and Susan Eggly. "Ethical or Unethical Persuasion?: The Rhetoric of Offers to Participate in Clinical Trials." Written Communication, vol. 26, no. 3, 2009, pp. 295-319.

Bellwoar, Hannah. Everyday Matters: Reception and Use as Productive Design of Health-Related Texts. Technical Communication Quarterly, vol. 21, no. 4, 2012, pp. $325-345$.

Benham, Jessica L. and James S. Kizer. "Aut-ors of Our Experience: Interrogating Intersections of Autistic Identity." Canadian Journal of Disability Studies, vol. 5, no. 3, 2016, pp. 77-113. 
Bennett, Jeffrey. “'Born This Way': Queer Vernacular and the Politics of Origins.” Communication and Critical/Cultural Studies, vol. 11, no. 3, 2014, pp. 211-230.

Berkenkotter, Carol. Patient Tales: Case Histories and the Uses of Narrative in Psychiatry. U South Carolina P, 2008.

Berkenkotter, Carol, and Doris Ravotas. "Genre as Tool in the Transmission of Practice Over Time and Across Professional Boundaries.” Mind, Culture, and Activity, vol. 4, no. 4, 1997, pp. 256-274.

Broderick, Alicia A, and Ari Ne'eman. “Autism As Metaphor: Narrative and CounterNarrative.” International Journal of Inclusive Education, vol. 12, no. 5/6, 2008, pp. $459-476$.

Brueggemann, Brenda Jo. "The Coming Out of Deaf Culture and American Sign Language: An Exploration into Visual Rhetoric and Literacy." Rhetoric Review, vol. 13 , no. 2 , 1995, pp. 409-20.

---. “On (Almost) Passing.” College English, vol. 59, no. 6, 1997, pp. 647-60.

---. Lend Me Your Ear: Rhetorical Constructions of Deafness. Gallaudet University Press, 1999.

---. "Delivering Disability, Willing Speech.” Bodies in Commotion: Disability and Performance, edited by Carrie Sandahl and Philip Auslander, U Michigan P, 2005, pp. 17-29.

Brueggemann, Brenda Jo, and James A. Fredal. "Studying Disability Rhetorically." Disability Discourse, edited by Mairian Corker and Sally French, Open UP, 1999, pp. 129-135. 
Brodkin, Lori C. Rhetorical Training for Physician Assistants: Reuniting the Science of Medical Care and the Art of Medical Rhetoric. Dissertation, New Mexico SU, 2002.

Carmack, Heather J. "Social and Tertiary Health Identities as Argument in the DSM-V Asperger's/Autism Debate." Western Journal of Communication, vol. 78, no. 4, 2014, pp. 462-479.

Casanova, Manuel. "The Neurodiversity Movement: Lack of Trust.” Cortical Chauvinism, 5 Jan. 2015, https://corticalchauvinism.com/2015/01/05/theneurodiversity-movement-lack-of-trust/

Charland, Maurice. "Constitutive Rhetoric: The Case of the Peuple Québécois." Quarterly Journal of Speech, vol. 73, no. 2, 1987, pp. 140-150.

Clare, Eli. Exile and Pride: Disability, Queerness, and Liberation. SouthEnd, 1999.

Clarke, Adele E., et al. "Biomedicalization: Technoscientific Transformations of Health, Illness, and U.S. Biomedicine.” American Sociological Review, vol. 68, no. 2, 2003, pp. 161-194.

Compton, Wilson M. and Samuel B. Guze. "The Neo-Kraepelinian Revolution in Psychiatric Diagnosis.: European Archives of Psychiatry and Clinical Neuroscience, vol. 245, no. 4-5, pp. 196-201.

Condit, Celeste M. Decoding Abortion Rhetoric: Communicating Social Change. U Illinois P, 1990.

---. "How Bad Science Stays That Way: Brain Sex, Demarcation, and the Status of Truth in the Rhetoric of Science." Rhetoric Society Quarterly, vol. 26, no. 4, 2009, pp. 83-109. 
---. The Meanings of the Gene: Public Debates About Human Heredity. U Wisconsin P, 1999.

---. "Women's Reproductive Choices and the Genetic Model of Medicine." Body Talk: Rhetoric, Technology, Reproduction. U Wisconsin P, 2000.

Condit, Celeste M., and Deirdre M Condit. "Blueprints and Recipes: Gendered Metaphors for Genetic Medicine.” Journal of Medical Humanities, vol. 22, no. 1, 2001, pp. 29-39.

Conrad, Peter. The Medicalization of Society: On the Transformation of Human Conditions into Treatable Disorders. Johns Hopkins UP, 2007.

Corpus of Contemporary American English. Brigham Young U, 2017, http://corpus.byu.edu/coca/

Crable, Bryan. "Rhetoric, Anxiety, and Character Armor: Burke's Interactional Rhetoric of Identity." Western Journal of Communication, vol. 70, no. 1, 2006, pp. 1-22.

Crow, Liz. "Including All of Our Lives: Renewing the Social Model of Disability." Exploring the Divide, edited by Colin Barnes and Geof Mercer, The Disability P, 1996, pp. 55-72.

Crowe, Marie. "Constructing Normality: A Discourse Analysis of the DSM-IV." Journal of Psychiatric and Mental Health Nursing, vol. 7, no. 1, pp. 69-77.

Cushman, Ellen. “The Public Intellectual, Service Learning, and Activist Research.” College English, vol. 61, no. 3, 1999, pp. 328-336. Davis, Lennard J. Enforcing Normalcy: Disability, Deafness, and the Body. Verso, 1995. De Certeau, Michel. The Practice of Everyday Life. U California P, 1984. 
Deans, Thomas. Writing Partnerships: Service-Learning in Composition. National Council of Teachers of English, 2000.

Derkatch, Colleen and Judy Z. Segal. "Realms of Rhetoric in Health and Medicine." Philosophy and Medicine, vol. 82, no. 2, 2005, pp. 138-142.

Detweiler, Jane. “To Design a Doctor(ate): Negotiating Professional Identities in a Mew Clinical-Doctoral Program.” Heifferon amd Brown, pp. 221-42.

DeVault, Marjorie L. "Introduction: What Is Institutional Ethnography?" Social Problems, vol. 53, no. 3, 2006.

Ding, Huiling. "Rhetorics of Alternative Media in an Emerging Epidemic: SARS, Censorship, and Extra-Institutional Risk Communication.” Technical Communication Quarterly, vol. 18, no. 4, 2009, pp. 327-350.

Dolmage, Jay Timothy. Disability Rhetoric. Syracuse UP, 2014.

Drash, Wayne and Sanjay Gupta. "Stem Cells Offer Hope for Autism." CNN, 5 Apr. 2017, http://www.cnn.com/2017/04/05/health/autism-cord-blood-stem-cells-dukestudy/index.html

Duffy, John and Melanie Yergeau, editors. Disability and Rhetoric, special issue of Disability Studies Quarterly, vol. 31, no. 3, 2011.

Eggins, Suzanne. An Introduction to Systemic Functional Linguistics. Pinter, 1994.

Eggly, Susan, et al. "A Disparity of Words: A Comparison of Offers to Participate in Cancer Clinical Trials by Patient Race." Cancer Epidemiology Biomarkers \& Prevention, vol. 21, no. 10 supplement, 2014, p. 11.

Eisenhart, Christopher and Barbara Johnstone. "Discourse Analysis and Rhetorical Studies." Rhetoric in Detail: Discourse Analyses of Rhetorical Talk and Text, 
edited by Barbara Johnstone and Christopher Eisenhart, John Benjamins Publishing Company, 2008, pp. 2-21.

Emmons, Kimberly. “'All on the List': Uptake in Talk About Depression.” Heifferon and Brown, pp. 159-80.

Estroff, Sue E, et al. "Everybody's Got a Little Mental Illness: Accounts of Illness and Self among People with Severe, Persistent Mental Illnesses." Medical Anthropology Quarterly, vol. 5, no. 4, 1991, pp. 331-369.

Fahnestock, Jeanne. "Accommodating Science: The Rhetorical Life of Scientific Facts." Written Communication, vol. 3, no. 3, 1986, pp. 275-296.

Fairclough, Norman. Language and Power. 2nd ed., Longman, 1989.

Flower, Linda. Community Literacy and the Rhetoric of Public Engagement. Southern Illinois UP, 2008.

Foucault, Michel. The Birth of the Clinic: An Archaeology of Medical Perception. Translated by A. M. Sheridan, Routledge, 2003.

---. Psychiatric Power: Lectures at the College de France 1973-1974. Edited by Jacques Lagrange, Palgrave Macmillan, 2006.

Frances, Allen. Saving Normal: An Insider's Revolt against Out-of-Control Psychiatric Diagnosis, DSM-5, Big Pharma, and the Medicalization of Ordinary Life. Harper Collins, 2013.

Gaines, Atwood D. "From DSM-I to III-R; Voices of Self, Mastery, and the Other: A Cultural Constructivist Reading of U.S. Psychiatric Classification.” Social Science and Medicine, vol. 35, no.1, 1992, pp. 3-24. 
Gajjala, Radhika. “An Interrupted Postcolonial/Feminist Cyberethnography: Complicity and Resistance in the 'Cyberfield."' Feminist Media Studies, vol. 2, no. 2, 2002, pp. 177-193.

Galegher, Jolene, Lee Sproull, and Sara Kiesler. "Legitimacy, Authority, and Community in Electronic Support Groups.” Written Communication, vol. 15, no. 4, 1998, pp. $493-530$.

Garland-Thomson, Rosemarie. Extraordinary Bodies: Figuring Physical Disability in American Culture and Literature. Columbia UP, 1997.

---. "Integrating Disability, Transforming Feminist Theory." NWSA Journal, vol. 13, no. 3, 2002, pp. 1-32.

Glaser, Barney G., and Anselm L. Strauss. The Discovery of Grounded Theory: Strategies for Qualitative Research. Aldine Pub, 1967.

Gledhill, Christopher J. Collocations in Science Writing. Gunter Narr Verlag Tübingen, 2000.

Graham, S. Scott. "Agency and the Rhetoric of Medicine: Biomedical Brain Scans and the Ontology of Fibromyalgia." Technical Communication Quarterly, vol. 18, no. 4, 2009, pp. 376-404

Graham, S. Scott, and Carl Herndl. "Multiple Ontologies in Pain Management: Toward a Postplural Rhetoric of Science.” Technical Communication Quarterly, vol. 22, no. 2, 2013, pp. 103-125.

Graham, S. Scott, et al. "Catalyzing Transdisciplinarity: A Systems Ethnography of Cancer-Obesity Comorbidity and Risk Coincidence." Qualitative Health Research, vol. 27, no. 6, 2016, pp. 877-892. 
Grinker, Roy Richard, and Kyungjin Cho. "Border Children: Interpreting Autism Spectrum Disorder in South Korea.” Ethos, vol. 41, no. 1, 2013, pp. 46-74.

Halliday, M. A. K., and Christian M. I. M. Matthiessen. Halliday's Introduction to Functional Grammar. 4th edition, Routledge, 2014.

Halliday, M. A. K., and J. R. Martin. Writing Science: Literacy and Discursive Power. Routledge, 2003.

Haswell, Richard H. “NCTE/CCCC's Recent War on Scholarship.” Written Communication, vol. 22, no. 2, 2005, pp. 198-223.

Heifferon, Barbara A. "The New Smallpox: An Epidemic of Words?” Rhetoric Review, vol. 25, no. 1, 2006, pp. 76-93.

Heifferon, Barbara, and Stuart C. Brown. Rhetoric of Healthcare: Essays Toward a New Disciplinary Inquiry. Hampton Press, 2008.

Heilker, Paul and Jason King. "The Rhetorics of Online Autism Advocacy: A Case for Rhetorical Listening." Rhetorics and Technologies: New Directions in Writing and Communication, edited by Stuart A. Selber, U South Carolina P, 2010, pp. 113-133.

Heilker, Paul and Melanie Yergeau. "Autism and Rhetoric.” College English, vol. 73, no. 5, 2011, pp. 485-497.

Hewings, Ann. (2004). “Developing Discipline-Specific Writing: An Analysis of UnderGraduate Geography Essays.” Analysing Academic Writing: Contextualized Frameworks, edited by Louise J. Ravelli and Robert A. Ellis, Continuum, 2004, pp. 131-152.

Horwitz, Allan V. Creating Mental Illness. U Chicago P, 2002. 
Horwitz, Allan V., and Jerome C. Wakefield. All We Have to Fear: Psychiatry's Transformation of Natural Anxieties into Mental Disorders. Oxford UP, 2012. Huckin, Thomas, et al. "Critical Discourse Analysis and Rhetoric and Composition." College Composition and Communication, vol. 64, no.1, 2012, pp. 107-129.

Hyde, Michael J. The Call of Conscience: Heidegger and Levinas, Rhetoric and the Euthanasia Debate. U South Carolina P, 2001.

--- "Medicine, Rhetoric, and Euthanasia: A Case Study in the Workings of a Postmodern Discourse.” Quarterly Journal of Speech, vol. 79, 1993, pp. 201-224.

Hyland, Ken. "Persuasion and Context: The Pragmatics of Academic Metadiscourse." Journal of Pragmatics, vol. 30, no. 4, 1998, pp. 437-455.

---. "Stance and Engagement: A Model of Interaction in Academic Discourse." Discourse Studies, vol. 7, no. 2, 2005, pp. 173-192.

Idalski Carcone, April, et al. "Exploring Ambivalence in Motivational Interviewing with Obese African American Adolescents and Their Caregivers: A Mixed Methods Analysis." Patient Education and Counseling, vol. 99, no. 7, 2016, pp. $1162-$ 1169.

Jack, Jordynn. Autism and Gender: From Refrigerator Mothers to Computer Geeks. U Illinois P, 2014.

-----. “What are Neurorhetorics?” Rhetoric Society Quarterly, vol. 40, no. 5, 2010, pp. 405-410.

Jack, Jordynn and L. Gregory Appelbaum. “'This is Your Brain on Rhetoric': Research Directions for Neurorhetorics." Rhetoric Society Quarterly, vol. 40, no. 5, 2010, pp. 411-437. 
Jarvis, Ava. "Post-Traumatic Stress Disorder in Fiction, Part 3." Tor.com, 29 Sept. 2009, http://www.tor.com/2009/09/29/post-traumatic-stress-disorder-in-fiction-part-3/

Jenkins, Emily K. “The Politics of Knowledge: Implications for Understanding and Addressing Mental Health and Illness.” Nursing Inquiry, vol. 21, no. 1, 2014, pp. $3-10$.

Johnson, Davi. “'How Do You Know Unless You Look?’: Brain Imaging, Biopower and Practical Neuroscience." Journal of Medical Humanities, vol. 29, no. 3, 2008, pp. $147-161$.

Johnson Thornton, Davi. Brain Culture: Neuroscience and Popular Media. Rutgers UP, 2011.

---. "Transformations of the Ideal Mother: The Story of Mommy Economicus and Her Amazing Brain." Women's Studies in Communication, vol. 37, no. 3, 2014, pp. 271-291.

Johnson, Jenell. "The Skeleton on the Couch: The Eagleton Affair, Rhetorical Disability, and the Stigma of Mental Illness." Rhetoric Society Quarterly, vol. 40, no. 5, 2010, pp. 459-478.

Kafer, Alison. Feminist, Queer, Crip. Indiana UP, 2013.

Karkazis, Katrina. Fixing Sex: Intersex, Medical Authority, and Lived Experience. Duke UP, 2008.

Kelland, Kate. "Scientists Find Common Antibiotic Could Prevent or Treat PTSD." Reuters, 4 Apr. 2017, http://www.reuters.com/article/us-health-ptsd-antibioticidUSKBN1760HV 
Keränen, Lisa. "Addressing the Epidemic of Epidemics: Germs, Security, and a Call for Biocriticism." Quarterly Journal of Speech, vol. 97, no. 2, 2011.

---. “'Cause Someday We All Die': Rhetoric, Agency, and the Case of the 'Patient' Preferences Worksheet." Quarterly Journal of Speech, vol. 93, no. 2, 2007, pp. $179-210$.

---. "Public Engagements with Health and Medicine.” Keränen and Scott, pp. 103-9.

Keränen Lisa, and J. Blake Scott. Medicine, Health, and Publics, special issue of Journal of Medical Humanities, vol. 35, no. 2, 2014, pp. 103-239.

Kerschbaum, Stephanie L. "Avoiding the Difference Fixation: Identity Categories, Markers of Difference, and the Teaching of Writing." College Composition and Communication, vol. 63, no. 4, 2012, pp. 616-644.

Kimball, Miles. "Cars, Culture, and Tactical Technical Communication.” Technical Communication Quarterly, vol. 15, no. 1, pp. 67-86.

Kirsch, Gesa E, and Joy S Ritchie. "Beyond the Personal: Theorizing a Politics of Location in Composition Research." College Composition and Communication, vol. 46, no. 1, 1995, pp. 7-29.

Kirschner, Suzanne R. (2013). "Diagnosis and its Discontents: Critical Perspectives on Psychiatric Nosology and the DSM." Feminism \& Psychology, vol. 23, no. 1, pp. $10-28$.

Koerber, Amy, et al. "Distortion and the Politics of Pain Relief." Journal of Business and Technical Communication, vol. 22, no. 3, 2008, pp. 364-391. 
---. “'You Just Don't See Enough Normal': Critical Perspectives on Infant-Feeding Discourse and Practice." Journal of Business and Technical Communication, vol. 19, no. 3, 2005, pp. 304-327.

Kolodziejski, Lauren R. "Harms of Hedging in Scientific Discourse: Andrew Wakefield and the Origins of the Autism Vaccine Controversy." Technical Communication Quarterly, vol. 23, no. 3, 2014, pp. 165-183.

Kopelson, Karen. "Risky Appeals: Recruiting to the Environmental Breast Cancer Movement in the Age of 'Pink Fatigue'.." Rhetoric Society Quarterly, vol. 43, no. 2, 2013, pp. 107-133.

Koteyko, Nelva. "Corpus-assisted analysis of internet-based discourses: from patterns to rhetoric." Rhetoric and the Digital Humanities, edited by Jim Ridolfo and William Hart-Davidson, U Chicago P, 2015, pp. 193-205.

Lafrance, Michelle N. \& McKenzie-Mohr, Suzanne. "The DSM and its Lure of Legitimacy." Feminism \& Psychology, vol. 23, no. 1, pp. 10-28.

Lancaster, Zak. (2014). "Exploring Valued Patterns of Stance in Upper-Level Student Writing in the Disciplines." Written Communication, vol. 31, no. 1, pp. 27-57. Lewiecki-Wilson, Cynthia. "Rethinking Rhetoric through Mental Disabilities." Rhetoric Review, vol. 22, no. 2, 2003, pp. 156-167.

Lewis, Bradley. "A Mad Fight: Psychiatry and Disability Activism.” The Disability Studies Reader, 2nd ed., edited by Lennard J. Davis, Routledge, 2006, pp. 339352.

---. Moving Beyond Prozac, DSM, and the New Psychiatry: The Birth of Postpsychiatry. U Michigan P, 2006. 
Linton, Simi. Claiming Disability: Knowledge and Identity. New York UP, 1998.

López-Ibor Aliño, Juan José, et al. Psychiatry As a Neuroscience. John Wiley \& Sons, 2002.

Mao, Luming R. "I Conclude Not: Toward a Pragmatic Account of Metadiscourse." Rhetoric Review, vol. 11, no. 2, 1993, pp. 265-289.

Markram, Kamila, and Henry Markram. "The Intense World Theory: A Unifying Theory of the Neurobiology of Autism." Frontiers in Human Neuroscience, vol. 4, no. 224, 2010, pp. 1-29.

Martin, Emily. Bipolar Expeditions: Mania and Depression in American Culture. Princeton UP, 2007.

Martinelli, Marissa. "An Autism Advocate Explains How She Helped Sesame Street Create Its New Autistic Muppet.” Slate, 12 Apr. 2017, http://www.slate.com/blogs/browbeat/2017/04/12/autistic_self_advocacy_networ k_s_julia_bascom_on_sesame_street_s_new_muppet.html McCarthy, Lucille P., \& Gerring, Joan P. “Revising Psychiatry's Charter Document DSM-IV." Written Communication, vol. 11, no. 2, 1994, pp. 147-192.

McKee, Heidi A., \& Porter, James E. The Ethics of Internet Research : A Rhetorical, Case-Based Process. Peter Lang, 2009.

McLaren, Neal. "The DSM-V Project: Bad Science Produces Bad Psychiatry." Ethical Human Psychology and Psychiatry, vol. 12, no. 3, 2010, pp. 189-199.

Metzl, Jonathan M. The Protest Psychosis: How Schizophrenia Became a Black Disease. Boston: Beacon P, 2009. 
---. (2003). Prozac on the couch: prescribing gender in the era of wonder drugs.

Durham: Duke University Press.

Mirel, Barbara. Interaction Design for Complex Problem Solving: Developing Useful and Usable Software. Morgan Kaufmann, 2004.

Mitchell, David T., and Sharon L. Snyder. Narrative Prosthesis: Disability and the Dependencies of Discourse. U Michigan P, 2001.

Molloy, Cathryn. "Recuperative Ethos and Agile Epistemologies: Toward a Vernacular Engagement with Mental Illness Ontologies." Rhetoric Society Quarterly, vol. 45, no. 2, 2015, pp. 138-163.

Moncrieff, Joanna. "Psychiatric Diagnosis as a Political Device." Social Theory \& Health, vol. 8, no. 4, 2010, pp. 370-382.

Morrison, Linda Joy. Talking Back to Psychiatry: The Psychiatric Consumer/Survivor/Ex-Patient Movement. Routledge, 2005.

North, Sarah. "Disciplinary Variation in the Use of Theme in Undergraduate Essays." Applied Linguistics, vol. 26, no. 3, 2005, pp. 431-452.

Novas, Carlos. “The Political Economy of Hope: Patients' Organizations, Science and Biovalue.” BioSocieties, vol. 1, 2006, pp. 289-305.

Osher, Christopher and Jennifer Brown. "Colorado Responds Slowly to Psychotropic Drug Use among Foster Kids.” Denver Post, 12 Apr. 2014.

Owens, Kim Hensley. "Confronting Rhetorical Disability: A Critical Analysis of Women's Birth Plans.” Written Communication, vol. 26, no. 3, 2009, pp. 247272. 
Peck, Wayne Campbell, et al. "Community Literacy.” College Composition and Communication, vol. 46, no. 2, 1995, pp. 199-222.

Pickering, Neil. The Metaphor of Mental Illness. Oxford University Press, 2006.

Pittenger, David J. "Cautionary Comments Regarding the Myers-Briggs Type Indicator." Consulting Psychology Journal: Practice \& Research, vol. 57, no. 2, 2005.

Popham, Susan L. \& Graham, Sage Lambert. “A Structural Analysis of Coherence in Electronic Charts in Juvenile Mental Health.” Technical Communication Quarterly, vol. 17, no. 2, 2008, pp. 149-172.

Potts, Laura. "Narratives of Risk and Collective Identity." Auto/Biography, vol. 14, 2006, pp. 116-133.

Powell, Katrina M, and Pamela Takayoshi. "Accepting Roles Created for Us: The Ethics of Reciprocity." College Composition and Communication, vol. 54, no. 3, 2003, pp. $394-422$.

Preidt, Robert. "FDA Warns Against Bogus Autism Treatments." US News and World Report, 25 Apr. 2014, http://health.usnews.com/healthnews/articles/2014/04/25/fda-warns-against-bogus-autism-treatments

Prendergrast, Catherine. "On the Rhetorics of Mental Disability." Embodied Rhetorics: Disability in Language and Culture, edited by James C. Wilson and Cynthia Lewiecki-Wilson, Southern Illinois UP, 2001, pp. 45-60.

---. "The Unexceptional Schizophrenic: A Post-Postmodern Introduction.” The Disability Studies Reader, 4th ed., edited by Lennard J. Davis, Routledge, 2013, pp. 236245. 
Price, Margaret. Mad at School: Rhetorics of Mental Disability and Academic Life. U Michigan P, 2011.

Price, Margaret and Stephanie Kerschbaum "Stories of Methodology: Interviewing Sideways, Crooked and Crip." Canadian Journal of Disability Studies, vol. 5, no. 3, 2016, pp. 19-56.

Roozen, Kevin. “Tracing Trajectories of Practice: Repurposing in One Student's Developing Disciplinary Writing Processes.” Written Communication, vol. 27, no. 3, 2010, pp. 318-354.

Rose, Nikolas. The Politics of Life Itself: Biomedicine, Power, and Subjectivity in the Twenty-First Century. Princeton UP, 2007.

Rose, Nikolas, and Joelle M. Abi-Rached. Neuro: The New Brain Sciences and the Management of the Mind. Princeton UP, 2013.

Rose, Nikolas and Carlos Novas. "Biological Citizenship." Global Assemblages: Technology, Politics, and Ethics as Anthropological Problems, edited by Aihwa Ong and Stephen J. Collier, Blackwell Publishing, 2005, pp. 439-463.

Russell, David R. "Rethinking Genre in School and Society: An Activity Theory Analysis." Written Communication, vol. 14, no. 4, 1997, pp. 504-554.

Schryer, Catherine F. "The Lab vs. the Clinic: Sites of Competing Genres." Genre and the New Rhetoric, edited by Aviva Freedman and Peter Medway, Taylor and Francis, 1994, pp. 105-24.

Schryer, Catherine, et al. "Creating Discursive Order at the End of Life: The Role of Genres in Palliative Care Settings." Written Communication, vol. 29, no. 2, 2012, pp. 111-141. 
Schryer, Cathryn F., et al. (2003) "Structure and Agency in Medical Case Presentations." Writing Selves, Writing Society: Research from Activity Perspectives, edited by Charles Bazerman and David R. Russell, WAC Clearinghouse, pp. 62-96.

Schryer, Catherine, and Philippa Spoel. "Genre Theory, Health-Care Discourse, and Professional Identity Formation.” Journal of Business and Technical Communication, vol. 19, no. 3, 2005, pp. 249-278.

Scott, J. Blake. Risky Rhetoric: AIDS and the Cultural Practices of HIV Testing. Southern Illinois UP, 2003.

Scott, Blake, et al. "The Rhetorics of Health and Medicine: Inventional Possibilities for Scholarship and Engaged Practice." Poroi, vol. 9, no. 1, 2013, pp. 1-6.

Scott, Mike, and Chris Tribble. Textual Patterns: Key Words and Corpus Analysis in Language Education. John Benjamins Publishing, 2006.

Segal, Judy Z. “'Compliance’ to 'Concordance’: A Critical View.” Journal of Medical Humanities, vol. 28, 2007, pp. 81-96.

---. "Illness As Argumentation: A Prolegomenon to the Rhetorical Study of Contestable Complaints." Health, vol. 11, no. 2, 2007, pp. 227-44.

---. "Interdisciplinarity and Bibliography in Rhetoric of Health and Medicine." Technical Communication Quarterly, vol. 14, no. 3, 2005, pp. 311-318.

---. "The Rhetoric of Female Sexual Dysfunction: Faux Feminism and the FDA.” Canadian Medical Association Journal, vol. 187, no. 12, 2015, pp. 915-916. ---. "Strategies of Influence in Medical Authorship." Social Science and Medicine, vol. 37, no. 4, 1993, pp. 521-530. 
---. (2011). "What, in Addition to Drugs, Do Pharmaceutical Ads Sell? The Rhetoric of Pleasure in Direct-to-Consumer Advertising for Prescription Pharmaceuticals." Rhetorical Questions of Health and Medicine, edited by Joan Leach and Deborah Dysart-Gale, Lexington Press, 2011, pp. 9-32.

Segal, Judy, et al. "The Researcher As Missionary: Problems with Rhetoric and Reform in the Disciplines." College Composition and Communication, vol. 50, no. 1, 1998, pp. 71-90.

Shah, Premal \& Mountain, Deborah. "The Medical Model is Dead—Long Live the Medical Model.” British Journal of Psychiatry, vol. 191, no. 5, pp. 375-377.

Shakespeare, Tom. Disability Rights and Wrongs. Routledge, 2006.

---. Disability Rights and Wrongs Revisited. 2nd ed., Routledge, 2014.

Sidler, Michelle and Natasha Jones. "Genetics Interfaces: Representing Science and Enacting Public Discourse in Online Spaces." Technical Communication Quarterly, vol. 18, no. 1, pp. 28-48.

Siebers, Tobin. Disability Theory. Ann Arbor: University of Michigan Press, 2008. Print. Simmons, W. Michelle \& Zoetewey, Meredith W. "Productive Usability: Fostering Civic Engagement and Creating More Useful Online Spaces for Public Deliberation.” Technical Communication Quarterly, vol. 21, 2012, pp. 251-276.

Spinuzzi, Clay. Tracing Genres through Organizations: A Sociocultural Approach to Information Design. MIT Press, 2003.

Spoel, Philippa. "Communicating Values, Valuing Community through Health-Care Websites: Midwifery's Online Ethos and Public Communication in Ontario.” Technical Communication Quarterly, vol. 17, no. 3, 2008, pp. 264-288. 
Stevenson, Jennifer L., et al. “Infantilizing Autism.” Disability Studies Quarterly, vol. 31, no. $3,2011$.

Stone, Mary Specker. "In Search of Patient Agency in the Rhetoric of Diabetes Care.” Technical Communication Quarterly, vol. 6, no. 2, 1997, pp. 201-17.

Thachuk, Angela K. "Stigma and the Politics of Biomedical Models of Mental Illness." International Journal of Feminist Approaches to Bioethics, vol. 4, no. 1, 2011, pp. 140-163.

Tremain, Shelley. "Foucault, Governmentality, and Critical Disability Theory: An Introduction." Foucault and the Government of Disability, edited by Shelley Tremain, U Michigan P, 2005, pp. 1-24.

Tucker, Patrick. "The Military Is Building Brain Chips to Treat PTSD." The Atlantic, 29 May 2014, https://www.theatlantic.com/technology/archive/2014/05/the-militaryis-building-brain-chips-to-treat-ptsd/371855/

UPIAS. 1976. "Fundamental Principles of Disability, Union of the Physically Impaired against Segregation.”

Van Leeuwen, Theo. Discourse and Practice: New Tools for Critical Discourse Analysis. Oxford University Press, 2008.

Vande Kopple, William P. "Metadiscourse, Discourse, and Issues in Composition and Rhetoric.” Discourse Studies in Composition, edited by Ellen L. Barton and Gail Stygall, Hampton Press, 2002, pp. 91-114.

Wardrope, Alistair. "Medicalization and Epistemic Justice.” Medicine, Health Care, and Philosophy, vol. 18, 2015, pp. 341-352. 
Wignell, Peter et al. "The Discourse of Geography: Ordering and Explaining the Experiential World.” Halliday and Martin, 151-183.

Wilson, James C. "Evolving Metaphors of Disease in Postgenomic Science: Stigmatizing Disability." Rhetoric Review, vol. 22, no. 2, 2003, pp. 197-202.

Wilson, Mitchell. "DSM-III and the Transformation of American Psychiatry: A History." American Journal of Psychiatry, vol. 150, no. 3, 1993, pp. 399-410.

Yergeau, Melanie. “Clinically Significant Disturbance: On Theorists who Theorize Theory of Mind.” Disability Studies Quarterly, vol. 33, no. 4, 2013.

Young, William B. et al. "Naming Migraine and Those Who Have It." Headache, vol. 52, 2012, pp. 283-291. 


\section{APPENDIX \\ INITIAL INTERVIEW QUESTIONNAIRE}

1. Why did you begin writing in [web forum]? Did you know others who had written there before?

2. What things (such as advice, information, help, friendship, understanding) were you looking for in [web forum]?

a. What have you gained from participating? Did it meet your goals/needs?

3. Why did you choose this particular place, as opposed to other forums? What did it offer that appealed to you?

4. How would you label your own way of describing mental experience?

5. What are the most important parts of your internal life?

6. How does your mental experience relate to your social behavior?

7. Do you have a condition, diagnosis, or label that you identify with, in regard to your mental experience?

a. Why did you choose this particular one?

b. Do you consider yourself part of a "community" connected with this label? Why or why not?

8. Are there any ways of describing or labeling mental experience that you disagree with or object to? Why?

9. What are some words or terms that come up often when you're talking or writing about your mental experience?

10. How do you describe your own writing in [web forum]?

11. What makes your style unique or interesting?

12. What kinds of conversations do you tend to start or engage with in [web forum]?

13. How do you interact with other people in [web forum]?

14. What are your goals in these relationships--to befriend, to convince, to support, to connect?

15. How do you adapt your writing in order to pursue those relational goals?

16. Do you think your writing on mental experience is "scientific"? Why or why not?

17. What is your attitude toward psychiatry in general?

18. How would you describe psychiatry's methods?

19. What kinds of scientific, medical, or psychiatric documents have you read, or read about? These might be very different from one another-medical websites, science magazines, doctor's brochures, diagnostic manuals, etc.

a. Which of these do you think have had an influence on how you think about your own experience? How so?

b. Did any of these present a view of mental experience that you disagreed with or objected to? Why? 
c. Have you encountered others who read about the same ideas?

20. What other documents or ideas, outside of those scientific and medical ones, have had an influence on how you think about your own mental and social experience? How so?

a. Have you encountered others who responded to the same ideas?

21. Have you read about your condition in accounts from medical professionals?

a. What was your reaction?

22. Have you interacted with medical documents that describe your condition or ask for you to disclose it? In what context?

a. How did you react to these documents? 


\section{CURRICULUM VITA}

NAME:

ADDRESS:

DOB:

EDUCATION

\& TRAINING:
Andrew Wesley Holladay

450 E. Lee St.

Louisville, KYMo 40217

Lexington, Kentucky - August 16, 1983

B.A., Religious Studies

Union University

2001-2005

M.A., English

University of Louisville

2007-2009

Ph.D., Rhetoric and Composition

University of Louisville

2012-2017

PROFESSIONAL SOCIETIES:

National Council of Teachers of English

Rhetoric Society of America

PUBLICATIONS: “Classified Conversations: Psychiatry and Tactical Technical Communication in Online Spaces." Technical Communication Quarterly, special issue on tactical technical communication, edited by Miles Kimball, vol. 26, no. 1, 2017, pp. 8-24.

"Responsivity and Unity in Rhetoric and Composition." Response essay. JAC: A Journal of Rhetoric, Culture, and Politics, vol. 34, no. 1-2, 2014, pp. 239-245.
CONFERENCE PRESENTATIONS:
"Differential Interpretations: The Mobility of Genre/Knowledge in Online Health Discourse." Thomas R. Watson Conference. Louisville, KY. October 2016. 
"Re-forming Mental Health: Rhetorical Innovation and the Primacy of Biology." Rhetoric Society of America Convention. Atlanta, GA. May 2016.

"The Rhetoric of Mental Health: Psychiatry, Disability, and Neurorhetorics." Conference on College Composition and Communication. Houston, TX. April 2016.

"The Will to (Self-)Define: Mental Disability and Medical Discourse." Society for Disability Studies Conference. Atlanta, GA. June 2015

"Contested Positions: Ethics, Disability, and Identity in Online Writing Research Methodology." Conference on College Composition and Communication. Tampa, FL. March 2015

"The State of Empowerment: Available and Evolving Notions of Agency in Rhetoric and Composition." Thomas R. Watson Conference. Louisville, KY. October 2014.

"The Competing Neurorhetorics of Autism: Advocacy and Power in Revising the DSM." Rhetoric Society of America Conference. San Antonio, TX. July 2014.

"Student/Writing in Composition: Critical Pedagogy, Subjectivity, and the Digital Architecture of Institutions." Conference on College Composition and Communication. Indianapolis, IN. March 2014.

"Serious Research vs. 'Shrimp on a Treadmill': Helping Composition Students Navigate the Modern Political Rhetoric of Science." Conference on College Composition and Communication. Las Vegas, NV. March 2013.

"Tutoring (Re)Scripted? Using Digital Notebooks for Asynchronous Online Writing Conferences." National Conference on Peer Tutoring in Writing. Miami, FL. November 2011.

"Democratic Deliberation and the Composition Classroom: Moving Beyond Policy-Centered Political Discourse.” Conference on College Composition and Communication. Atlanta, GA. March 2011. 